\title{
Rhodium-Catalyzed Synthesis of 2-Aroylpyrimidines via Cascade Heteropolyene Rearrangement
}

\author{
Nikolai Yu. Tiuftiakov ${ }^{\dagger}$ Julia O. Strelnikova, ${ }^{\dagger}$ Ilya P. Filippov ${ }^{\dagger}$ Adel R. Khaidarov, ${ }^{\dagger}$ Alexander \\ F. Khlebnikov,$^{\dagger}$ Alexander S. Bunev, ${ }^{\dagger}$ Mikhail S. Novikov ${ }^{\dagger}$ and Nikolai V. Rostovskii ${ }^{\dagger *}$
}

${ }^{\dagger}$ St. Petersburg State University, Institute of Chemistry, 7/9 Universitetskaya nab., St. Petersburg 199034, Russia †ogliatti State University, Medicinal Chemistry Center, 14 Belorusskaya St., Togliatti, 445020, Russia *Email: n.rostovskiy@spbu.ru

\section{TABLE OF CONTENTS}

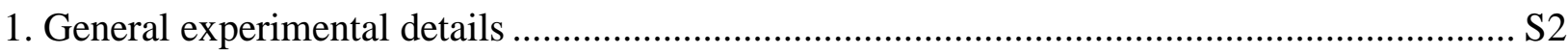

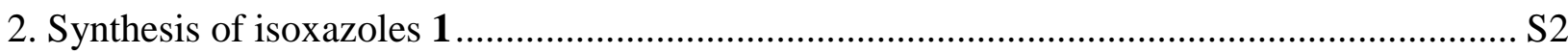

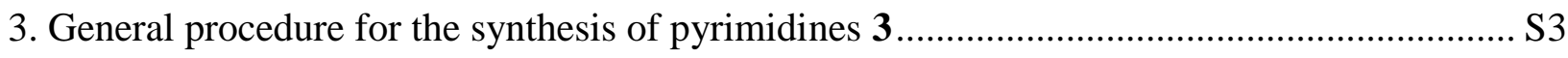

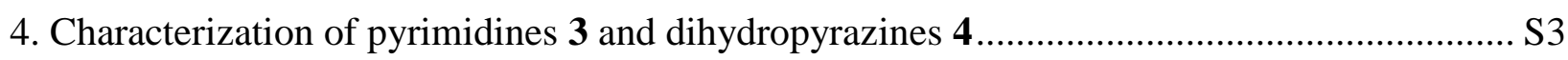

5. Table S-1. Optimization of reaction conditions for synthesis of 3a................................. S12

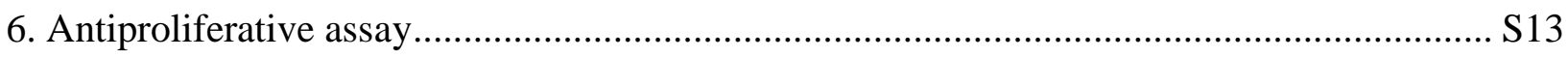

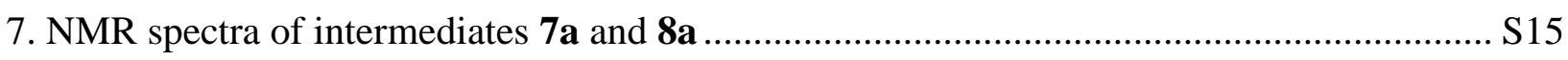

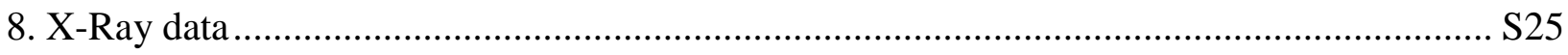

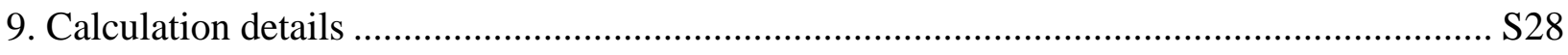

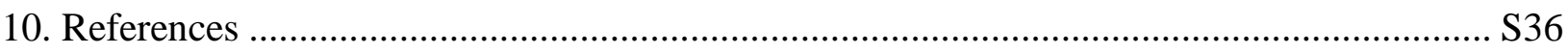

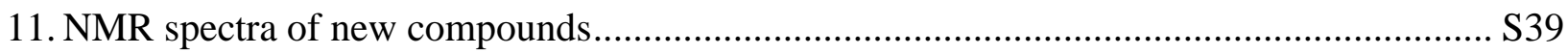




\section{General experimental details}

Melting points were determined on a melting point apparatus and are uncorrected. ${ }^{1} \mathrm{H}(400 \mathrm{MHz})$ and ${ }^{13} \mathrm{C}(100 \mathrm{MHz}) \mathrm{NMR}$ spectra were recorded in the solvents indicated below. Chemical shifts ( $\delta)$ are reported in parts per million downfield from tetramethylsilane. High-resolution mass spectra were recorded on an HRMS-ESI-QTOF instrument, electrospray ionization, positive mode. Thin-layer chromatography (TLC) was conducted on aluminum sheets precoated with $\mathrm{SiO}_{2}$ ALUGRAM SIL G/UV254. Column chromatography was performed on silica gel $60 \mathrm{M}$ $(0.04-0.063 \mathrm{~mm})$. All solvents were distilled and dried prior to use. Toluene was distilled and stored over sodium metal. The catalysts $\mathrm{Rh}_{2}(\mathrm{Piv})_{4},{ }^{1} \mathrm{Rh}_{2}(\mathrm{Oct})_{4},{ }^{2}$ and $\mathrm{Rh}_{2}(\mathrm{esp})_{2}{ }^{3}$ were prepared by the reported procedures and gave satisfactory elemental analyses. Isoxazoles $\mathbf{1 a}-\mathbf{d}, \mathbf{f}, \mathbf{g}, \mathbf{l},{ }^{4} \mathbf{1 h}, \mathbf{i},{ }^{5}$ $\mathbf{1 j},{ }^{6} \mathbf{1 k},{ }^{7} \mathbf{1 n},{ }^{8} 1,2,3$-triazoles $\mathbf{2} \mathbf{a}-\mathbf{g}, \mathbf{i},{ }^{9} \mathbf{2 h},{ }^{10}$ and azirine $\mathbf{6}^{11}$ are known compounds, which were prepared by the reported procedures.

\section{Synthesis of isoxazoles 1}

\section{3,5-Dimethyl-4-(o-tolyl)isoxazole (1e)}

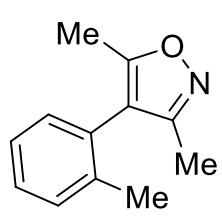

This compound was obtained according to the reported procedure. ${ }^{4}$ Colorless oil (19 mg, yield 14\%); ${ }^{1} \mathrm{H}$ NMR (400 MHz, $\left.\mathrm{CDCl}_{3}\right) \delta 7.32$ (d, $\left.J=3.8 \mathrm{~Hz}, 2 \mathrm{H}\right), 7.29-7.22(\mathrm{~m}, 1 \mathrm{H}), 7.10(\mathrm{~d}, J=$ $7.2 \mathrm{~Hz}, 1 \mathrm{H}), 2.26(\mathrm{~s}, 3 \mathrm{H}), 2.16(\mathrm{~s}, 3 \mathrm{H}), 2.12$ (s, 3H). ${ }^{13} \mathrm{C}\left\{{ }^{1} \mathrm{H}\right\} \mathrm{NMR}\left(100 \mathrm{MHz}, \mathrm{CDCl}_{3}\right) \delta 165.3$, 159.4, 137.5, 130.8, 130.3, 129.4, 128.3, 126.0, 116.2, 19.7, 11.3, 10.5; HRMS (ESI/Q-TOF) $m / z:[\mathrm{M}+\mathrm{H}]^{+}$Calcd for $\mathrm{C}_{12} \mathrm{H}_{14} \mathrm{NO}^{+}$188.1070; Found 188.1062.

\section{3-(3-Chloro-4-methylphenyl)-4,5,6,7-tetrahydrobenzo[d]isoxazole (1m)}

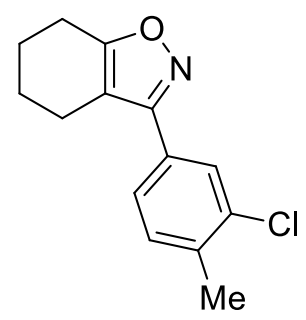

This compound was obtained according to the reported procedure. ${ }^{12}$ Pale-yellow solid (30 mg, yield 20\%). Mp: $67-69^{\circ} \mathrm{C} .{ }^{1} \mathrm{H}$ NMR $\left(400 \mathrm{MHz}, \mathrm{CDCl}_{3}\right) \delta 7.76(\mathrm{~d}, J=1.8 \mathrm{~Hz}, 1 \mathrm{H}), 7.57$ (dd, $J=$ 7.9, $1.8 \mathrm{~Hz}, 1 \mathrm{H}), 7.33$ (d, $J=7.8 \mathrm{~Hz}, 1 \mathrm{H}), 2.79-2.75(\mathrm{~m}, 2 \mathrm{H}), 2.67-2.64(\mathrm{~m}, 2 \mathrm{H}), 2.44(\mathrm{~s}, 3 \mathrm{H})$, 1.96-1.90 (m, 2H), 1.87-1.81 (m, 2H); ${ }^{13} \mathrm{C}\left\{{ }^{1} \mathrm{H}\right\}$ NMR (100 MHz, $\left.\mathrm{CDCl}_{3}\right) \delta 169.1,159.0,137.3$, 
134.7, 131.2, 129.1, 127.8, 125.5, 110.8, 22.8, 22.7, 21.8, 21.0, 19.9; HRMS (ESI/Q-TOF) $m / z$ : $[\mathrm{M}+\mathrm{H}]^{+}$Calcd for $\mathrm{C}_{14} \mathrm{H}_{15}{ }^{35} \mathrm{ClNO}^{+} 248.0837$; Found 248.0837 .

\section{3,5-Diethyl-4-methylisoxazole (10)}<smiles>CCc1noc(CC)c1C</smiles>

This compound was obtained according to the reported procedure. ${ }^{13}$ Pale-yellow oil (0.87 g, yield 52\%). ${ }^{1} \mathrm{H}$ NMR (400 MHz, $\left.\mathrm{CDCl}_{3}\right) \delta 2.69(\mathrm{q}, J=7.7 \mathrm{~Hz}, 2 \mathrm{H}), 2.62(\mathrm{q}, J=7.6 \mathrm{~Hz}, 2 \mathrm{H})$, $1.91(\mathrm{~s}, 3 \mathrm{H}), 1.30-1.25(\mathrm{~m}, 6 \mathrm{H}) ;{ }^{13} \mathrm{C}\left\{{ }^{1} \mathrm{H}\right\} \mathrm{NMR}\left(100 \mathrm{MHz}, \mathrm{CDCl}_{3}\right) \delta$ 169.0, 164.5, 107.2, 18.9, 18.6, 11.90, 11.87, 6.5; HRMS (ESI/Q-TOF) $m / z:[\mathrm{M}+\mathrm{H}]^{+}$Calcd for $\mathrm{C}_{8} \mathrm{H}_{14} \mathrm{NO}^{+} 140.1070$; Found 140.1070.

\section{General procedure for the synthesis of pyrimidines 3}

Isoxazole $1 \mathbf{a}-\mathbf{o}$ or azirine $\mathbf{6}(0.2 \mathrm{mmol})$, triazole $\mathbf{2} \mathbf{a}-\mathbf{i}(1.4-3.5$ equiv. $)$ and anhydrous toluene $(2.4 \mathrm{~mL})$ were placed in a screw cap glass tube. The solution was heated to $110{ }^{\circ} \mathrm{C}$ and $\mathrm{Rh}_{2}(\mathrm{Piv})_{4}$ (6.1 $\mathrm{mg}, 5 \mathrm{~mol} \%$, calcd on isoxazole) was added. The cap was screwed, and the resulting mixture was stirred at $110^{\circ} \mathrm{C}$ (oil bath temperature) for $30 \mathrm{~min}$ or until complete disappearance of the azirine/isoxazole (up to $2.5 \mathrm{~h}$, control by TLC every $30 \mathrm{~min}$, eluent is specified below for each product). If necessary, an additional amount of the triazole was added (total amount see below). The solvent was removed in vacuo, and the residue was purified by column chromatography on silica gel to give the desired product.

\section{Characterization of pyrimidines 3 and dihydropyrazines 4}

(4,6-Dimethyl-5-phenylpyrimidin-2-yl)(phenyl)methanone (3a)<smiles>Cc1nc(C(=O)c2ccccc2)nc([N+](=O)[O-])c1-c1ccccc1</smiles>

This compound was obtained from isoxazole $\mathbf{1 a}(35 \mathrm{mg}, 0.2 \mathrm{mmol})$ and triazole $\mathbf{2 a}$ (1.75 equiv., $105 \mathrm{mg}, 0.35 \mathrm{mmol}$ ) according to the general procedure (eluent hexane/EtOAc 3:1), yield: $50 \mathrm{mg}$ $(88 \%)$.

Synthesis on $1 \mathrm{mmol}$ scale. Compound 3a was obtained from isoxazole 1a (173 mg, $1 \mathrm{mmol}$ ) and triazole $2 \mathrm{a}$ (1.75 equiv., $523 \mathrm{mg}, 1.75 \mathrm{mmol})$ according to the general procedure $(20 \mathrm{mg}$ of 
$\mathrm{Rh}_{2}$ (Piv) 4 (3.3 mol \%, calcd on isoxazole), $8 \mathrm{~mL}$ of toluene, eluent hexane/ EtOAc 3:1), yield: $210 \mathrm{mg}(73 \%)$.

Synthesis from $2 \mathrm{H}$-azirine. Compound 3a was also obtained from $2 \mathrm{H}$-azirine 6 (52 mg, 0.3 $\mathrm{mmol}$ ) and triazole $\mathbf{2 a}$ (1.4 equiv., $124 \mathrm{mg}, 0.415 \mathrm{mmol}$ ) according to the general procedure (9.3 $\mathrm{mg}$ of $\mathrm{Rh}_{2}(\mathrm{OAc})_{4}\left(7 \mathrm{~mol} \%\right.$, calcd on azirine), $3.5 \mathrm{~mL}$ of toluene, eluent hexane/ $\left.\mathrm{Et}_{2} \mathrm{O} 1: 1\right)$, yield: $39 \mathrm{mg}(45 \%)$.

A yellow oil. ${ }^{1} \mathrm{H}$ NMR (400 MHz, $\left.\mathrm{CDCl}_{3}\right) \delta 8.14(\mathrm{~d}, J=8.5 \mathrm{~Hz}, 2 \mathrm{H}), 7.66-7.62(\mathrm{~m}, 1 \mathrm{H})$, $7.57-7.46(\mathrm{~m}, 5 \mathrm{H}), 7.24(\mathrm{~d}, J=8.1 \mathrm{~Hz}, 2 \mathrm{H}), 2.40(\mathrm{~s}, 6 \mathrm{H}) ;{ }^{13} \mathrm{C}\left\{{ }^{1} \mathrm{H}\right\} \mathrm{NMR}\left(100 \mathrm{MHz}, \mathrm{CDCl}_{3}\right) \delta$ $191.8,165.1,160.7,136.0,135.3,134.7,133.5,131.0,129.1,128.5,128.29,128.26,23.1$; HRMS (ESI/Q-TOF) m/z: [M + H] ${ }^{+}$Calcd for $\mathrm{C}_{19} \mathrm{H}_{17} \mathrm{~N}_{2} \mathrm{O}^{+}$289.1335; Found 289.1335.

\section{(5-(4-Chlorophenyl)-4,6-dimethylpyrimidin-2-yl)(phenyl)methanone (3b)}

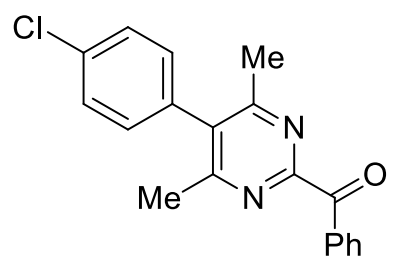

This compound was obtained from isoxazole $\mathbf{1 b}(42 \mathrm{mg}, 0.2 \mathrm{mmol})$ and triazole $\mathbf{2 a}$ (1.75 equiv., $105 \mathrm{mg}, 0.35 \mathrm{mmol}$ ) according to the general procedure (eluent hexane/EtOAc 3:1) as a paleyellow solid (39 mg, yield 60\%). Mp: $130-133{ }^{\circ} \mathrm{C} .{ }^{1} \mathrm{H}$ NMR (400 MHz, $\left.\mathrm{CDCl}_{3}\right) \delta 8.16-8.09(\mathrm{~m}$, 2H), 7.68-7.61 (m, 1H), 7.56-7.48 (m, 4H), 7.23-7.17 (m, 2H), $2.39(\mathrm{~s}, 6 \mathrm{H}) ;{ }^{13} \mathrm{C}\left\{{ }^{1} \mathrm{H}\right\}$ NMR $\left(100 \mathrm{MHz}, \mathrm{CDCl}_{3}\right) \delta 191.7,165.1,161.0,135.2,134.5,134.39,133.6,133.5,131.0,129.9$, 129.5, 128.3, 23.1; HRMS (ESI/Q-TOF) $m / z:[\mathrm{M}+\mathrm{Na}]^{+}$Calcd for $\mathrm{C}_{19} \mathrm{H}_{15}{ }^{35} \mathrm{ClN}_{2} \mathrm{NaO}^{+} 345.0765$; Found 345.0776 .

(5-(4-Methoxyphenyl)-4,6-dimethylpyrimidin-2-yl)(phenyl)methanone (3c)<smiles>COc1ccc(-c2c(C)nc(C(=O)c3ccccc3)nc2C)cc1</smiles>

This compound was obtained from isoxazole $1 \mathbf{c}(41 \mathrm{mg}, 0.2 \mathrm{mmol})$ and triazole $2 \mathbf{a}$ (1.75 equiv., $105 \mathrm{mg}, 0.35 \mathrm{mmol}$ ) according to the general procedure (eluent hexane/EtOAc 5:1) as a paleyellow solid (30 mg, yield 47\%). Mp: 80-82 ${ }^{\circ} \mathrm{C}$. ${ }^{1} \mathrm{H}$ NMR (400 MHz, $\left.\mathrm{CDCl}_{3}\right) \delta 8.16-8.11(\mathrm{~m}$, 2H), $7.63(\mathrm{t}, J=7.4 \mathrm{~Hz}, 1 \mathrm{H}), 7.51(\mathrm{t}, J=7.6 \mathrm{~Hz}, 2 \mathrm{H}), 7.16(\mathrm{t}, J=8.7 \mathrm{~Hz}, 2 \mathrm{H}), 7.06(\mathrm{t}, J=8.7$ $\mathrm{Hz}, 2 \mathrm{H}), 3.90(\mathrm{~s}, 3 \mathrm{H}), 2.39(\mathrm{~s}, 6 \mathrm{H}) ;{ }^{13} \mathrm{C}\left\{{ }^{1} \mathrm{H}\right\} \mathrm{NMR}\left(100 \mathrm{MHz}, \mathrm{CDCl}_{3}\right) \delta 191.9,165.5,160.5$, 
159.5, 135.3, 134.5, 133.4, 131.0, 129.7, 128.2, 128.0, 114.5, 55.3, 23.2; HRMS (ESI/Q-TOF) $m / z:[\mathrm{M}+\mathrm{Na}]^{+}$Calcd for $\mathrm{C}_{20} \mathrm{H}_{18} \mathrm{~N}_{2} \mathrm{NaO}_{2}{ }^{+}$341.1260; Found 341.1253.

(4,6-Dimethyl-5-(4-(trifluoromethyl)phenyl)pyrimidin-2-yl)(phenyl)methanone (3d)<smiles>Cc1nc(C(=O)c2ccccc2)nc(C)c1-c1ccc(C(F)(F)F)cc1</smiles>

This compound was obtained from isoxazole $1 \mathbf{d}(48 \mathrm{mg}, 0.2 \mathrm{mmol})$ and triazole $2 \mathbf{a}$ (2.6 equiv., $157 \mathrm{mg}, 0.52 \mathrm{mmol}$ ) according to the general procedure (eluent hexane/EtOAc 5:1) as a paleyellow solid (60 mg, yield 84\%). Mp: 55-57 ${ }^{\circ} \mathrm{C} .{ }^{1} \mathrm{H}$ NMR $\left(400 \mathrm{MHz}, \mathrm{CDCl}_{3}\right) \delta 8.12$ (d, J=8.4 $\mathrm{Hz}, 2 \mathrm{H}), 7.82(\mathrm{~d}, J=8.0 \mathrm{~Hz}, 2 \mathrm{H}), 7.67-7.60(\mathrm{~m}, 1 \mathrm{H}), 7.51(\mathrm{t}, J=7.7 \mathrm{~Hz}, 2 \mathrm{H}), 7.41(\mathrm{~d}, J=7.9$ $\mathrm{Hz}, 2 \mathrm{H}), 2.37(\mathrm{~s}, 6 \mathrm{H}) ;{ }^{13} \mathrm{C}\left\{{ }^{1} \mathrm{H}\right\} \mathrm{NMR}\left(100 \mathrm{MHz}, \mathrm{CDCl}_{3}\right) \delta 191.6,164.9,161.2,139.9,135.1$, 133.6, 133.4, 130.9, 130.7 (q, $J=32.5 \mathrm{~Hz}), 129.1,128.3,126.2$ (q, $J=3.6 \mathrm{~Hz}), 123.8(\mathrm{q}, J=$ 272.1 Hz), 23.08; HRMS (ESI/Q-TOF) $\mathrm{m} / z$ : $[\mathrm{M}+\mathrm{Na}]^{+}$Calcd for $\mathrm{C}_{20} \mathrm{H}_{15} \mathrm{~F}_{3} \mathrm{~N}_{2} \mathrm{NaO}^{+} 379.1029$; Found 379.1032 .

\section{(4,6-Dimethyl-5-(o-tolyl)pyrimidin-2-yl)(phenyl)methanone (3e)}<smiles>Cc1ccccc1-c1c(C)nc(C(=O)c2ccccc2)nc1C</smiles>

This compound was obtained from isoxazole 1 e $(19 \mathrm{mg}, 0.1 \mathrm{mmol})$ and triazole $2 \mathbf{a}$ (1.75 equiv., $52 \mathrm{mg}, 0.175 \mathrm{mmol})$ according to the general procedure $(1.2 \mathrm{~mL}$ of toluene, eluent hexane/EtOAc 5:1) as a white solid (11 mg, yield 36\%). Mp: $114-116{ }^{\circ} \mathrm{C} .{ }^{1} \mathrm{H}$ NMR (400 MHz, $\left.\mathrm{CDCl}_{3}\right) \delta 8.15(\mathrm{~d}, J=7.1 \mathrm{~Hz}, 2 \mathrm{H}), 7.67-7.61(\mathrm{~m}, 1 \mathrm{H}), 7.52(\mathrm{t}, J=7.7 \mathrm{~Hz}, 2 \mathrm{H}), 7.42-7.31(\mathrm{~m}$, $3 \mathrm{H}), 7.10(\mathrm{~d}, J=7.2 \mathrm{~Hz}, 1 \mathrm{H}), 2.32(\mathrm{~s}, 6 \mathrm{H}), 2.08(\mathrm{~s}, 3 \mathrm{H}) ;{ }^{13} \mathrm{C}\left\{{ }^{1} \mathrm{H}\right\} \mathrm{NMR}\left(100 \mathrm{MHz}, \mathrm{CDCl}_{3}\right) \delta$ $191.9,165.3,160.9,135.4$ (2C), 134.2, 133.5 (2C), 131.1, 130.7, 128.7, 128.4, 128.3, 126.7, 22.7, 19.5; HRMS (ESI/Q-TOF) $m / z:[\mathrm{M}+\mathrm{H}]^{+}$Calcd for $\mathrm{C}_{20} \mathrm{H}_{19} \mathrm{~N}_{2} \mathrm{O}^{+}$303.1492; Found 303.1501 .

(4,6-Dimethyl-5-(naphthalen-2-yl)pyrimidin-2-yl)(phenyl)methanone (3f)<smiles>Cc1nc(C(=O)c2ccccc2)nc(C)c1-c1ccc2ccccc2c1</smiles> 
This compound was obtained from isoxazole $\mathbf{1 f}(45 \mathrm{mg}, 0.2 \mathrm{mmol})$ and triazole $\mathbf{2 a}$ (1.75 equiv., $105 \mathrm{mg}, 0.35 \mathrm{mmol}$ ) according to the general procedure (eluent hexane/EtOAc 5:1) as a yellow solid (59 mg, yield 87\%). Mp: $104-107{ }^{\circ} \mathrm{C} .{ }^{1} \mathrm{H}$ NMR (400 MHz, $\left.\mathrm{CDCl}_{3}\right) \delta 8.21-8.14(\mathrm{~m}, 2 \mathrm{H})$, $8.03(\mathrm{~d}, J=8.5 \mathrm{~Hz}, 1 \mathrm{H}), 7.99-7.89(\mathrm{~m}, 2 \mathrm{H}), 7.74(\mathrm{~s}, 1 \mathrm{H}), 7.68-7.56(\mathrm{~m}, 3 \mathrm{H}), 7.53$ (t, J = 7.7 Hz, $2 \mathrm{H}), 7.35(\mathrm{dd}, J=8.4,1.7 \mathrm{~Hz}, 1 \mathrm{H}), 2.43(\mathrm{~s}, 6 \mathrm{H}) ;{ }^{13} \mathrm{C}\left\{{ }^{1} \mathrm{H}\right\} \mathrm{NMR}\left(100 \mathrm{MHz}, \mathrm{CDCl}_{3}\right) \delta 191.8$, 165.2, 160.8, 135.3, 134.7, 133.5, 133.4, 133.3, 132.8, 131.0, 129.0, 128.2, 127.9, 127.9, 127.7, 126.8, 126.7, 126.1, 23.2; HRMS (ESI/Q-TOF) $m / z$ : $[\mathrm{M}+\mathrm{Na}]^{+}$Calcd for $\mathrm{C}_{23} \mathrm{H}_{18} \mathrm{~N}_{2} \mathrm{NaO}^{+}$ 361.1311; Found 361.1296.

(4,6-Dimethyl-5-(thiophen-3-yl)pyrimidin-2-yl)(phenyl)methanone (3g)<smiles>Cc1nc(C(=O)c2ccccc2)nc([N+](=O)[O-])c1-c1ccsc1</smiles>

This compound was obtained from isoxazole $1 \mathrm{~g}$ (36 $\mathrm{mg}, 0.2 \mathrm{mmol}$ ) and triazole $\mathbf{2 a}$ (1.75 equiv., $105 \mathrm{mg}, 0.35 \mathrm{mmol}$ ) according to the general procedure (eluent hexane/EtOAc 5:1) as a brown solid (33 mg, yield 56\%). Mp: $73-76{ }^{\circ} \mathrm{C} .{ }^{1} \mathrm{H} \mathrm{NMR}\left(400 \mathrm{MHz}, \mathrm{CDCl}_{3}\right) \delta 8.12(\mathrm{~d}, J=7.2 \mathrm{~Hz}$, 2H), $7.62(\mathrm{t}, J=7.4 \mathrm{~Hz}, 1 \mathrm{H}), 7.55(\mathrm{dd}, J=4.9,2.9 \mathrm{~Hz}, 1 \mathrm{H}), 7.52(\mathrm{t}, J=7.6 \mathrm{~Hz}, 2 \mathrm{H}), 7.26(\mathrm{dd}, J$ $=3.0,1.3 \mathrm{~Hz}, 1 \mathrm{H}), 7.05(\mathrm{dd}, J=4.9,1.4 \mathrm{~Hz}, 1 \mathrm{H}), 2.44(\mathrm{~s}, 6 \mathrm{H}) ;{ }^{13} \mathrm{C}\left\{{ }^{1} \mathrm{H}\right\} \mathrm{NMR}(100 \mathrm{MHz}$, $\left.\mathrm{CDCl}_{3}\right) \delta 191.8,165.8,160.7,135.5,135.3,133.5,131.0,130.3,128.3,127.8,127.0,124.0$, 23.1; HRMS (ESI/Q-TOF) $m / z:[\mathrm{M}+\mathrm{H}]^{+}$Calcd for $\mathrm{C}_{17} \mathrm{H}_{15} \mathrm{~N}_{2} \mathrm{SO}^{+} 295.0900$; Found 295.0901.

\section{(4,6-Dimethyl-5-((trimethylsilyl)ethynyl)pyrimidin-2-yl)(phenyl)methanone (3h)}

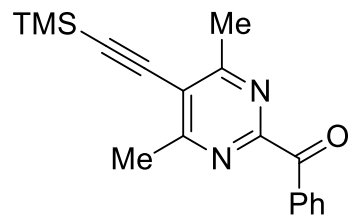

This compound was obtained from isoxazole $\mathbf{1 h}(39 \mathrm{mg}, 0.2 \mathrm{mmol})$ and triazole $\mathbf{2 a}$ (1.75 equiv., $105 \mathrm{mg}, 0.35 \mathrm{mmol}$ ) according to the general procedure (eluent hexane/EtOAc 5:1) as a yellow oil (39 mg, yield 63\%); ${ }^{1} \mathrm{H}$ NMR (400 MHz, $\left.\mathrm{CDCl}_{3}\right) \delta 8.07-8.01(\mathrm{~m}, 2 \mathrm{H}), 7.65-7.58(\mathrm{~m}, 1 \mathrm{H})$, $7.52-7.45(\mathrm{~m}, 2 \mathrm{H}), 2.43(\mathrm{~s}, 6 \mathrm{H}), 0.33(\mathrm{~s}, 9 \mathrm{H}) ;{ }^{13} \mathrm{C}\left\{{ }^{1} \mathrm{H}\right\} \mathrm{NMR}\left(100 \mathrm{MHz}, \mathrm{CDCl}_{3}\right) \delta$ 191.3, 169.0, 158.8, 135.19, 133.5, 130.9, 128.3, 118.4, 110.1, 98.1, 23.4, -0.3; HRMS (ESI/Q-TOF) $m / z:$ [M $+\mathrm{Na}]^{+}$Calcd for $\mathrm{C}_{18} \mathrm{H}_{20} \mathrm{~N}_{2} \mathrm{SiNaO}^{+} 331.1237$; Found 331.1250. 


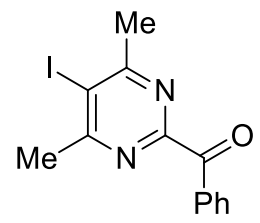

This compound was obtained from isoxazole $1 \mathbf{i}(45 \mathrm{mg}, 0.2 \mathrm{mmol})$ and triazole $2 \mathbf{a}$ (1.75 equiv., $105 \mathrm{mg}, 0.35 \mathrm{mmol}$ ) according to the general procedure (eluent hexane/EtOAc 1:1) as a white solid (38 mg, yield 56\%). Mp: 74-77 ${ }^{\circ} \mathrm{C} .{ }^{1} \mathrm{H}$ NMR (400 MHz, $\mathrm{CDCl}_{3}$ ) $\delta 8.07-8.04(\mathrm{~m}, 2 \mathrm{H}), 7.62$ (t, $J=7.4 \mathrm{~Hz}, 1 \mathrm{H}), 7.50(\mathrm{t}, J=7.7 \mathrm{~Hz}, 2 \mathrm{H}), 2.85(\mathrm{~s}, 6 \mathrm{H}) ;{ }^{13} \mathrm{C}\left\{{ }^{1} \mathrm{H}\right\} \mathrm{NMR}\left(100 \mathrm{MHz}, \mathrm{CDCl}_{3}\right) \delta$ 191.0, 169.9, 161.0, 135.1, 133.6, 130.9, 128.3, 102.0, 29.7; HRMS (ESI/Q-TOF) $\mathrm{m} / \mathrm{z}:[\mathrm{M}+$ $\mathrm{Na}]^{+}$Calcd for $\mathrm{C}_{13} \mathrm{H}_{11} \mathrm{IN}_{2} \mathrm{NaO}^{+} 360.9808$; Found 360.9810.

Ethyl 2-benzoyl-4,6-dimethylpyrimidine-5-carboxylate (3j)<smiles>CCOC(=O)c1c(C)nc(C(=O)c2ccccc2)nc1[N+](=O)[O-]</smiles>

This compound was obtained from isoxazole $\mathbf{1 j}$ (34 $\mathrm{mg}, 0.2 \mathrm{mmol})$ and triazole $\mathbf{2 a}$ (3.5 equiv., $210 \mathrm{mg}, 0.7 \mathrm{mmol}$ ) according to the general procedure (eluent hexane/EtOAc 5:1) as a yellow oil (26 mg, yield 46\%). ${ }^{1} \mathrm{H}$ NMR (400 MHz, $\left.\mathrm{CDCl}_{3}\right) \delta 8.03(\mathrm{~d}, J=6.9 \mathrm{~Hz}, 2 \mathrm{H}), 7.63(\mathrm{t}, J=7.4 \mathrm{~Hz}$, $1 \mathrm{H}), 7.49(\mathrm{t}, J=7.7 \mathrm{~Hz}, 2 \mathrm{H}), 4.51(\mathrm{q}, J=7.1 \mathrm{~Hz}, 2 \mathrm{H}), 2.66(\mathrm{~s}, 6 \mathrm{H}), 1.46(\mathrm{t}, J=7.1 \mathrm{~Hz}, 3 \mathrm{H})$; ${ }^{13} \mathrm{C}\left\{{ }^{1} \mathrm{H}\right\}$ NMR $\left(100 \mathrm{MHz}, \mathrm{CDCl}_{3}\right) \delta 191.1,166.9,164.8,161.9,134.9,133.8,130.9,128.4$, 127.2, 62.2, 22.8, 14.1; HRMS (ESI/Q-TOF) $m / z:[\mathrm{M}+\mathrm{H}]^{+}$Calcd for $\mathrm{C}_{16} \mathrm{H}_{17} \mathrm{~N}_{2} \mathrm{O}_{3}{ }^{+}$285,1234; Found 285,1244.

\section{(4,6-Dimethyl-5-phenylpyrimidin-2-yl)(p-tolyl)methanone (3k)}<smiles>Cc1ccc(C(=O)c2nc(C)c(-c3ccccc3)c(C)n2)cc1</smiles>

This compound was obtained from isoxazole $\mathbf{1 a}(35 \mathrm{mg}, 0.2 \mathrm{mmol})$ and triazole $\mathbf{2 d}$ (2.25 equiv., $140 \mathrm{mg}, 0.45 \mathrm{mmol}$ ) according to the general procedure (eluent hexane/EtOAc 3:1) as a yellow oil (27 mg, yield 45\%). ${ }^{1} \mathrm{H}$ NMR (400 MHz, $\left.\mathrm{CDCl}_{3}\right) \delta 8.04(\mathrm{~d}, J=8.3 \mathrm{~Hz}, 2 \mathrm{H}), 7.57-7.44$ (m, $3 \mathrm{H}), 7.31(\mathrm{~d}, J=8.0 \mathrm{~Hz}, 2 \mathrm{H}), 7.27-7.22(\mathrm{~m}, 2 \mathrm{H}), 2.46(\mathrm{~s}, 3 \mathrm{H}), 2.38(\mathrm{~s}, 6 \mathrm{H}) ;{ }^{13} \mathrm{C}\left\{{ }^{1} \mathrm{H}\right\} \mathrm{NMR}(100$ $\left.\mathrm{MHz}, \mathrm{CDCl}_{3}\right) \delta 191.6,165.1,161.0,144.5,136.1,134.6,132.8,131.2,129.1,129.0,128.5$, 128.3, 23.1, 21.8; HRMS (ESI/Q-TOF) $m / z$ : $[\mathrm{M}+\mathrm{H}]^{+}$Calcd for $\mathrm{C}_{20} \mathrm{H}_{19} \mathrm{~N}_{2} \mathrm{O}^{+}$303.1492; Found 303.1501 . 
(4-Chlorophenyl)(4,6-dimethyl-5-phenylpyrimidin-2-yl)methanone (3l)

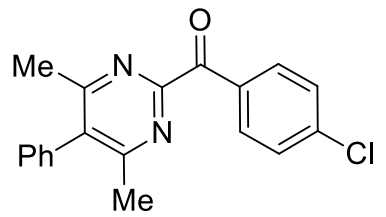

This compound was obtained from isoxazole $\mathbf{1 a}(35 \mathrm{mg}, 0.2 \mathrm{mmol})$ and triazole $\mathbf{2 e}$ (1.75 equiv., $117 \mathrm{mg}, 0.35 \mathrm{mmol}$ ) according to the general procedure (eluent hexane/EtOAc 5:1) as a yellow oil (58 mg, yield 90\%). ${ }^{1} \mathrm{H}$ NMR (400 MHz, $\left.\mathrm{CDCl}_{3}\right) \delta 8.12(\mathrm{~d}, J=8.6 \mathrm{~Hz}, 2 \mathrm{H}), 7.57-7.44(\mathrm{~m}$, 5H), 7.25-7.21 (m, 2H), $2.38(\mathrm{~s}, 6 \mathrm{H}) ;{ }^{13} \mathrm{C}\left\{{ }^{1} \mathrm{H}\right\} \mathrm{NMR}\left(100 \mathrm{MHz}, \mathrm{CDCl}_{3}\right) \delta$ 190.4, 165.2, 160.1, 140.0, 135.8, 135.0, 133.7, 132.4, 129.1, 128.6, 128.4, 128.3, 23.1; HRMS (ESI/Q-TOF) m/z: [M $+\mathrm{H}]^{+}$Calcd for $\mathrm{C}_{19} \mathrm{H}_{16}{ }^{35} \mathrm{ClN}_{2} \mathrm{O}^{+}$323.0946; Found 323.0950.

(4-Methoxyphenyl)(4,6-dimethyl-5-phenylpyrimidin-2-yl)methanone (3m)<smiles>COc1ccc(C(=O)c2nc(C)c(-c3ccccc3)c([N+](=O)[O-])n2)cc1</smiles>

This compound was obtained from isoxazole $\mathbf{1 a}(35 \mathrm{mg}, 0.2 \mathrm{mmol})$ and triazole $\mathbf{2 f}$ (1.75 equiv., $115 \mathrm{mg}, 0.35 \mathrm{mmol}$ ) according to the general procedure (eluent hexane/EtOAc 3:1) as a paleyellow solid (44 mg, yield 69\%). Mp: $104-107{ }^{\circ} \mathrm{C} .{ }^{1} \mathrm{H}$ NMR $\left(400 \mathrm{MHz}, \mathrm{CDCl}_{3}\right) \delta 8.14(\mathrm{~d}, J=$ $8.9 \mathrm{~Hz}, 2 \mathrm{H}), 7.56-7.44(\mathrm{~m}, 3 \mathrm{H}), 7.26-7.21(\mathrm{~m}, 2 \mathrm{H}), 6.99$ (d, J = 8.9 Hz, 2H), 3.90 (s, 3H), 2.38 $(\mathrm{s}, 6 \mathrm{H}) ;{ }^{13} \mathrm{C}\left\{{ }^{1} \mathrm{H}\right\}$ NMR $\left(100 \mathrm{MHz}, \mathrm{CDCl}_{3}\right) \delta 190.4,165.0,164.0,161.2,136.1,134.5,133.5$, 129.1, 128.5, 128.2, 128.2, 113.63, 55.5, 23.1; HRMS (ESI/Q-TOF) $\mathrm{m} / z:[\mathrm{M}+\mathrm{Na}]^{+}$Calcd for $\mathrm{C}_{20} \mathrm{H}_{18} \mathrm{~N}_{2} \mathrm{NaO}_{2}{ }^{+}$341.1260; Found 341.1256.

(4,6-Dimethyl-5-phenylpyrimidin-2-yl)(4-(trifluoromethyl)phenyl)methanone (3n)<smiles>Cc1nc(C(=O)c2ccc(C(F)(F)F)cc2)nc(C)c1-c1ccccc1</smiles>

This compound was obtained from isoxazole $\mathbf{1 a}(35 \mathrm{mg}, 0.2 \mathrm{mmol})$ and triazole $\mathbf{2 g}$ (1.75 equiv., $128 \mathrm{mg}, 0.35 \mathrm{mmol}$ ) according to the general procedure (eluent hexane/EtOAc 3:1) as a yellow oil (43 mg, yield 61\%). ${ }^{1} \mathrm{H} \mathrm{NMR}\left(400 \mathrm{MHz}, \mathrm{CDCl}_{3}\right) \delta 8.28(\mathrm{~d}, J=8.1 \mathrm{~Hz}, 2 \mathrm{H}), 7.78(\mathrm{~d}, J=8.2$ $\mathrm{Hz}, 2 \mathrm{H}), 7.54(\mathrm{t}, J=7.3 \mathrm{~Hz}, 2 \mathrm{H}), 7.48(\mathrm{t}, J=7.3 \mathrm{~Hz}, 1 \mathrm{H}), 7.24(\mathrm{~d}, J=6.7 \mathrm{~Hz}, 2 \mathrm{H}), 2.40(\mathrm{~s}, 6 \mathrm{H})$; ${ }^{13} \mathrm{C}\left\{{ }^{1} \mathrm{H}\right\}$ NMR $\left(100 \mathrm{MHz}, \mathrm{CDCl}_{3}\right) \delta 190.6,165.4,159.6,138.4,135.8,135.3,134.4$ (q, $J=32.7$ Hz), 131.3, 129.2, 128.4, 128.4, 125.2 (q, $J=3.8 \mathrm{~Hz}), 123.7(\mathrm{q}, J=272.8 \mathrm{~Hz}), 23.1$; HRMS (ESI/Q-TOF) $m / z:[\mathrm{M}+\mathrm{H}]^{+}$Calcd for $\mathrm{C}_{20} \mathrm{H}_{16} \mathrm{~F}_{3} \mathrm{~N}_{2} \mathrm{O}^{+}$357.1209; Found 357.1199. 


\section{(4,6-Dimethyl-5-phenylpyrimidin-2-yl)(4-nitrophenyl)methanone (3o)}<smiles>Cc1nc(C(=O)c2ccc([N+](=O)[O-])cc2)nc(C)c1-c1ccccc1</smiles>

This compound was obtained from isoxazole $\mathbf{1 a}(35 \mathrm{mg}, 0.2 \mathrm{mmol})$ and triazole $\mathbf{2 h}$ (1.75 equiv., $121 \mathrm{mg}, 0.35 \mathrm{mmol}$ ) according to the general procedure (washing with hexane/Et $2 \mathrm{O} 1: 1$ instead of column chromatography) as a yellow solid (26 mg, yield 39\%). Mp: $103-104{ }^{\circ} \mathrm{C} .{ }^{1} \mathrm{H} \mathrm{NMR}$ $\left(400 \mathrm{MHz}, \mathrm{CDCl}_{3}\right) \delta 8.35(\mathrm{~s}, 4 \mathrm{H}), 7.59-7.44(\mathrm{~m}, 3 \mathrm{H}), 7.28-7.21(\mathrm{~m}, 2 \mathrm{H}), 2.40(\mathrm{~s}, 6 \mathrm{H}) ;{ }^{13} \mathrm{C}\left\{{ }^{1} \mathrm{H}\right\}$ NMR $\left(100 \mathrm{MHz}, \mathrm{CDCl}_{3}\right) \delta 190.0,165.5,159.1,150.3,140.5,135.6,135.6,132.0,129.2,128.5$, 128.3, 123.3, 23.2; HRMS (ESI/Q-TOF) $m / z$ : $[\mathrm{M}+\mathrm{H}]^{+}$Calcd for $\mathrm{C}_{19} \mathrm{H}_{16} \mathrm{~N}_{3} \mathrm{O}_{3}{ }^{+}$334.1186; Found 334.1183.

\section{Ethyl 2-(4-(tert-butyl)benzoyl)-4,6-dimethylpyrimidine-5-carboxylate (3p)}<smiles>CCOC(=O)c1c(C)nc(C(=O)c2ccc(C(C)(C)C)cc2)nc1O</smiles>

This compound was obtained from isoxazole $\mathbf{1 j}(33.8 \mathrm{mg}, 0.2 \mathrm{mmol})$ and triazole $2 \mathbf{i}$ ( 2 equiv., $142 \mathrm{mg}, 0.35 \mathrm{mmol}$ ) according to the general procedure (eluent hexane/EtOAc 4:1) as a yellow oil (41 mg, yield 60\%). ${ }^{1} \mathrm{H}$ NMR $\left(400 \mathrm{MHz}, \mathrm{CDCl}_{3}\right) \delta 7.98(\mathrm{~d}, J=8.5 \mathrm{~Hz}, 2 \mathrm{H}), 7.52(\mathrm{~d}, J=8.6$ $\mathrm{Hz}, 2 \mathrm{H}), 4.51(\mathrm{q}, J=7.1 \mathrm{~Hz}, 2 \mathrm{H}), 2.66(\mathrm{~s}, 6 \mathrm{H}), 1.47(\mathrm{t}, J=7.1 \mathrm{~Hz}, 3 \mathrm{H}), 1.37(\mathrm{~s}, 9 \mathrm{H}) .{ }^{13} \mathrm{C}\left\{{ }^{1} \mathrm{H}\right\}$ NMR (100 MHz, $\left.\mathrm{CDCl}_{3}\right) \delta 190.7,166.9,164.7,162.2,157.7,132.2,130.9,127.1,125.4,62.1$, 35.2, 31.0, 22.8, 14.1.; HRMS (ESI/Q-TOF) $m / z$ : $[\mathrm{M}+\mathrm{H}]^{+}$Calcd for $\mathrm{C}_{20} \mathrm{H}_{25} \mathrm{~N}_{2} \mathrm{O}_{3}{ }^{+} 341.1860$; Found 341.1861 .

\section{(4-Methyl-5,6-diphenylpyrimidin-2-yl)(phenyl)methanone (3q)}<smiles>Cc1nc(C(=O)c2ccccc2)nc(-c2ccccc2)c1-c1ccccc1</smiles>

This compound was obtained from isoxazole $1 \mathbf{k}(48 \mathrm{mg}, 0.2 \mathrm{mmol})$ and triazole $2 \mathbf{a}$ (2.62 equiv., $157 \mathrm{mg}, 0.52 \mathrm{mmol}$ ) according to the general procedure (eluent hexane/EtOAc 5:1) as a paleyellow solid (52 mg, yield 74\%). Mp: $118-121{ }^{\circ} \mathrm{C} .{ }^{1} \mathrm{H}$ NMR (400 MHz, $\left.\mathrm{CDCl}_{3}\right) \delta 8.21-8.19$ (m, 2H), 7.67-7.63 (m, 1H), $7.53(\mathrm{t}, J=7.7 \mathrm{~Hz}, 2 \mathrm{H}), 7.44-7.38(\mathrm{~m}, 5 \mathrm{H}), 7.30-7.26(\mathrm{~m}, 1 \mathrm{H}), 7.24-$ $7.18(\mathrm{~m}, 4 \mathrm{H}) 2.54(\mathrm{~s}, 3 \mathrm{H}) ;{ }^{13} \mathrm{C}\left\{{ }^{1} \mathrm{H}\right\} \mathrm{NMR}\left(100 \mathrm{MHz}, \mathrm{CDCl}_{3}\right) \delta$ 191.7, 167.2, 163.4, 161.0, 137.3, 
136.0, 135.3, 133.5, 133.2, 131.0, 129.9, 129.7, 129.1, 128.8, 128.3, 128.1, 127.9, 23.7.; HRMS (ESI/Q-TOF) $m / z:[\mathrm{M}+\mathrm{H}]^{+}$Calcd for $\mathrm{C}_{24} \mathrm{H}_{19} \mathrm{~N}_{2} \mathrm{O}^{+} 351.1492$; Found 351.1504.

(4-(3-Chloro-4-methylphenyl)-5,6,7,8-tetrahydroquinazolin-2-yl)(phenyl)methanone (3r)<smiles>COc1ccc(-c2nc(C(=O)c3ccccc3)nc3c2CCCC3)cc1Cl</smiles>

This compound was obtained from isoxazole $1 \mathbf{m}(27 \mathrm{mg}, 0.11 \mathrm{mmol})$ and triazole $2 \mathbf{a}$ (3 equiv., $99 \mathrm{mg}, 0.33 \mathrm{mmol}$ ) according to the general procedure (eluent hexane/EtOAc 5:1) as a paleyellow oil (19 mg, yield 48\%). ${ }^{1} \mathrm{H} \mathrm{NMR}\left(400 \mathrm{MHz} \mathrm{CDCl}_{3}\right) \delta 8.11$ (dd, $J=8.4,1.4 \mathrm{~Hz}, 2 \mathrm{H}$ ), 7.64-7.59 (m, 2H), $7.49(\mathrm{dd}, J=8.4,7.0 \mathrm{~Hz}, 2 \mathrm{H}), 7.44(\mathrm{dd}, J=7.8,1.9 \mathrm{~Hz}, 1 \mathrm{H}), 7.34(\mathrm{~d}, J=7.8$ $\mathrm{Hz}, 1 \mathrm{H}), 3.10$ (t, $J=6.6 \mathrm{~Hz}, 2 \mathrm{H}), 2.88$ (t, $J=6.2 \mathrm{~Hz}, 2 \mathrm{H}), 2.45$ (s, 3H), 2.04-1.98 (m, 2H), 1.89 $1.83(\mathrm{~m}, 2 \mathrm{H}) ;{ }^{13} \mathrm{C}\left\{{ }^{1} \mathrm{H}\right\} \mathrm{NMR}\left(100 \mathrm{MHz}, \mathrm{CDCl}_{3}\right) \delta 191.7,167.7,163.6,159.9,137.6,136.6$, 135.4, 134.4, 133.4, 131.0, 130.8, 129.6, 129.1, 128.2, 127.3, 32.6, 27.3, 22.5, 22.1, 20.; HRMS (ESI/Q-TOF) $m / z:[\mathrm{M}+\mathrm{H}]^{+}$Calcd for $\mathrm{C}_{22} \mathrm{H}_{20}{ }^{35} \mathrm{ClN}_{2} \mathrm{O}^{+} 363.1259$; Found 363.1260.

\section{(2,3-Dimethyl-5-phenyl-1-(4-methylphenylsulfonyl)-1,2-dihydropyrazin-2-} yl)(phenyl)methanone (4b)

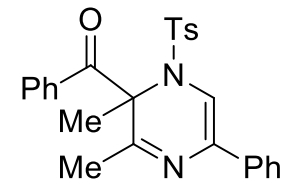

Obtained from isoxazole $1 \mathrm{n}(52 \mathrm{mg}, 0.3 \mathrm{mmol})$ and triazole 2a (1.38 equiv., $124 \mathrm{mg}, 0.415$ mmol) according to the general procedure (12.8 $\mathrm{mg}$ of $\mathrm{Rh}_{2}(\mathrm{Piv})_{4}(7 \mathrm{~mol} \%$, calcd on isoxazole), $3.5 \mathrm{~mL}$ of toluene, eluent hexane/EtOAc $3: 1$ ) as an unstable orange oil (98 $\mathrm{mg}$, yield $73 \%) .{ }^{1} \mathrm{H}$ NMR (400 MHz, $\left.\mathrm{CDCl}_{3}\right) \delta 8.03(\mathrm{~d}, J=7.2 \mathrm{~Hz}, 2 \mathrm{H}), 7.70(\mathrm{~d}, J=7.1 \mathrm{~Hz}, 2 \mathrm{H}), 7.58-7.46(\mathrm{~m}, 2 \mathrm{H})$, 7.44-7.36 (m, 4H), 7.35-7.25 (m, 2H), $7.14(\mathrm{~d}, J=8.1 \mathrm{~Hz}, 2 \mathrm{H}), 6.85$ (s, 1H), 2.39 (s, 3H), 2.02 (s, 3H), $1.87(\mathrm{~s}, 3 \mathrm{H}) ;{ }^{13} \mathrm{C}\left\{{ }^{1} \mathrm{H}\right\} \mathrm{NMR}\left(100 \mathrm{MHz}, \mathrm{CDCl}_{3}\right) \delta 195.3,159.3,144.6,135.9,135.7$, 135.7, 132.7, 129.7, 129.5, 129.0, 128.6, 128.1, 127.5, 127.3, 124.2, 111.2, 68.7, 22.7, 21.5, 19.3; HRMS (ESI/Q-TOF) $m / z:[\mathrm{M}+\mathrm{H}]^{+}$Calcd for $\mathrm{C}_{26} \mathrm{H}_{25} \mathrm{~N}_{2} \mathrm{O}_{3} \mathrm{~S}^{+} 445.1580$; Found 445.1590 . 
1-one (4c)

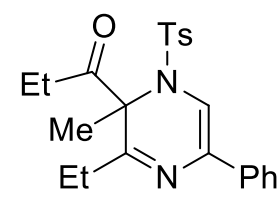

Obtained from isoxazole $10(21 \mathrm{mg}, 0.15 \mathrm{mmol}$ ) and triazole 2a (2 equiv., $90 \mathrm{mg}, 0.3 \mathrm{mmol}$ ) according to the general procedure (4.5 $\mathrm{mg}$ of $\mathrm{Rh}_{2}(\mathrm{Piv})_{4}(5 \mathrm{~mol} \%$, calcd on isoxazole), $1.8 \mathrm{~mL}$ of toluene, eluent hexane/EtOAc 10:1) as an unstable orange oil (55 mg, yield 90\%). ${ }^{1} \mathrm{H} \mathrm{NMR}$ (400 MHz, $\left.\mathrm{CDCl}_{3}\right) \delta$ 7.73-7.71 (m, 2H), 7.68-7.66 (m, 2H), 7.41-7.36 (m, 2H), 7.33-7.29 (m, 3H), $7.10(\mathrm{~s}, 1 \mathrm{H}), 2.98(\mathrm{dq}, J=18.3,7.2 \mathrm{~Hz}, 1 \mathrm{H}), 2.66(\mathrm{dq}, J=18.3,7.2 \mathrm{~Hz}, 1 \mathrm{H}), 2.44$ (s, 3H), 2.35-2.26 (m, 1H), 2.02-1.95 (m, 1H), $1.72(\mathrm{~s}, 3 \mathrm{H}), 1.11-1.04(\mathrm{~m}, 6 \mathrm{H}) ;{ }^{13} \mathrm{C}\left\{{ }^{1} \mathrm{H}\right\}$ NMR (100 $\left.\mathrm{MHz}, \mathrm{CDCl}_{3}\right) \delta 209.3,162.8,144.6,137.7,135.6,132.0,129.9,128.5,127.7,126.6,124.6$, 111.9, 69.5, 31.4, 27.8, 21.6, 18.0, 10.0, 8.2; HRMS (ESI/Q-TOF) $m / z:[\mathrm{M}+\mathrm{H}]^{+}$Calcd for $\mathrm{C}_{23} \mathrm{H}_{26} \mathrm{~N}_{2} \mathrm{NaO}_{3} \mathrm{~S}^{+} 433.1556$; Found 433.1559 . 


\section{Table S-1. Optimization of reaction conditions for synthesis of 3a. ${ }^{a}$}

In comparison with $\mathrm{Rh}_{2}(\mathrm{OAc})_{4}$, bulkier catalysts such as $\mathrm{Rh}_{2}(\mathrm{Piv})_{4}, \mathrm{Rh}_{2}(\mathrm{esp})_{2} \mathrm{Rh}_{2}(\mathrm{Oct})_{4}$ displayed improved activity with distinctly higher yields of $\mathbf{3 a}$ (entries 1-4). The use of $\mathrm{Rh}_{2}(\mathrm{tfa})_{4}$ led to poor conversion of substrates. The experiments were carried out with an increased $\mathbf{2 a / 1 a}$ ratio using two superior catalysts $\mathrm{Rh}_{2}(\mathrm{Piv})_{4}$ and $\mathrm{Rh}_{2}(\mathrm{esp})_{2}$ (entries 5, 6). While $\mathrm{Rh}_{2}(\mathrm{Piv})_{4}$ provided excellent yield of pyrimidine 3a $(91 \%), \mathrm{Rh}_{2}(\mathrm{esp})_{2}$ afforded almost quantitative formation of 3a (99\%). $\mathrm{Rh}_{2}(\mathrm{Piv})_{4}$ turned out to be less effective in DCE (entry 7). The minimum catalyst loading, providing high product yields, was $5 \mathrm{~mol} \%$ (entries 8,9). A noticeable decrease in the reaction efficiency was found with an increase in the concentration of reagents (entry 10), as well as with an increase in temperature to $140{ }^{\circ} \mathrm{C}$ (entry 11). 1-Mesyl-1,2,3-triazole $\mathbf{2 b}$ and 1((4-methoxyphenyl)sulfonyl) triazole $\mathbf{2 c}$ were tested (entries 12,13), in both cases the yields of pyrimidine 3a were lower compared to that for tosyltriazole $\mathbf{2 a}$.

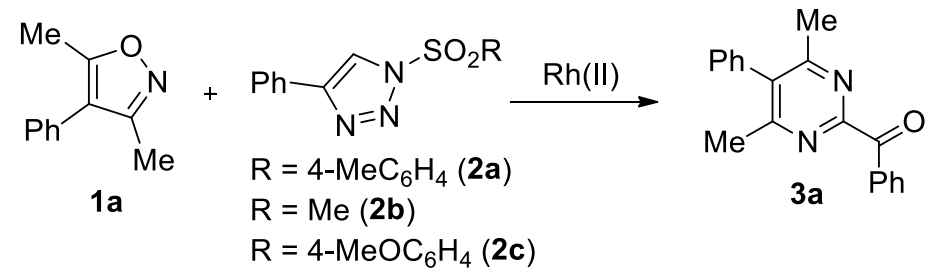

$\begin{array}{cccccc}\text { entry } & \mathrm{R} & \text { solvent } & \text { catalyst, mol \% } & \mathbf{2 / 1 a} \text { ratio } & \text { yield of 3a }(\%)^{c} \\ 1 & p \text {-Tol } & \text { toluene } & \mathrm{Rh}_{2}(\mathrm{OAc})_{4}, 7.0 & 1.4 & 55 \\ 2 & p \text {-Tol } & \text { toluene } & \mathrm{Rh}_{2}(\mathrm{Piv})_{4}, 7.0 & 1.4 & 74 \\ 3 & p \text {-Tol } & \text { toluene } & \mathrm{Rh}_{2}(\mathrm{esp})_{2}, 7.0 & 1.4 & 80 \\ 4 & p \text {-Tol } & \text { toluene } & \mathrm{Rh}_{2}(\mathrm{Oct})_{4}, 7.0 & 1.4 & 71 \\ 5 & p \text {-Tol } & \text { toluene } & \mathrm{Rh}_{2}(\mathrm{Piv})_{4}, 7.0 & 1.75 & 91 \\ 6 & p \text {-Tol } & \text { toluene } & \mathrm{Rh}_{2}(\mathrm{esp})_{2}, 7.0 & 1.75 & 99 \\ 7 & p \text {-Tol } & \text { DCE } & \mathrm{Rh}_{2}(\mathrm{Piv})_{4}, 7.0 & 1.75 & 78 \\ 8 & p \text {-Tol } & \text { toluene } & \mathrm{Rh}_{2}(\mathrm{Piv})_{4}, 3.0 & 1.75 & 54 \\ 9 & p-\text { Tol } & \text { toluene } & \mathrm{Rh}_{2}(\mathrm{Piv})_{4}, 5.0 & 1.75 & 91 \\ 10 & p-\text { Tol } & \text { toluene }{ }^{d} & \mathrm{Rh}_{2}(\mathrm{Piv})_{4}, 5.0 & 1.75 & 79 \\ 11^{e} & p-\mathrm{Tol} & \text { toluene } & \mathrm{Rh}_{2}(\mathrm{Piv})_{4}, 5.0 & 1.75 & 82 \\ 12 & \mathrm{Me} & \text { toluene } & \mathrm{Rh}_{2}(\mathrm{Piv})_{4}, 7.0 & 1.75 & 64 \\ 13 & 4-\mathrm{MeOC}{ }_{6} \mathrm{H}_{4} & \text { toluene } & \mathrm{Rh}_{2}(\mathrm{OAc})_{4}, 7.0 & 1.4 & 54\end{array}$

${ }^{a}$ Reaction conditions (unless otherwise noted): isoxazole $(0.1 \mathrm{mmol})$, triazole $(0.14-0.175 \mathrm{mmol})$, toluene $(1.2 \mathrm{~mL}), 110{ }^{\circ} \mathrm{C}$, in sealed tube. ${ }^{b}$ Calculated on 1a. ${ }^{c}{ }^{1} \mathrm{H}$ NMR yields using dibromomethane as an internal standard. ${ }^{d} 0.5 \mathrm{~mL} .{ }^{e} 140{ }^{\circ} \mathrm{C}$. 


\section{Antiproliferative assay}

Cell culture. PC-3 prostate cancer cell, HCT 116 colorectal carcinoma, MCF7 breast cancer cell, A549 lung carcinoma, WI-26 VA4 embryonic lung fibroblast cell were purchased from the ATCC. PC-3 cells and A549 cells were maintained in F12-K (Gibco, UK) supplemented with $10 \%$ fetal bovine serum (FBS, Gibco, UK), penicillin (100 UI mL ${ }^{-1}$ ), streptomycin $\left(100 \mu \mathrm{g} \mathrm{mL}^{-1}\right)$ and GlutaMax $(2 \mathrm{mM}$, Gibco, UK). HCT 116 cells were maintained in McCoy's 5A media (Gibco, UK) supplemented with 10\% fetal bovine serum (FBS, Gibco, UK), penicillin (100 UI mL $\left.\mathrm{mL}^{-1}\right)$, streptomycin $\left(100 \mu \mathrm{g} \mathrm{m}^{-1}\right)$, and GlutaMax (1.5 mM, Gibco, UK). MCF7 and WI-26 VA4 cells were maintained in Advanced MEM (Gibco, UK) supplemented with 5\% fetal bovine serum (FBS, Gibco, UK), penicillin (100 UI mL ${ }^{-1}$ ), streptomycin $\left(100 \mu \mathrm{g} \mathrm{mL}^{-1}\right)$, and GlutaMax (1.87 mM, Gibco, UK). All cell lines were cultivated under a humidified atmosphere of $95 \%$ air $/ 5 \% \mathrm{CO}_{2}$ at $37{ }^{\circ} \mathrm{C}$. Subconfluent monolayers, in the $\log$ growth phase, were harvested by a brief treatment with TrypLE Express solution (Gibco, UK) in phosphate buffered saline (PBS, Capricorn Scientific, Germany) and washed three times in serum-free PBS. The number of viable cells was determined by trypan blue exclusion.

Antiproliferative assay. The effects of the synthesized compounds on cell viability were determined using the MTT colorimetric test. ${ }^{14}$ All examined cells were diluted with the growth medium to $3.5 \times 10^{4}$ cells per $\mathrm{mL}$, and the aliquots $\left(7 \times 10^{3}\right.$ cells per $\left.200 \mu \mathrm{L}\right)$ were placed in individual wells in 96-multiplates (Eppendorf, Germany) and incubated for $24 \mathrm{~h}$. The cells were then treated with $100 \mu \mathrm{M}$ of the synthesized compounds and incubated for $72 \mathrm{~h}$ at $37{ }^{\circ} \mathrm{C}$ in $5 \%$ $\mathrm{CO}_{2}$ atmosphere. Each compound was tested in triplicate. After incubation, the cells were then treated with $40 \mu \mathrm{L}$ MTT solution (3-(4,5-dimethylthiazol-2-yl)-2,5-diphenyltetrazolium bromide, $5 \mathrm{mg} \mathrm{mL}^{-1}$ in PBS) and incubated $4 \mathrm{~h}$. After an additional $4 \mathrm{~h}$ incubation, the medium with MTT was removed, and DMSO $(150 \mu \mathrm{L})$ was added to dissolve the crystals of formazan. The plates were shaken for $10 \mathrm{~min}$. The optical density of each well was determined at $560 \mathrm{~nm}$ using a microplate reader GloMax Multi+ (Promega, USA). Each of the tested compounds was evaluated for cytotoxicity in three separate experiments. 
Table S-2. Antiproliferative effect of the obtained compounds against human cancer cell lines.

\begin{tabular}{|c|c|c|c|c|c|c|}
\hline \multirow{2}{*}{ Compound } & \multirow{2}{*}{ Structure } & \multicolumn{5}{|c|}{ Survival, $\%^{\mathrm{a}}$} \\
\hline & & WI-26 VA4 & A549 & PC-3 & HCT 116 & MCF7 \\
\hline $3 \mathbf{a}$ & & 92.51 & 86.47 & 87.84 & 76.75 & 77.12 \\
\hline $3 \mathbf{b}$ & & 87.85 & 81.57 & 78.59 & 69.2 & 76.92 \\
\hline $3 c$ & & 96.02 & 93.92 & 83.71 & 83.89 & 84.85 \\
\hline 3d & & 87.78 & 75.67 & 70.05 & 68.63 & 73.1 \\
\hline $3 e$ & & 85.62 & 81.75 & 89.74 & 80.74 & 81.21 \\
\hline $3 f$ & & 96.57 & 87.62 & 63.91 & 56.34 & 54.58 \\
\hline $3 g$ & & 90.66 & 87.85 & 89.34 & 88.11 & 106.1 \\
\hline $3 h$ & & 85.32 & 79.89 & 81.52 & 73.25 & 71.21 \\
\hline $3 \mathbf{i}$ & & 88.39 & 93.7 & 89.16 & 94.00 & 103.17 \\
\hline $3 \mathbf{j}$ & & 96,21 & 99.08 & 92.55 & 104.29 & 10.8 \\
\hline $3 \mathbf{k}$ & & 92.67 & 77.96 & 87.19 & 72.85 & 86.04 \\
\hline 31 & & 91.2 & 87.98 & 86.17 & 85.88 & 69.95 \\
\hline $3 m$ & & 98,28 & 97.93 & 95.77 & 93.48 & 103.99 \\
\hline $3 n$ & & 79.91 & 67.55 & 64.35 & 57.43 & 57.19 \\
\hline $3 q$ & & 102.34 & 96.26 & 88.67 & 74.85 & 73.03 \\
\hline
\end{tabular}

${ }^{\text {a }}$ Data represent mean values for three independent determinations. 


\section{NMR spectra of intermediates $7 \mathbf{a}$ and $8 \mathrm{a}$}

Table S-3. Identified signals in NMR spectra of intermediates 7a, 8a and the corresponding signals in previously reported 1,3-oxazine (ref. 15).

\begin{tabular}{|c|c|c|c|}
\hline & 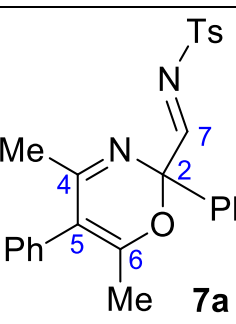 & $\mathrm{Ph}_{\mathbf{8 a}}^{\mathrm{Ts}}$ & [ref. 15] \\
\hline & \multicolumn{3}{|c|}{${ }^{1} \mathrm{H}$ NMR, $\delta, \mathrm{ppm}$} \\
\hline $\mathrm{CH}_{3}$ & $1.83(3 \mathrm{H})$ & $1.24(3 \mathrm{H})$ & $1.89(3 \mathrm{H})$ \\
\hline $\mathrm{CH}_{3}$ & $1.92(3 \mathrm{H})$ & $1.55(3 \mathrm{H})$ & $1.96(3 \mathrm{H})$ \\
\hline $\mathrm{H}^{7}$ & $8.45(1 \mathrm{H})$ & $6.81(1 \mathrm{H})$ & \\
\hline \multirow[t]{2}{*}{$\mathrm{H}^{8}, \mathrm{H}^{8^{\prime}}$} & & $6.57(1 \mathrm{H}), 6.76(1 \mathrm{H})$ & \\
\hline & \multicolumn{3}{|c|}{${ }^{13} \mathrm{C} \mathrm{NMR}, \delta, \mathrm{ppm}$} \\
\hline $\mathrm{CH}_{3}$ & 17.7 & 17.2 & 17.4 \\
\hline $\mathrm{CH}_{3}$ & 24.0 & 20.7 & 23.6 \\
\hline $\mathrm{C}^{2}$ & 91.2 & 156.0 & 91.2 \\
\hline $\mathrm{C}^{4}$ & 166.8 & 86.9 & 165.5 \\
\hline $\mathrm{C}^{5}$ & 115.8 & 117.5 & 116.2 \\
\hline $\mathrm{C}^{6}$ & 159.4 & 146.3 & 158.7 \\
\hline $\mathrm{C}^{7}$ & 170.4 & 87.8 & - \\
\hline
\end{tabular}


${ }^{1} \mathrm{H}$ NMR spectra $\left(400 \mathrm{MHz}, \mathrm{CDCl}_{3}\right)$ of the reaction mixtures containing compounds $7 \mathbf{a}$ and $\mathbf{8 a}$<smiles>Cc1noc(C)c1-c1ccccc1</smiles>

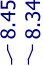

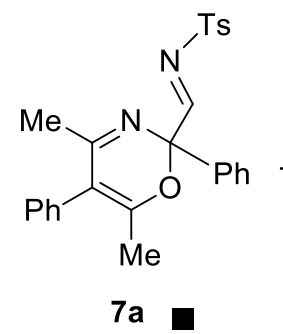

$7 a$

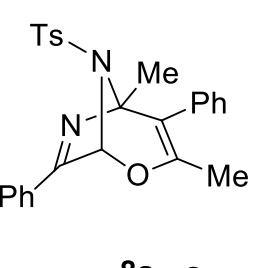

$8 a$

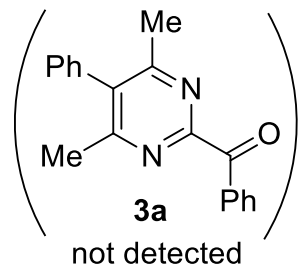

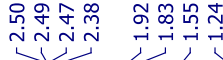

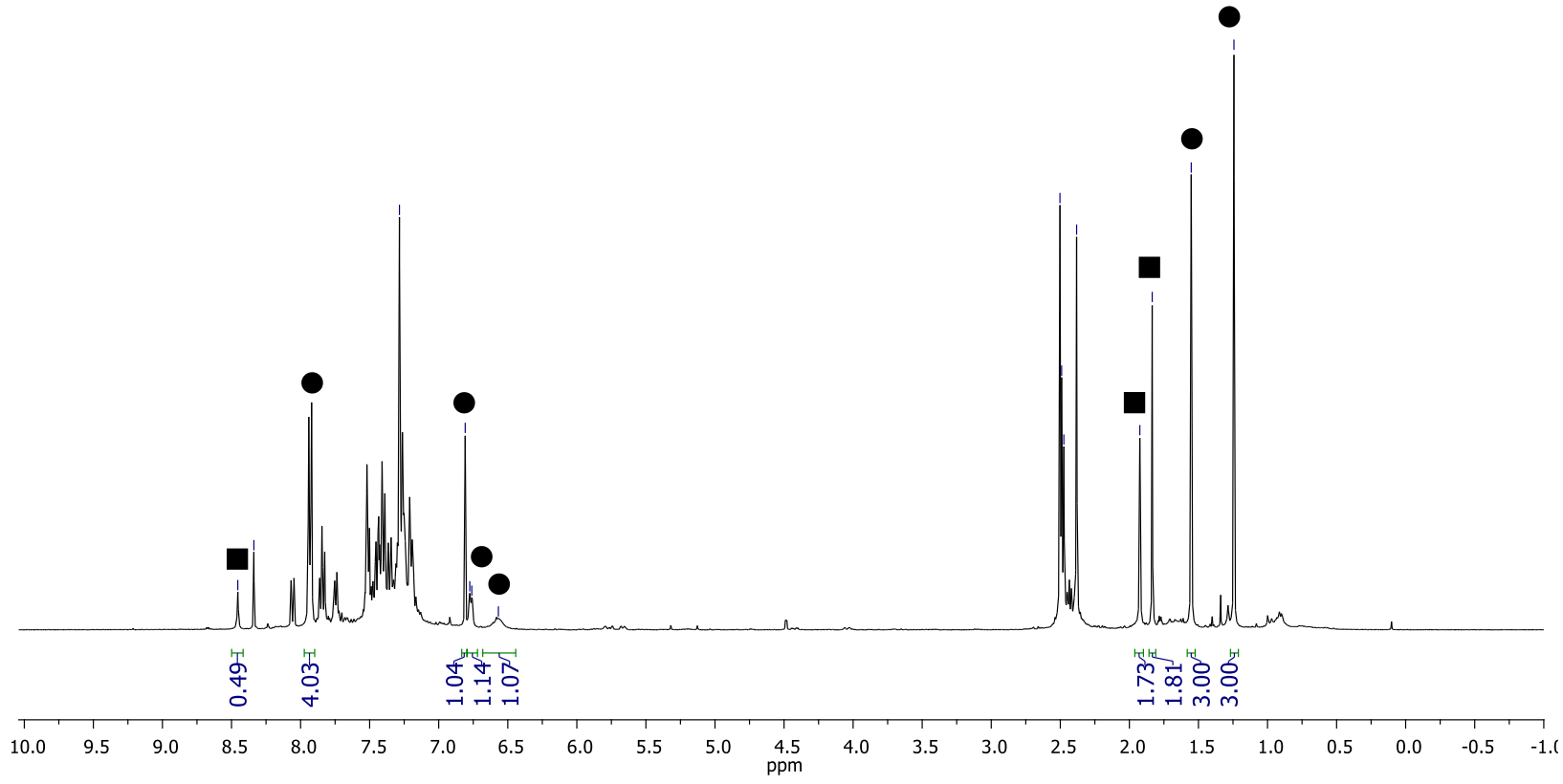




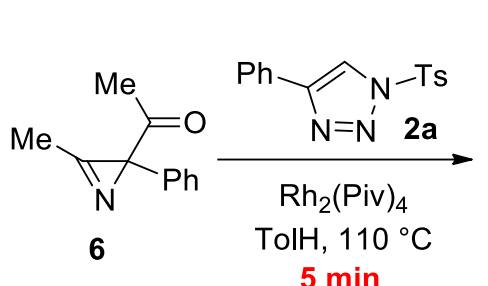
5 min

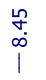

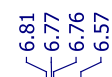<smiles>CC1=C(C)C(c2ccccc2)=C(C)C(/C=N/[As])(c2ccccc2)O1</smiles>

$7 a$

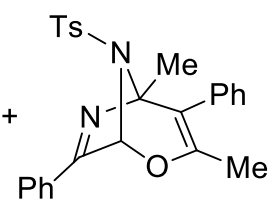

$8 a$<smiles>Cc1nc(C(=O)c2ccccc2)nc(C)c1-c1ccccc1</smiles>

not detected

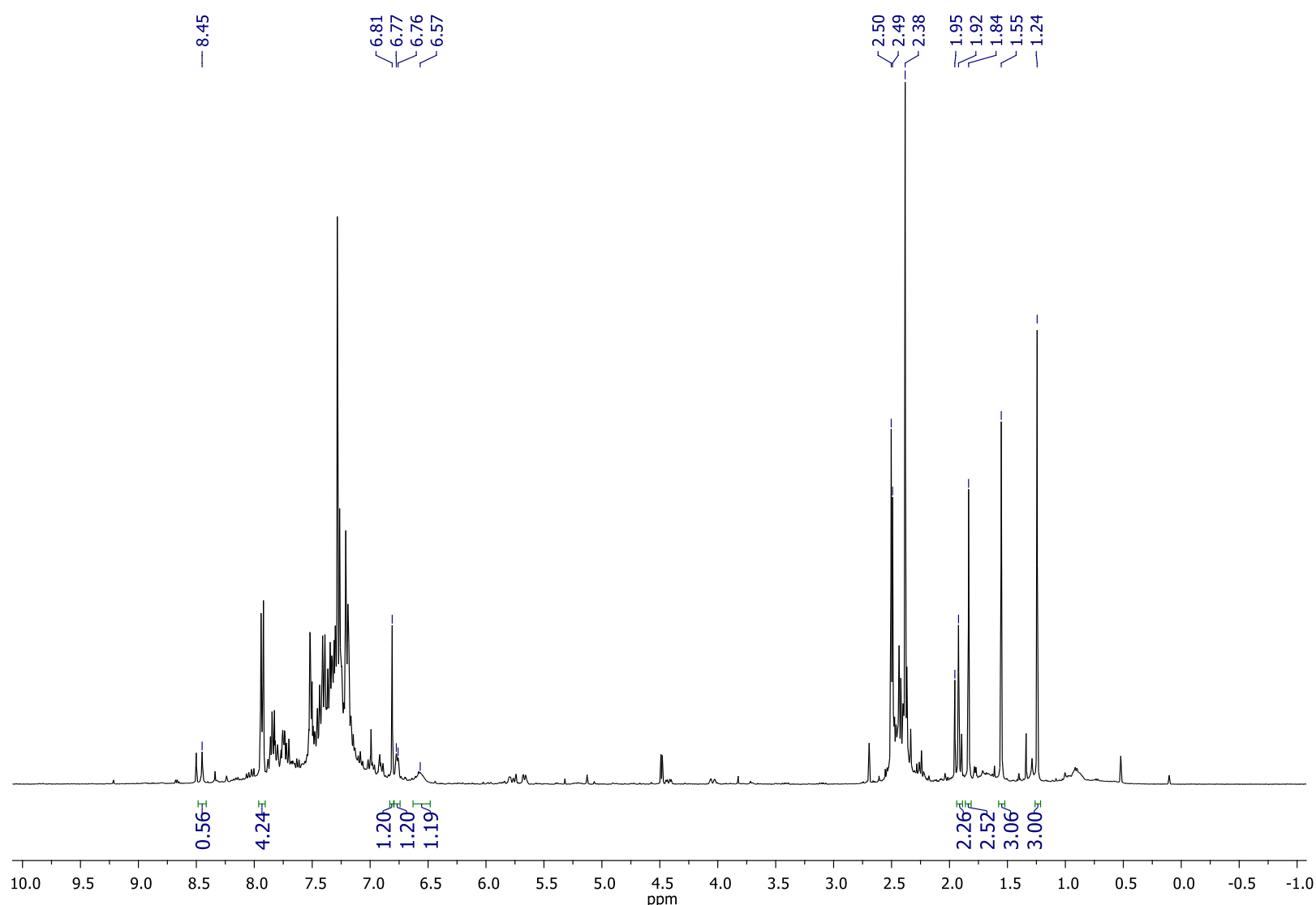




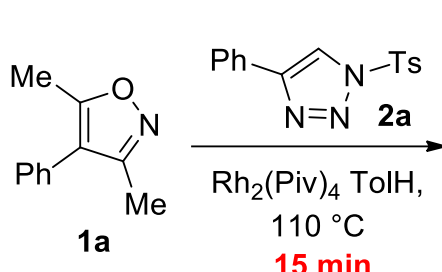

$15 \mathrm{~min}$

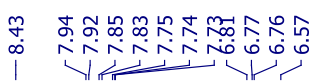<smiles>CC1=NC(C=N[As])(c2ccccc2)OC(C)=C1c1ccccc1</smiles>

$7 a$

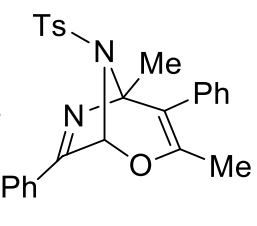

$8 a$<smiles>Cc1nc(C(=O)c2ccccc2)nc(C)c1-c1ccccc1</smiles>

not detected

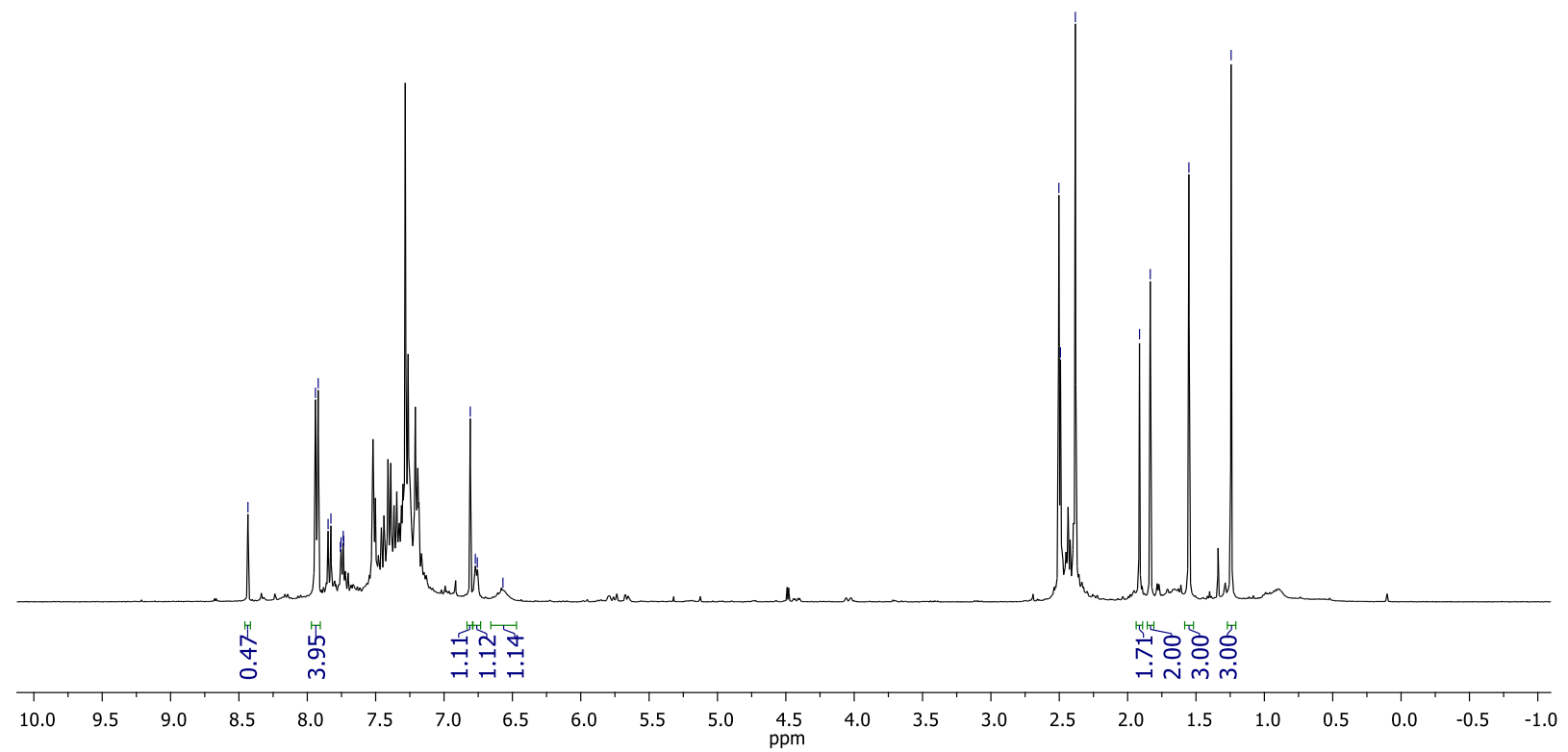




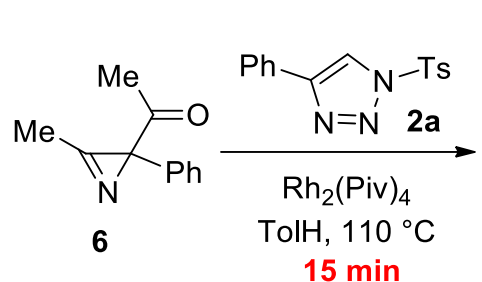
$15 \mathrm{~min}$

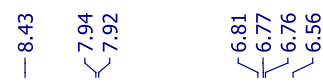

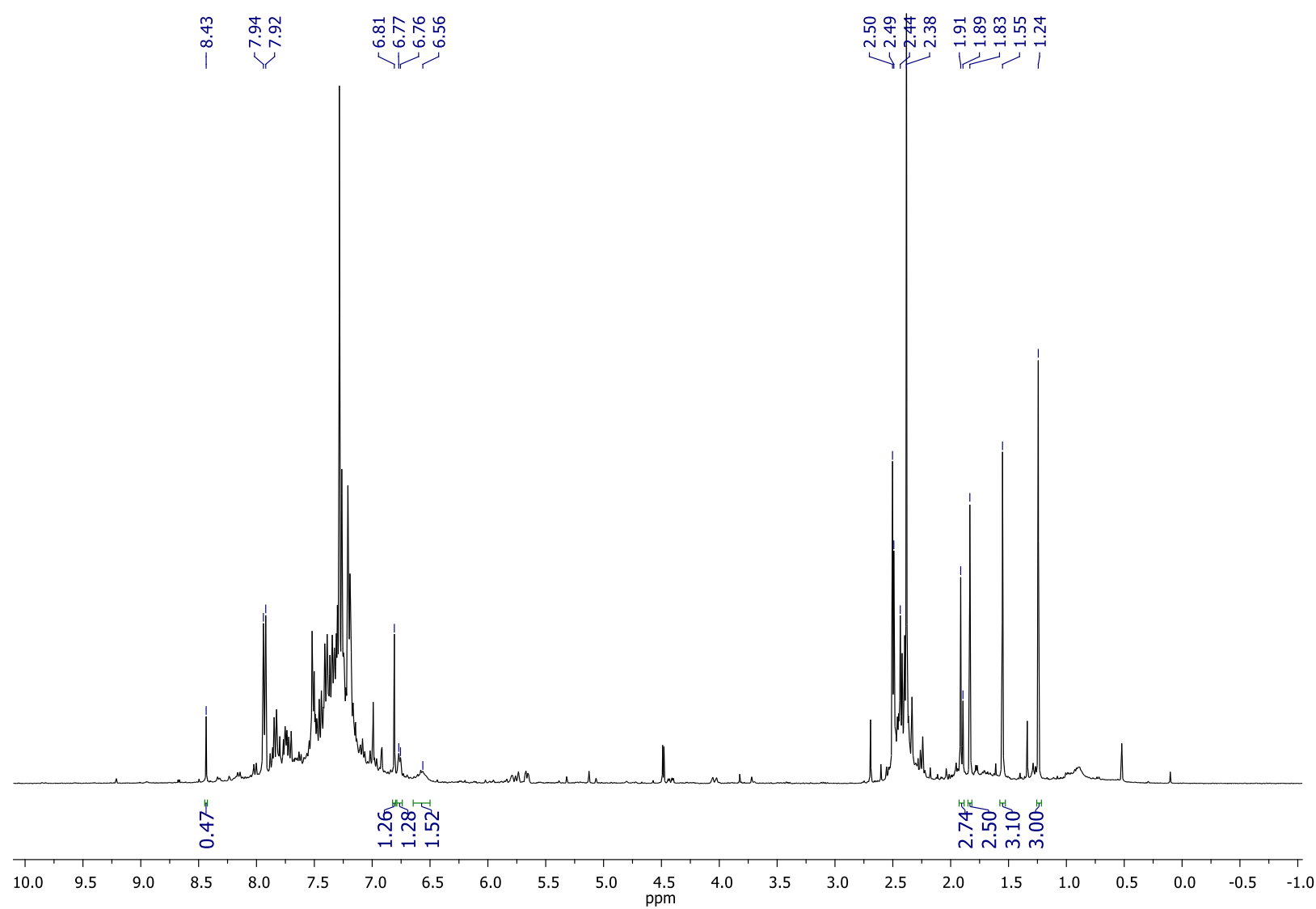<smiles>CC1=NC(C=N[As])(c2ccccc2)OC(C)=C1c1ccccc1</smiles>

$7 a$
$8 a$

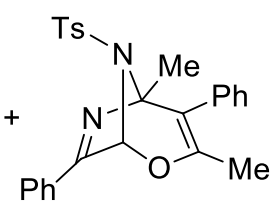

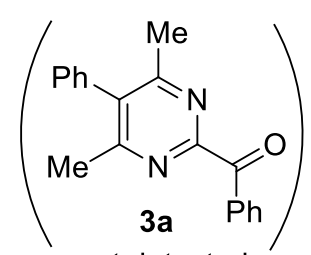

not detected 

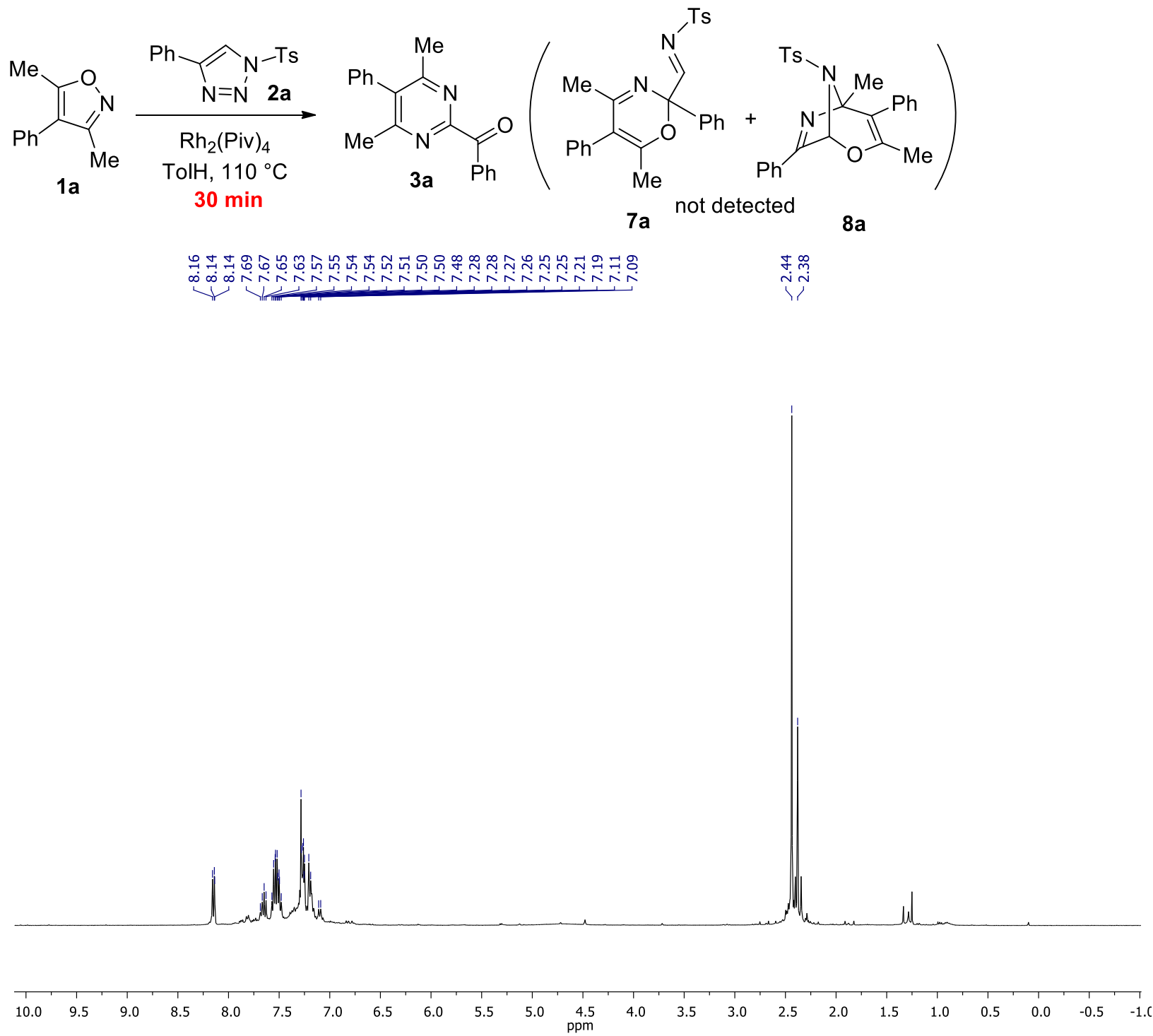

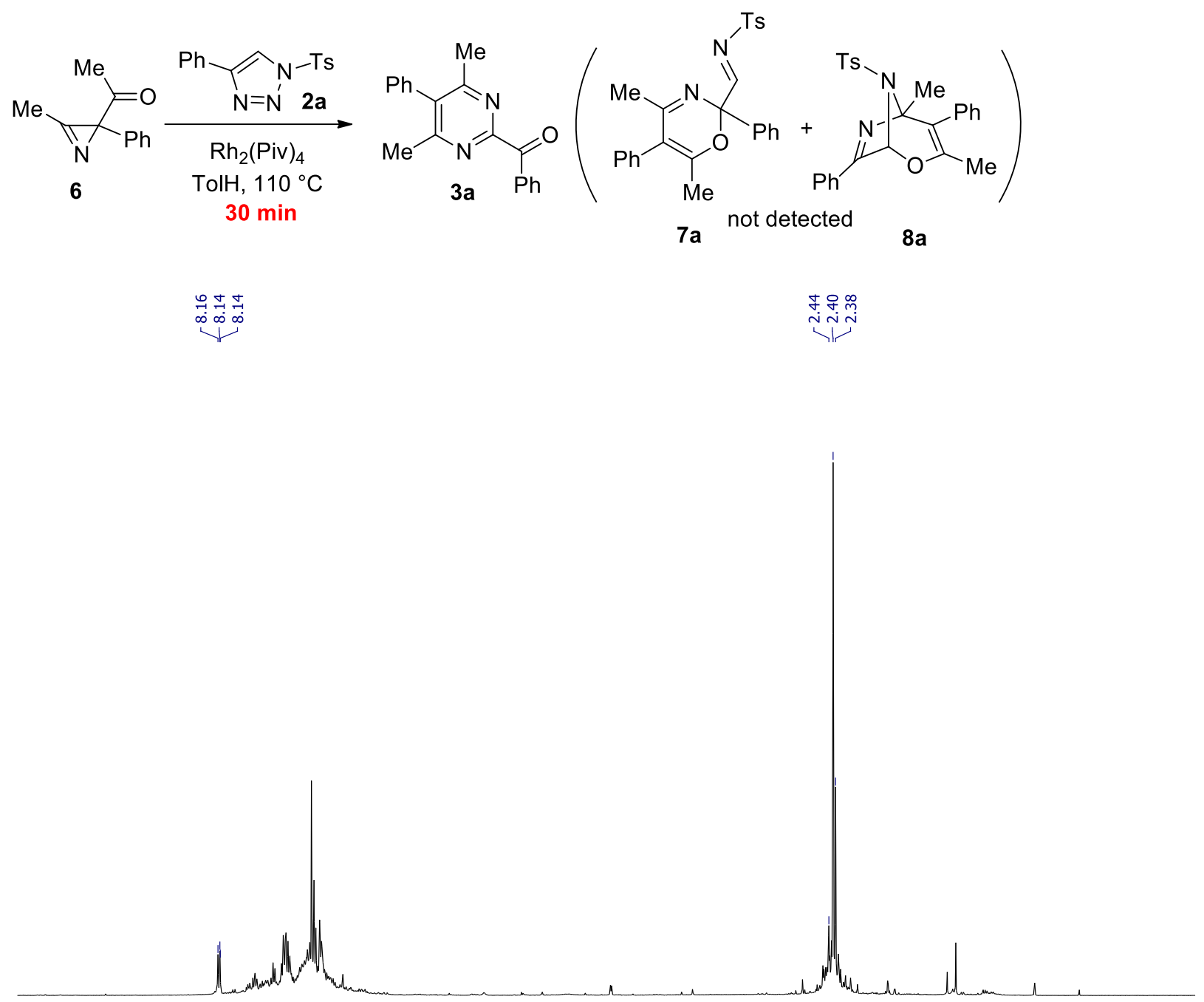

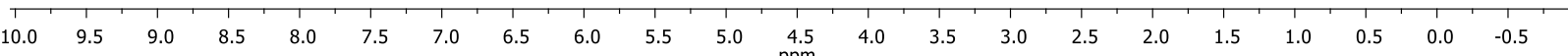


${ }^{13} \mathrm{C}\left\{{ }^{1} \mathrm{H}\right\}$ NMR spectrum $\left(100 \mathrm{MHz}, \mathrm{CDCl}_{3}\right)$ of the reaction mixture containing compounds $7 \mathbf{a}$ and $\mathbf{8 a}$
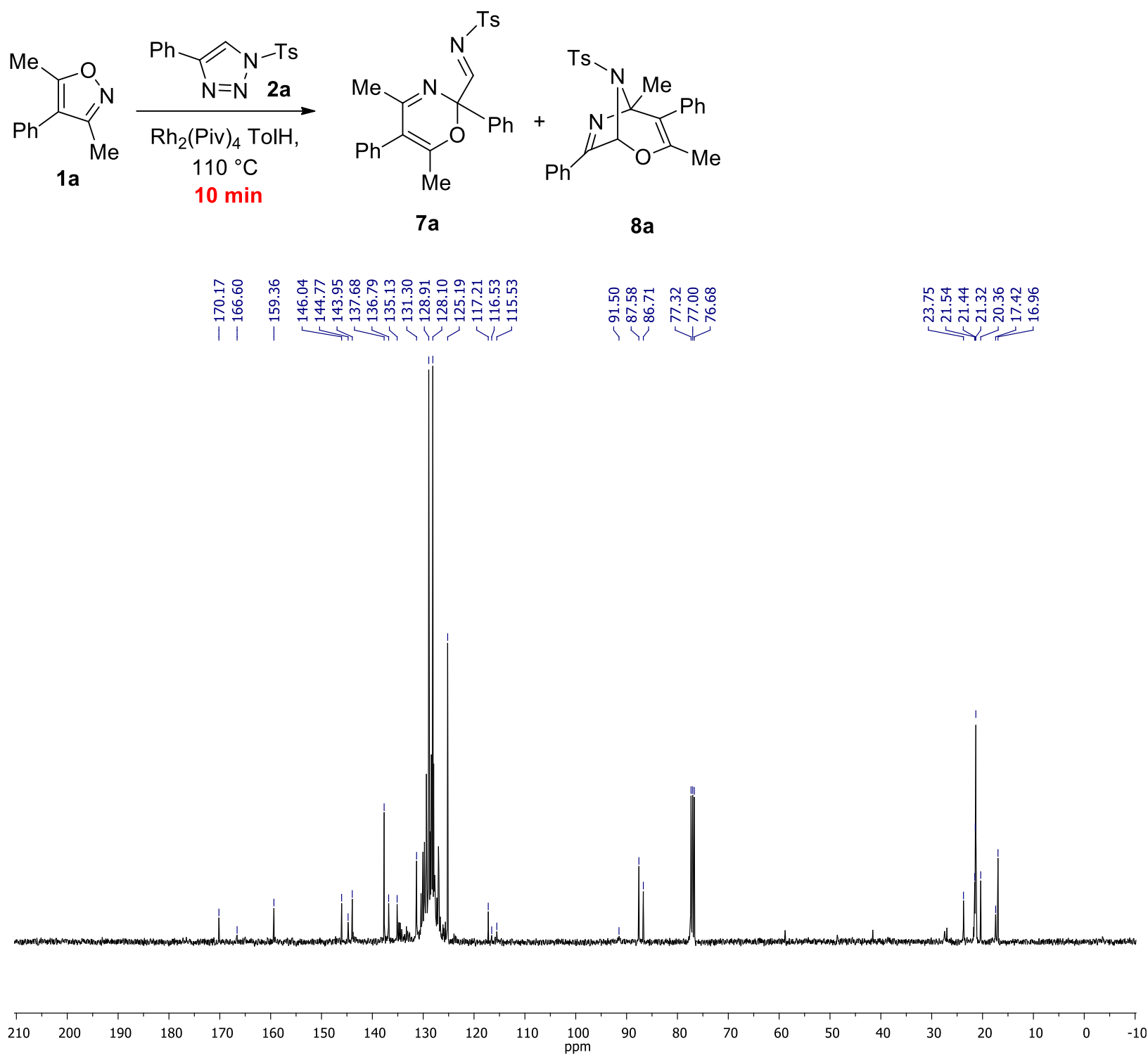
$2 \mathrm{D}{ }^{1} \mathrm{H}-{ }^{13} \mathrm{C}$ HSQC spectrum $\left(\mathrm{CDCl}_{3}\right)$ of the reaction mixture containing compounds $7 \mathbf{a}$ and $\mathbf{8 a}$

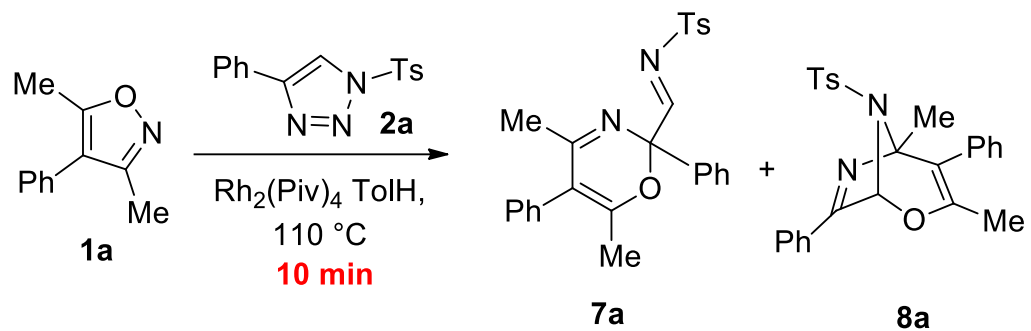

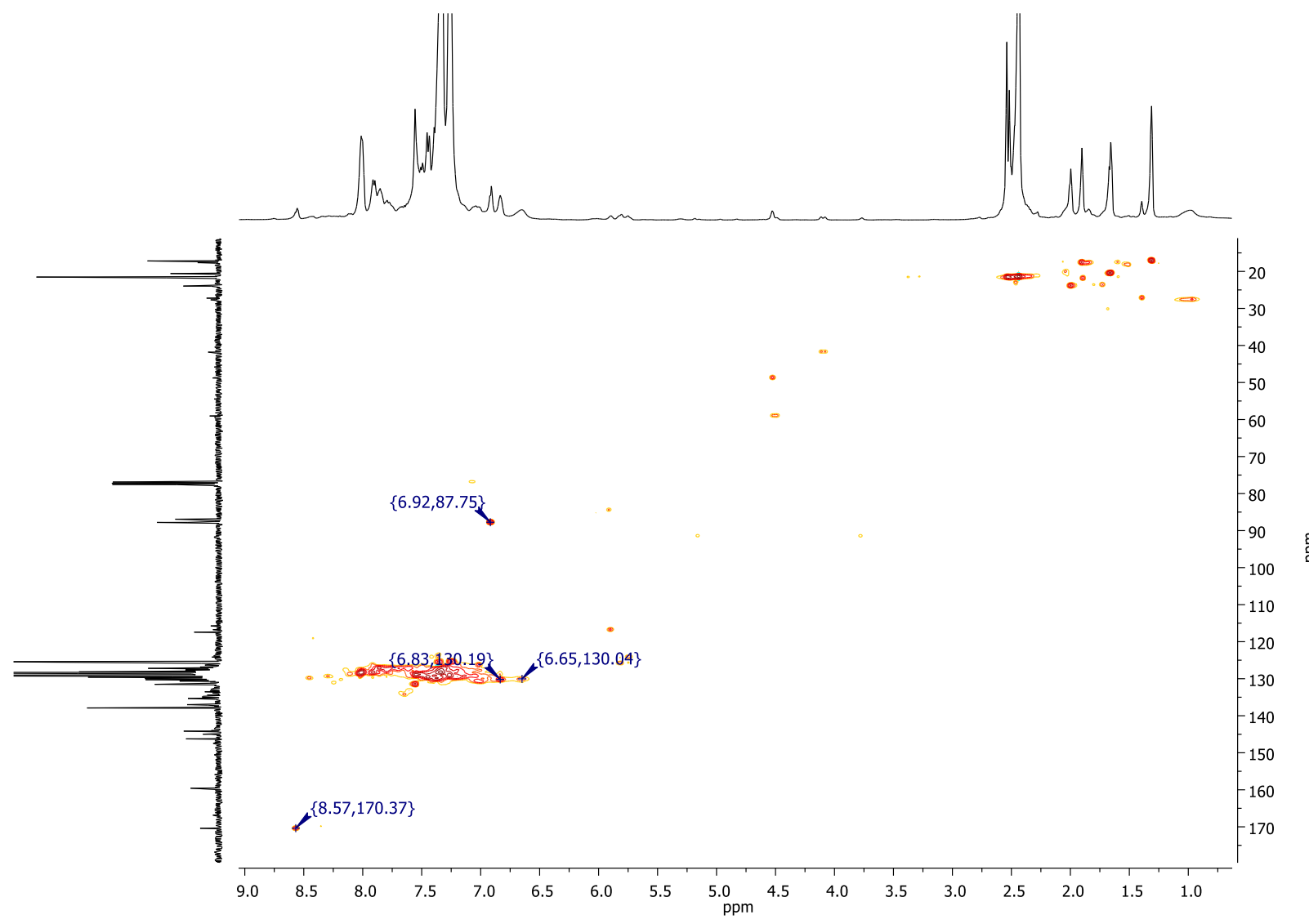


$2 \mathrm{D}{ }^{1} \mathrm{H}_{-}{ }^{13} \mathrm{C}$ HMBC spectrum $\left(\mathrm{CDCl}_{3}\right)$ of the reaction mixture containing compounds $7 \mathbf{a}$ and $\mathbf{8 a}$<smiles>Cc1noc(C)c1-c1ccccc1</smiles><smiles>CC1=NC(/C=N/[As])(c2ccccc2)OC(C)=C1c1ccccc1</smiles>

$7 a$

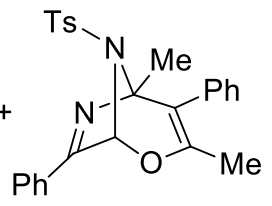

$8 a$

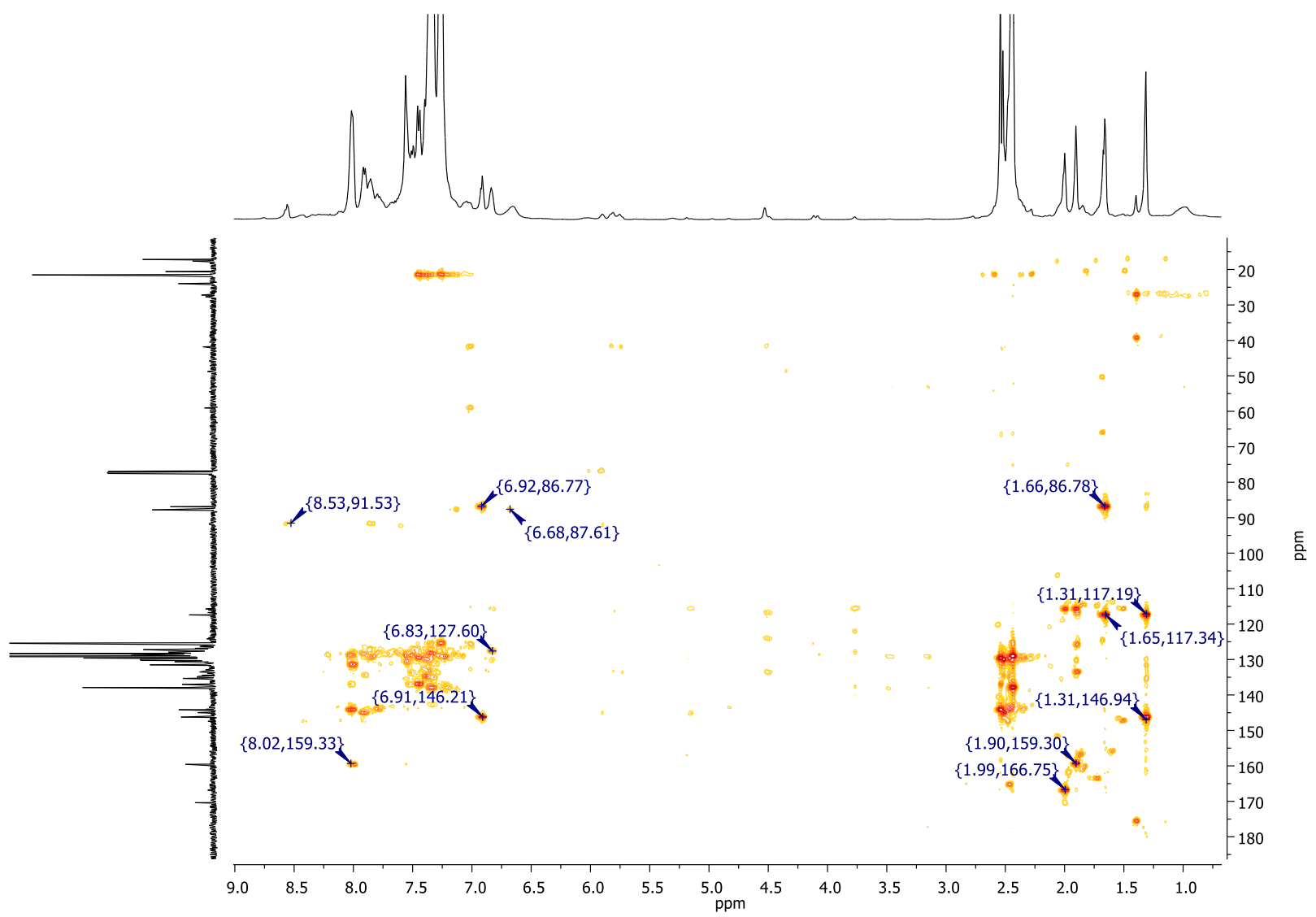




\section{X-Ray data}

\section{Compound 3c (CCDC 2081725)}

Single crystals of $\mathbf{3 c}$ were grown by slow evaporation of its solution in $\mathrm{Et}_{2} \mathrm{O}$-hexane mixture. A suitable crystal was selected and intensity data were collected on a Xcalibur, Eos diffractometer using monochromated Mo K $\alpha$ radiation. The crystal was kept at 100(1) K during data collection. Using Olex $2,{ }^{16}$ the structure was solved with the ShelXT ${ }^{17}$ structure solution program using Intrinsic Phasing and refined with the ShelXL ${ }^{18}$ refinement package using Least Squares minimization.

Figure S-1. X-Ray crystal structure of compound 3c with $50 \%$ ellipsoid probability (CCDC 2081725)<smiles>COc1ccc(-c2c(C)nc(C(=O)c3ccccc3)nc2C)cc1</smiles>

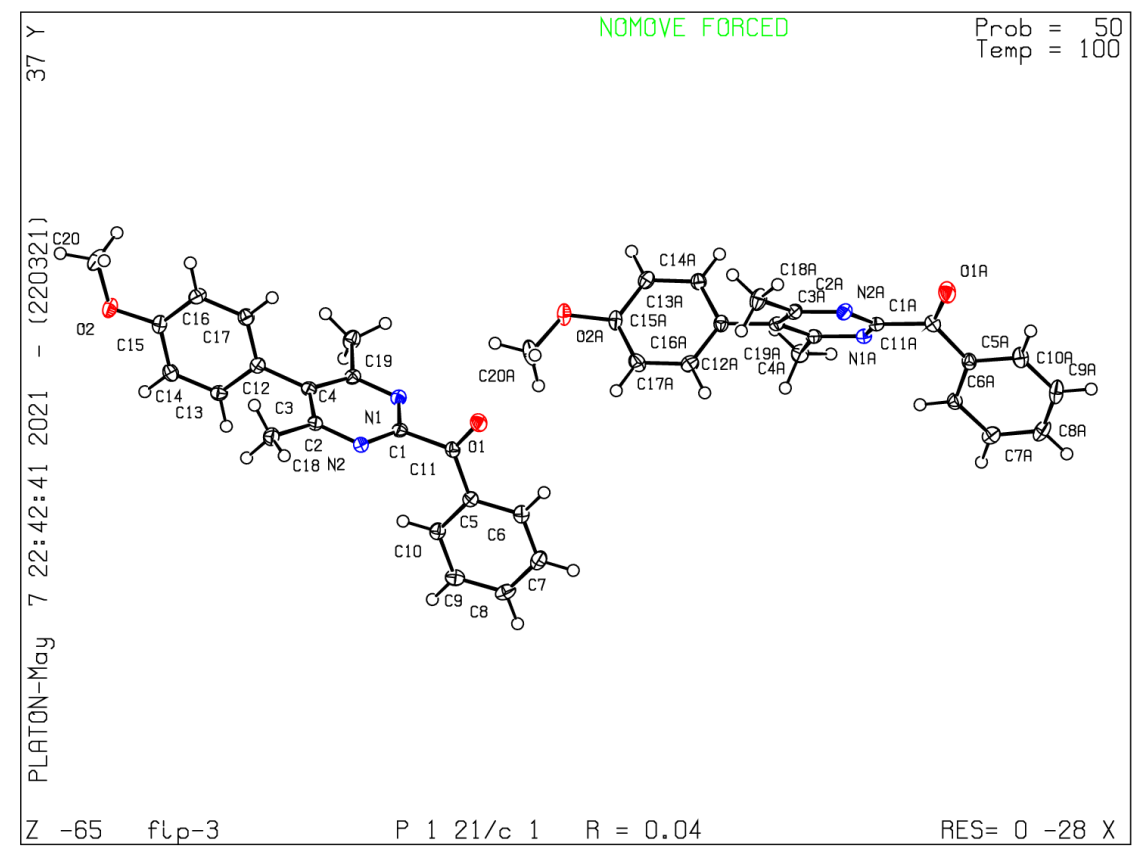

Table S-4. Crystal data and structure refinement for 3c.

Empirical formula

Formula weight

Temperature/K

Crystal system

Space group

$\mathrm{a} / \AA \AA$

$\mathrm{b} / \AA \AA$

$\mathrm{c} / \AA$

$\alpha /{ }^{\circ}$

$\beta /{ }^{\circ}$

$\gamma /{ }^{\circ}$

Volume $/ \AA^{3}$

$\mathrm{Z}$
$\mathrm{C}_{40} \mathrm{H}_{36} \mathrm{~N}_{4} \mathrm{O}_{4}$

636.73

100(1)

monoclinic

$\mathrm{P} 2{ }_{1} / \mathrm{c}$

14.4446(3)

11.3977(2)

19.9839(4)

90

98.258(2)

90

3255.94(11)

4 
$\rho_{\text {calc }} \mathrm{g} / \mathrm{cm}^{3}$

$\mu / \mathrm{mm}^{-1}$

$\mathrm{F}(000)$

Crystal size $/ \mathrm{mm}^{3}$

Radiation

$2 \Theta$ range for data collection ${ }^{\circ}$

Index ranges

Reflections collected

Independent reflections

Data/restraints/parameters

Goodness-of-fit on $\mathrm{F}^{2}$

Final R indexes $[\mathrm{I}>=2 \sigma(\mathrm{I})]$

Final $\mathrm{R}$ indexes [all data]

Largest diff. peak/hole / e $\AA^{-3}$
1.299

0.085

1344.0

$0.2 \times 0.18 \times 0.16$

Mo $\mathrm{K} \alpha(\lambda=0.71073)$

5.336 to 58.848

$-19 \leq \mathrm{h} \leq 18,-15 \leq \mathrm{k} \leq 13,-26 \leq 1 \leq 25$

21301

$7696\left[\mathrm{R}_{\text {int }}=0.0362, \mathrm{R}_{\text {sigma }}=0.0437\right]$

$7696 / 0 / 439$

1.020

$\mathrm{R}_{1}=0.0440, \mathrm{wR}_{2}=0.0996$

$\mathrm{R}_{1}=0.0596, \mathrm{wR}_{2}=0.1094$

$0.32 /-0.28$

\section{Compound 3m (CCDC 2081726)}

Single crystals of $\mathbf{3 m}$ were grown by slow evaporation of its solution in $\mathrm{Et}_{2} \mathrm{O}$-hexane mixture. A suitable crystal was selected and intensity data were collected on a SuperNova, Dual, $\mathrm{Cu}$ at home/near, Atlas diffractometer using monochromated $\mathrm{CuK \alpha}$ radiation. The crystal was kept at 99.99(1) K during data collection. Using Olex2, ${ }^{16}$ the structure was solved with the ShelXT ${ }^{17}$ structure solution program using Intrinsic Phasing and refined with the ShelXL ${ }^{18}$ refinement package using Least Squares minimization.

Figure S-2. X-Ray crystal structure of compound 3m with $50 \%$ ellipsoid probability (CCDC 2081726)<smiles>COc1ccc(C(=O)c2nc(C)c(-c3ccccc3)c(C)n2)cc1</smiles>

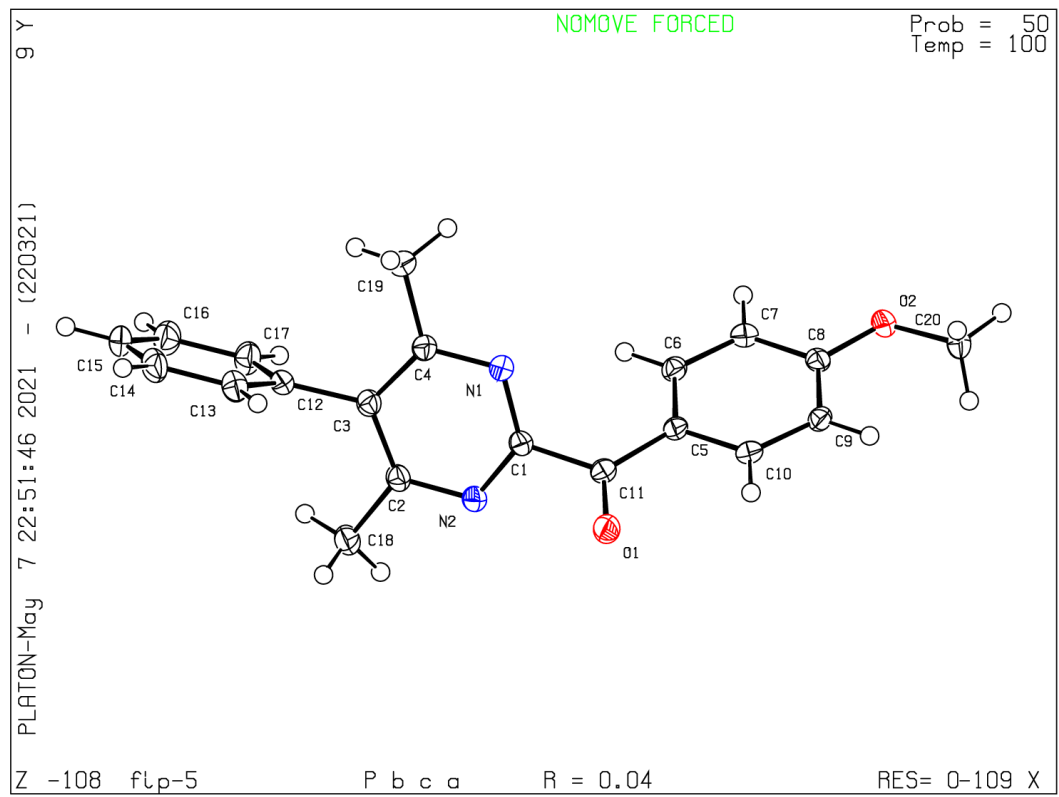


Table S-5. Crystal data and structure refinement for $\mathbf{3 m}$.

Empirical formula

Formula weight

Temperature/K

Crystal system

Space group

$\mathrm{a} / \AA$

$\mathrm{b} / \AA$

$\mathrm{c} / \AA$

$\alpha /{ }^{\circ}$

$\beta /{ }^{\circ}$

$\gamma /{ }^{\circ}$

Volume $/ \AA^{3}$

$\mathrm{Z}$

$\rho_{\text {calc }} \mathrm{g} / \mathrm{cm}^{3}$

$\mu / \mathrm{mm}^{-1}$

$\mathrm{F}(000)$

Crystal size $/ \mathrm{mm}^{3}$

Radiation

$2 \Theta$ range for data collection/ ${ }^{\circ}$

Index ranges

Reflections collected

Independent reflections

Data/restraints/parameters

Goodness-of-fit on $\mathrm{F}^{2}$

Final $R$ indexes [I $>=2 \sigma(\mathrm{I})]$

Final $\mathrm{R}$ indexes [all data]

Largest diff. peak/hole / e $\AA^{-3}$
$\mathrm{C}_{20} \mathrm{H}_{18} \mathrm{~N}_{2} \mathrm{O}_{2}$

318.36

99.99(10)

orthorhombic

Pbca

7.69980(10)

10.30920(10)

40.8071(5)

90

90

90

$3239.22(7)$

8

1.306

0.683

1344.0

$0.2 \times 0.18 \times 0.16$

$\mathrm{Cu} \mathrm{K \alpha}(\lambda=1.54184)$

8.668 to 147.248

$-9 \leq \mathrm{h} \leq 9,-12 \leq \mathrm{k} \leq 12,-50 \leq 1 \leq 50$

51408

$3264\left[\mathrm{R}_{\text {int }}=0.0531, \mathrm{R}_{\text {sigma }}=0.0156\right]$

$3264 / 0 / 220$

1.025

$\mathrm{R}_{1}=0.0396, \mathrm{w}_{2}=0.1048$

$\mathrm{R}_{1}=0.0424, \mathrm{wR}_{2}=0.1074$

$0.34 /-0.36$ 


\section{Calculation details}

All calculations were performed by using the Gaussian 09 suite of quantum chemical programs. ${ }^{19}$ Geometry optimizations of compounds $\mathbf{4 d}, \mathbf{7 b}, \mathbf{8 b}, \mathbf{1 0}-\mathbf{1 2}$ and transition states TS1-TS5 were performed at the DFT B3LYP/6-31+G(d,p) level using PCM model for toluene. Stationary points on the respective potential-energy surfaces were characterized at the same level of theory by evaluating the corresponding Hessian indices. Careful verification of the unique imaginary frequencies for transition states was carried out to check whether the frequency indeed pertains to the desired reaction coordinate. Single point calculations of Gibbs free energies for stationary points were carried out at the DFT wB97xd/cc-pVTZ level (PCM solvation model for toluene). Thermal corrections to Gibbs free energies obtained in optimization calculations were used.

Table S-6. Energies (au) and cartesian coordinates of stationary points for compounds 4d,7b,8b,10-12 and transition states TS1-TS5 (DFT wB97XD/cc-pVTZ/PCM, toluene, $383 \mathrm{~K}$ ).

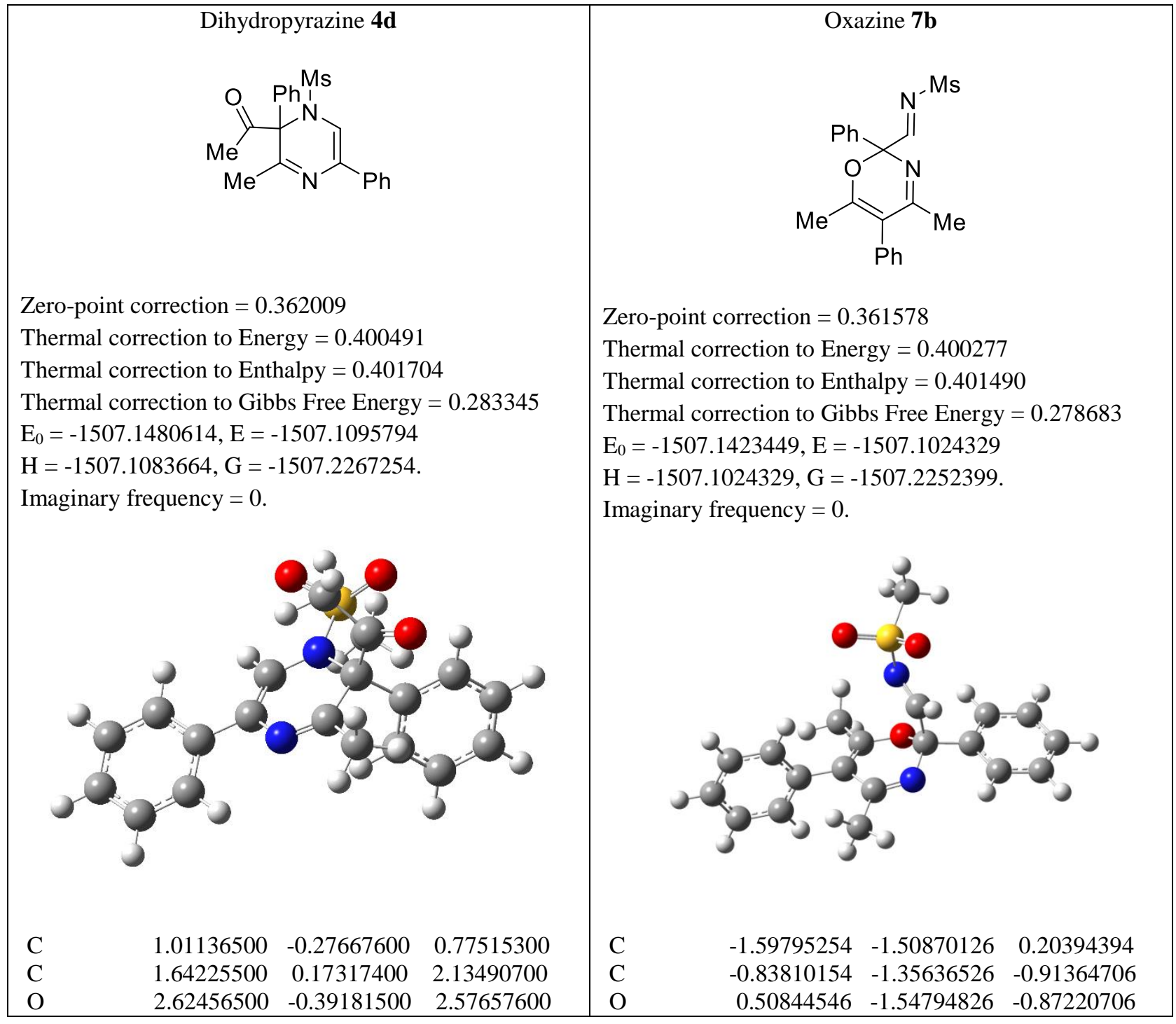




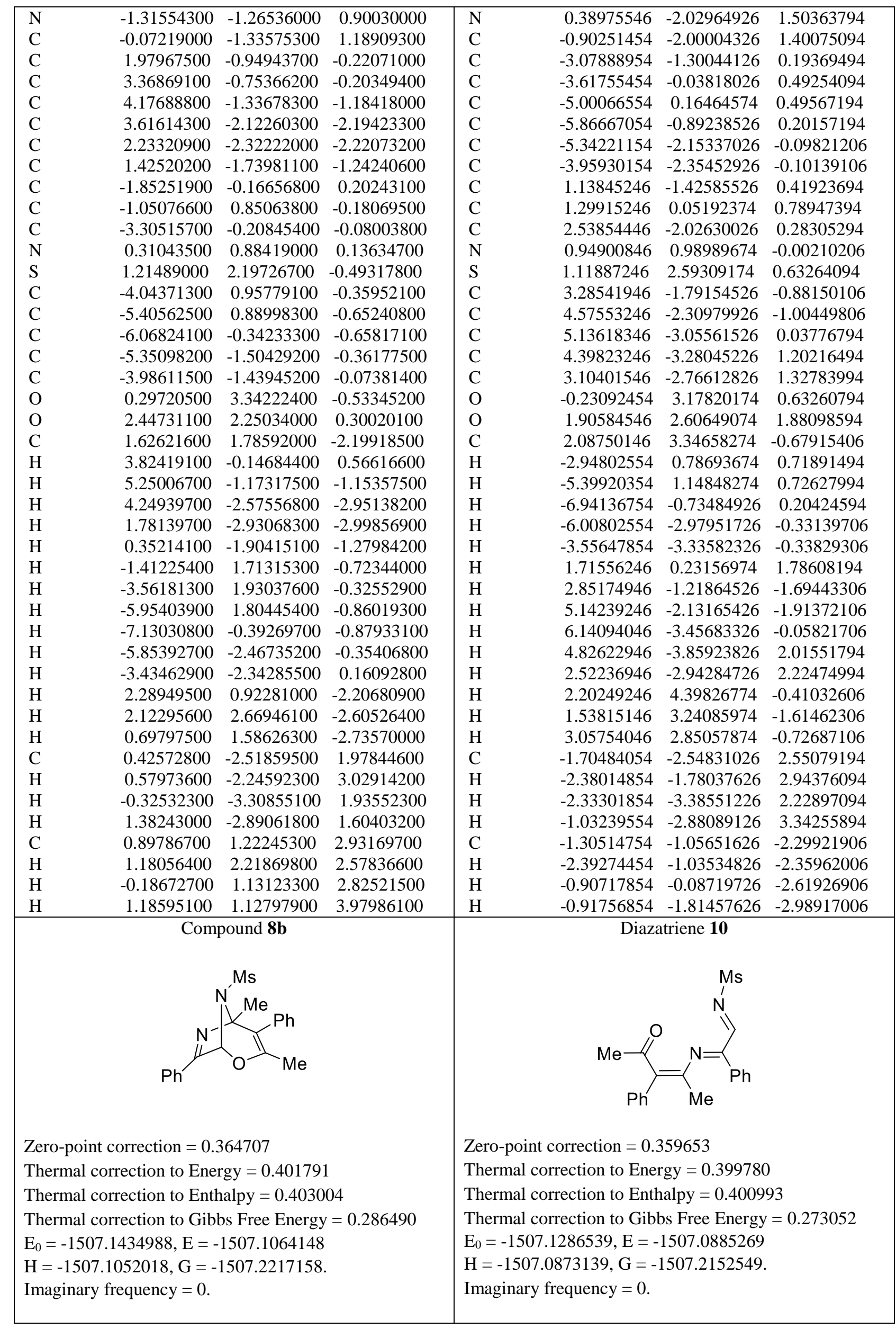




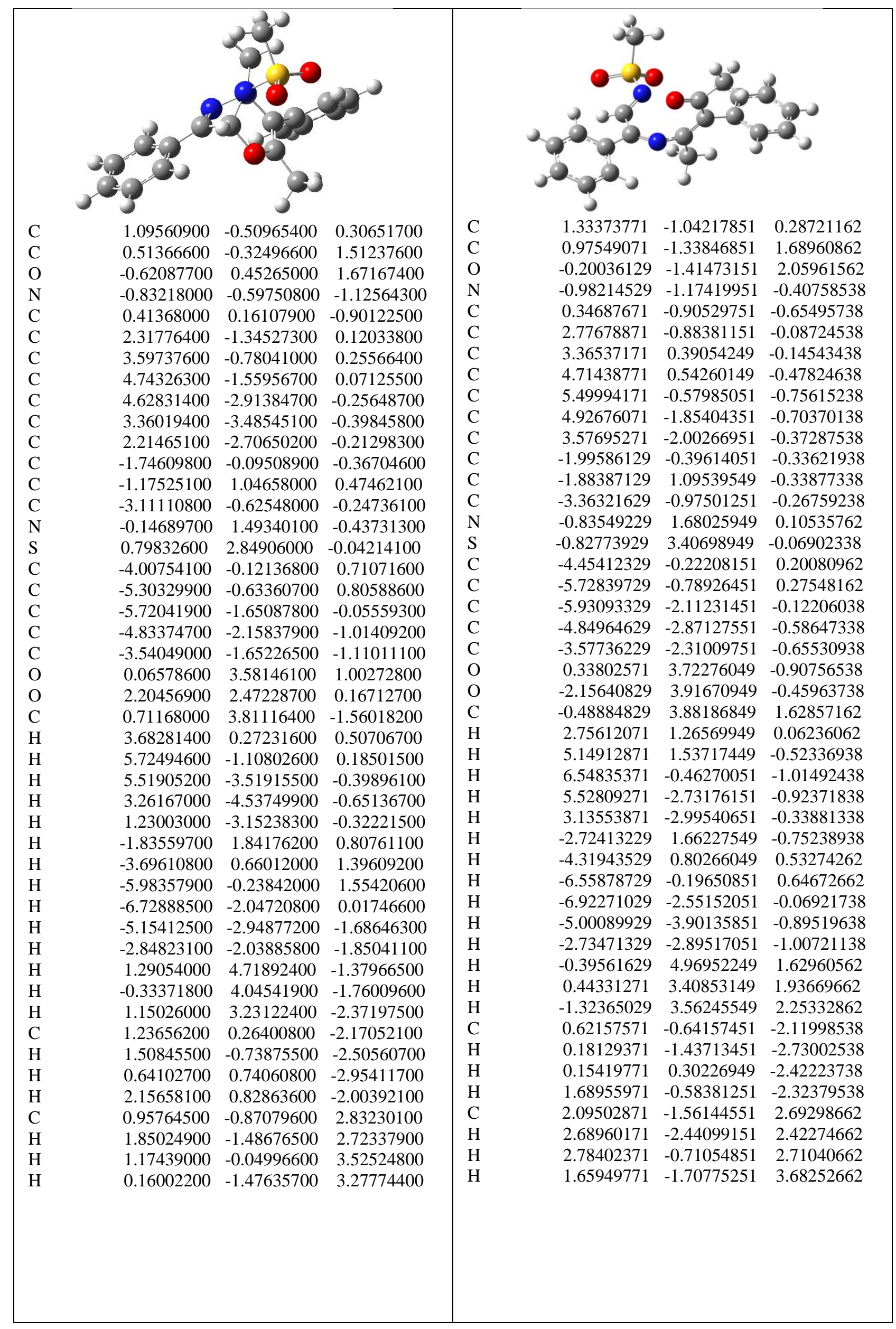




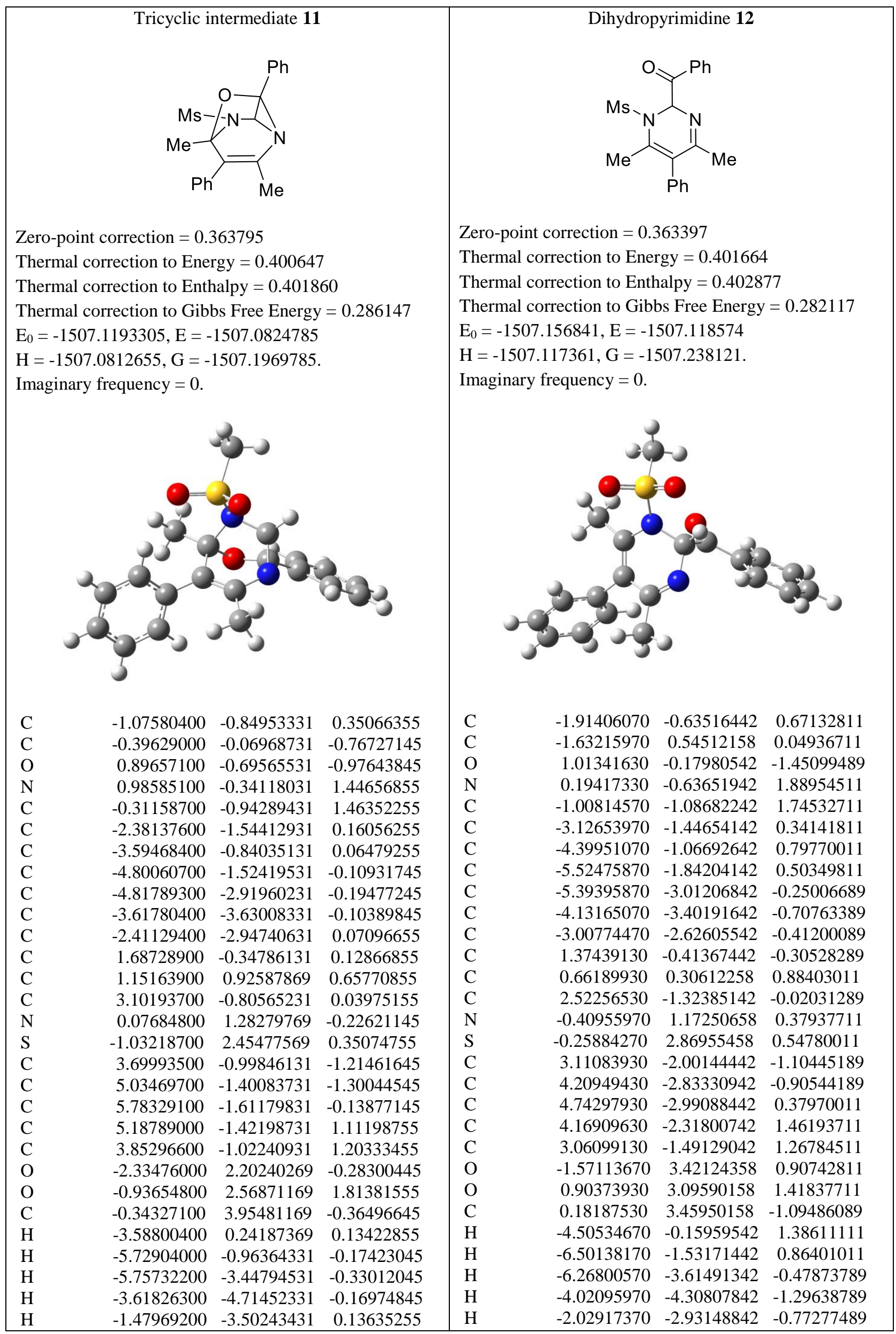




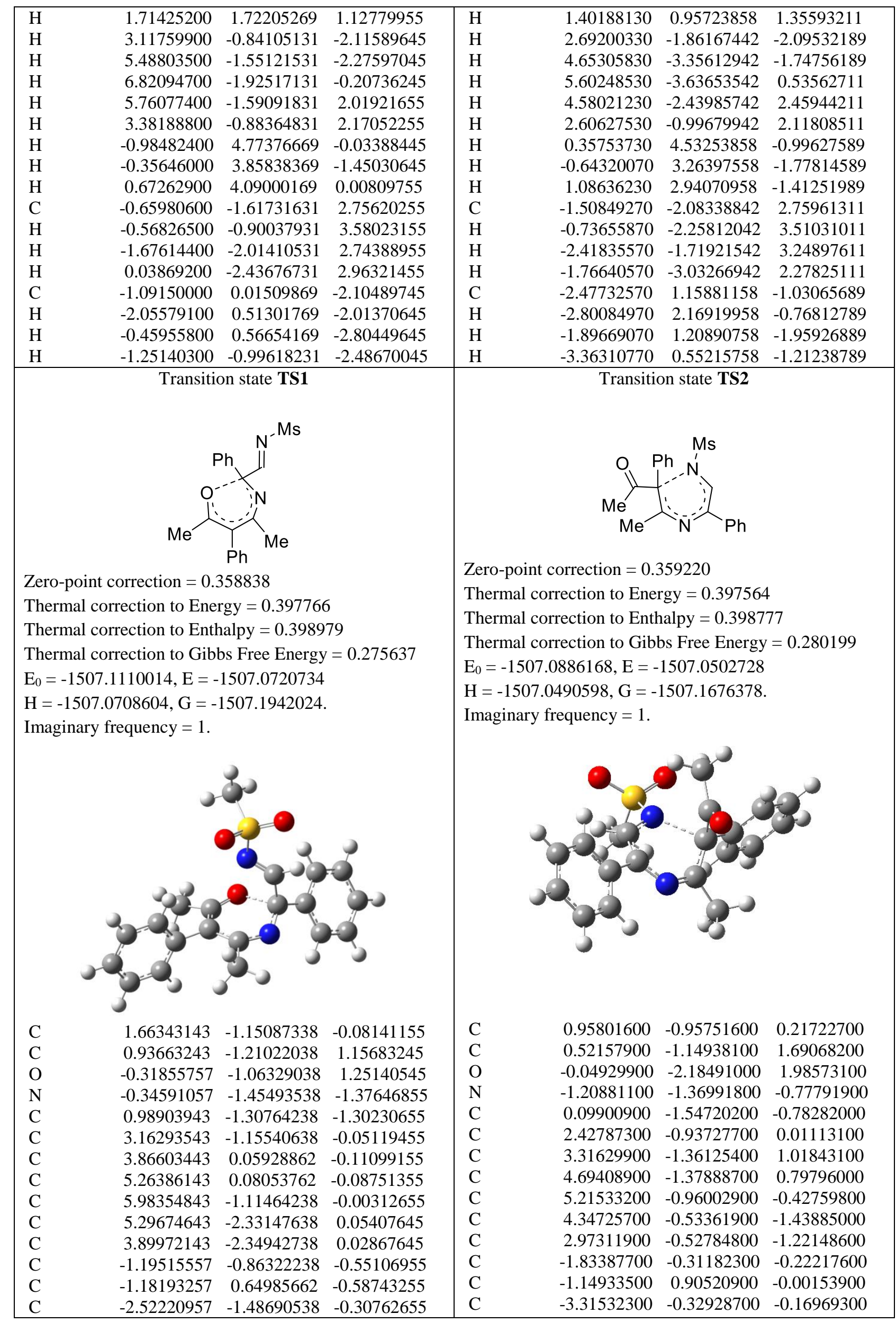




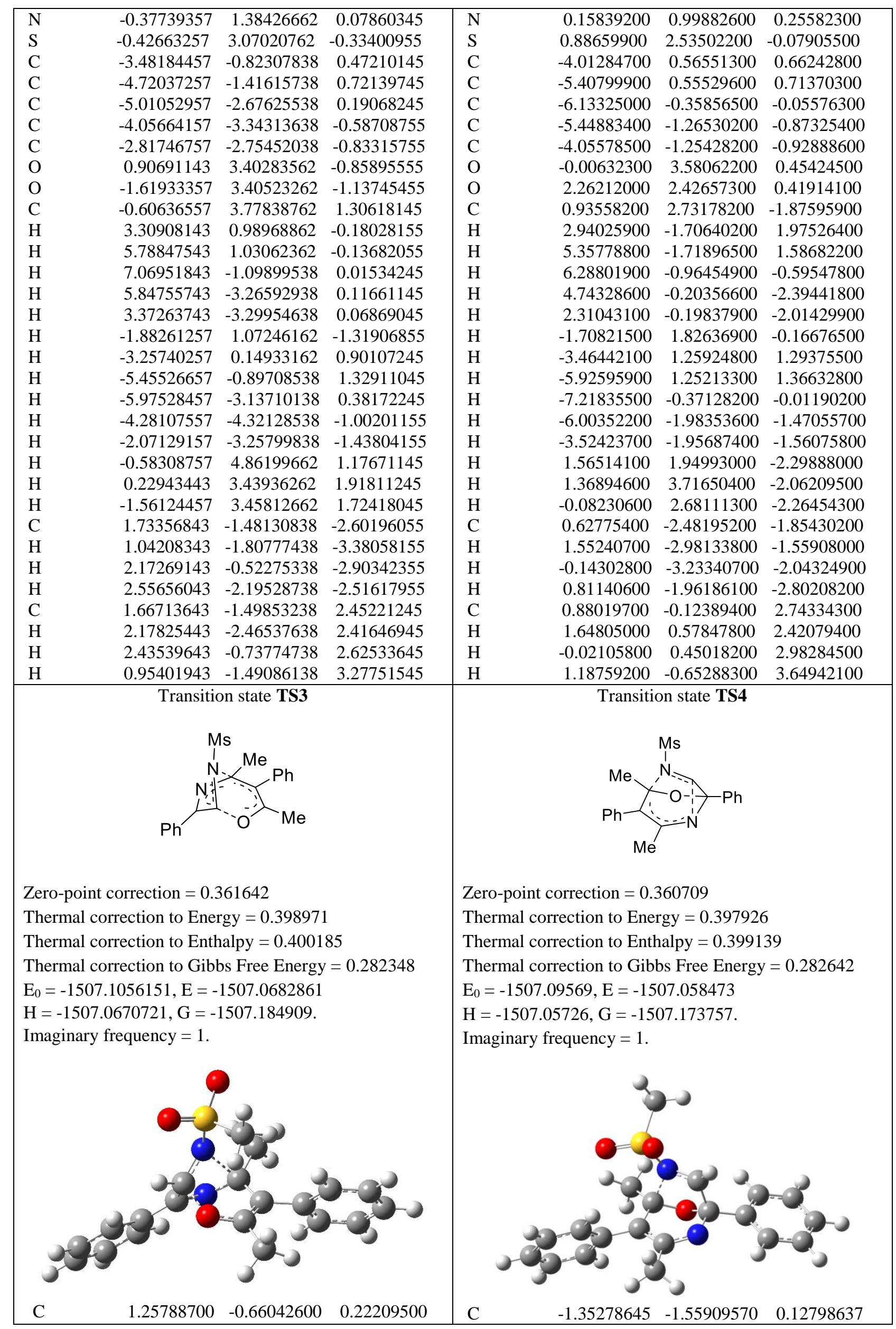




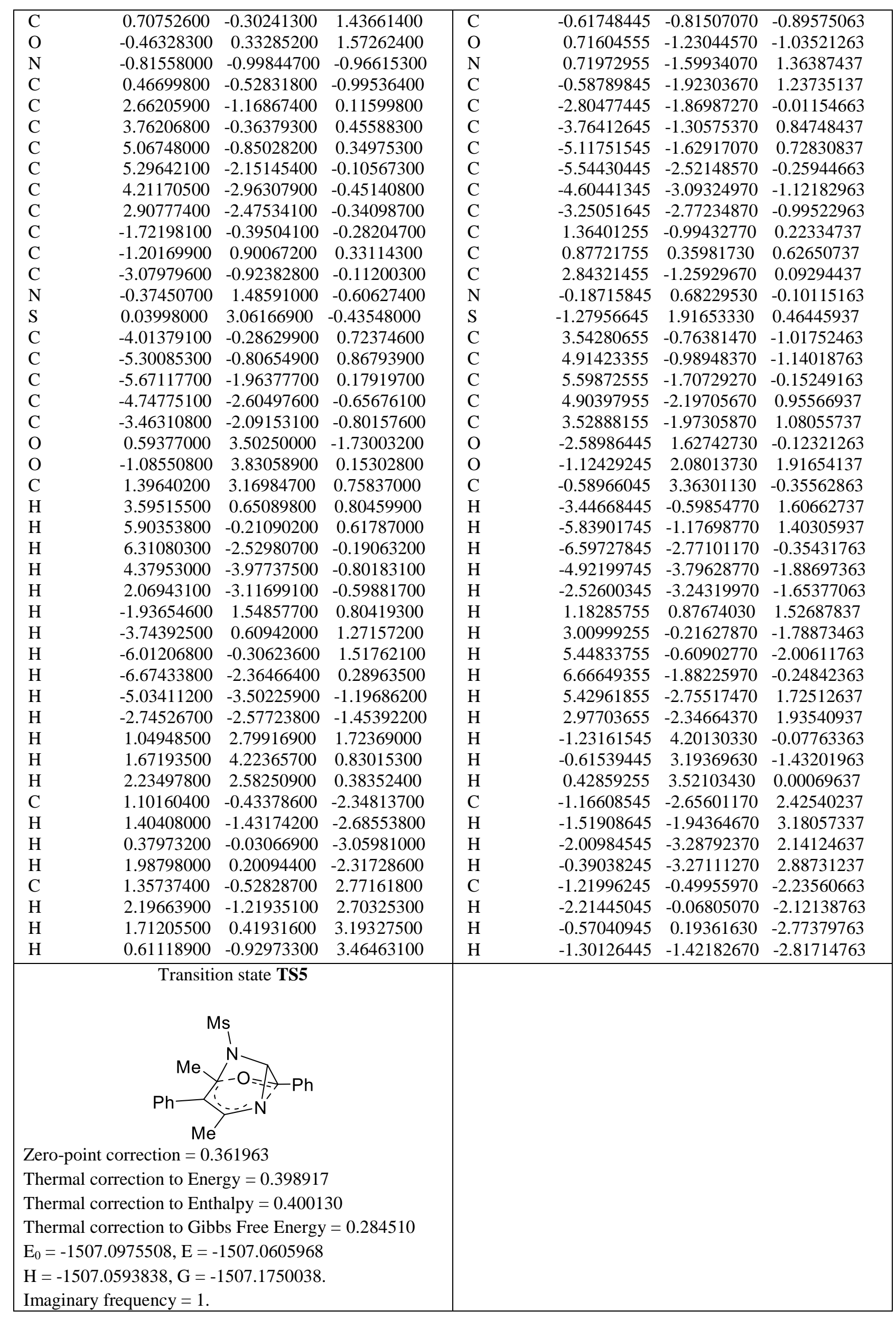




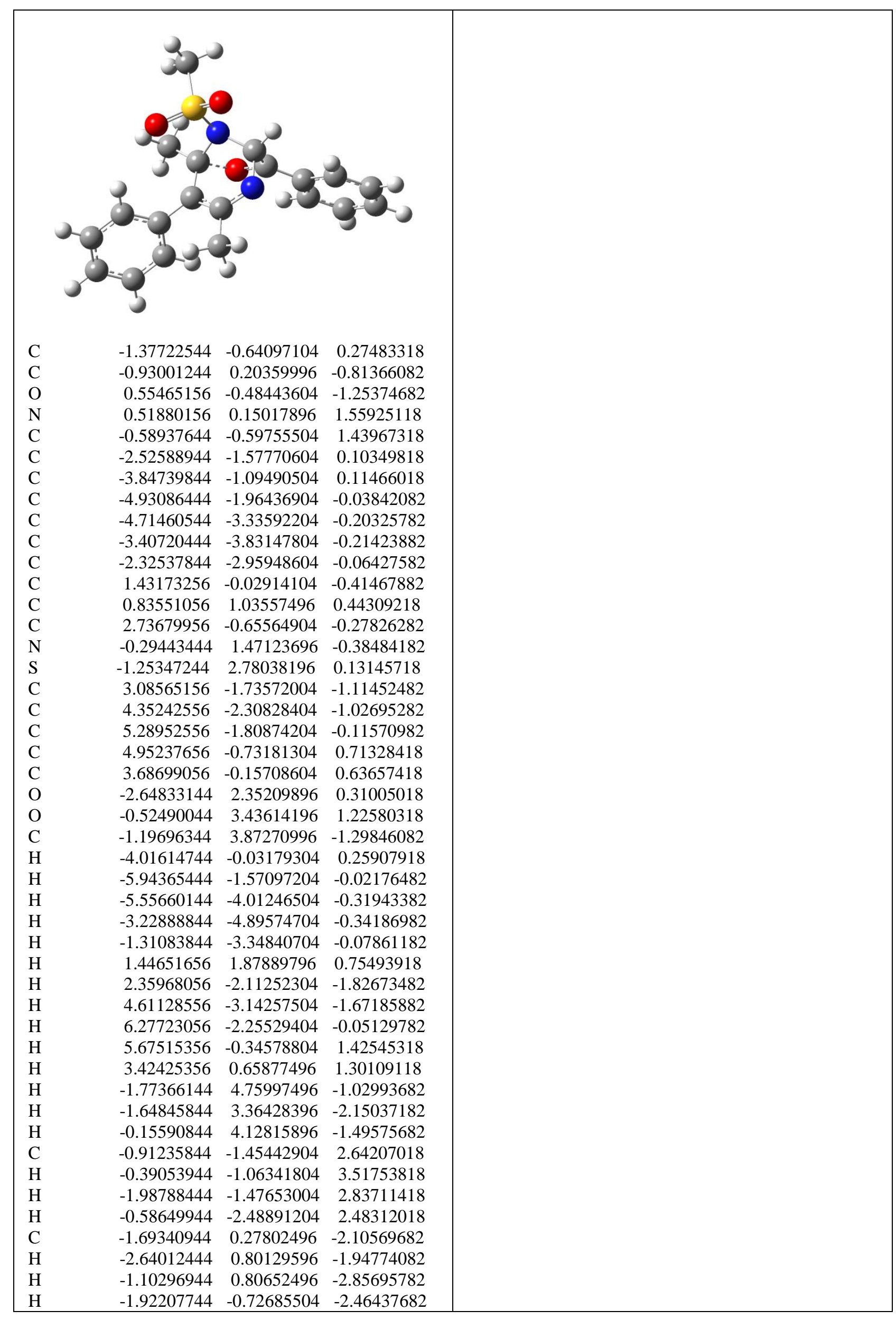




\section{References}

1. Cotton, F. A.; Felthouse, T. R. Structural Studies of Three Tetrakis(carboxylato)dirhodium(II) Adducts in Which Carboxylate Groups and Axial Ligands are Varied. Inorg. Chem. 1980, 19, $323-328$.

2. Giroud-Godquin, A.-M.; Marchon, J.-C.; Guillon, D.; Skoulios, A. Discotic Mesophases of Dirhodium Tetracarboxylates. J. Phys. Chem. 1986, 90, 5502-5503.

3. Kornecki, K. P.; Berry, J. F. Dirhodium Catalysts That Bear Redox Noninnocent Chelating Dicarboxylate Ligands and Their Performance in Intra- and Intermolecular $\mathrm{C}-\mathrm{H}$ Amination. Eur. J. Inorg. Chem. 2012, 2012, 562-568.

4. Zhu, X.-Q.; Wang, Z.-S.; Hou, B.-S.; Zhang, H.-W.; Deng, C.; Ye, L.-W. Zinc-Catalyzed Asymmetric Formal [4+3] Annulation of Isoxazoles with Enynol Ethers by $6 \pi$ Electrocyclization: Stereoselective Access to 2H-Azepines. Angew. Chem., Int. Ed. 2020, 59, $1666-1673$.

5. Naud, S.; Westwood, I. M.; Faisal, A.; Sheldrake, P.; Bavetsias, V.; Atrash, B.; Cheung, K.M. J.; Liu, M.; Hayes, A.; Schmitt, J.; Wood, A.; Choi, V.; Boxall, K.; Mak, G.; Gurden, M.; Valenti, M.; de Haven Brandon, A.; Henley, A.; Baker, R.; McAndrew, C.; Matijssen, B.; Burke, R.; Hoedler, S.; Eccles, S. A.; Raynaud, F. I.; Linardopoulos, S.; van Montfort, R. L. M.; Blagg, J. Structure-Based Design of Orally Bioavailable $1 H$-Pyrrolo[3,2-c]pyridine Inhibitors of Mitotic Kinase Monopolar Spindle 1 (MPS1). J. Med. Chem. 2013, 56, 1004510065.

6. Alberola, A.; Serrano, A.P.; Rodriguez, T.; Orozco, C. Synthesis of 4-Carbosubstituted Isoxazole Derivatives. Heterocycles 1989, 29, 667-677.

7. Reddy, A. R.; Goverdhan, G.; Sampath, A.; Mukkanti, K.; Reddy, P. P.; Bandichhor, R. Application of [3+2]-cycloaddition in the Synthesis of Valdecoxib. Synth. Commun. 2012, 42, 639-649.

8. Ning, Y.; Otani, Y.; Ohwada, T. Contrasting C- and O-Atom Reactivities of Neutral Ketone and Enolate Forms of 3-Sulfonyloxyimino-2-methyl-1-phenyl-1-butanones. J. Org. Chem. 2018, 83, 203-219.

9. Shi, Y.; Yu, X.; Li, C. Y. Rhodium-Catalyzed Synthesis of 2,5-Epoxybenzo[f ][1,4] oxazepines by Tandem Reaction of 1-Sulfonyl-1,2,3-triazoles and Salicylaldehydes. Eur. J. Org. Chem. 2015, 2015, 6429-6433.

10. Strelnikova, J. O.; Rostovskii, N. V.; Starova, G. L.; Khlebnikov, A. F.; Novikov, M. S. $\mathrm{Rh}(\mathrm{II})$-Catalyzed Transannulation of 1,2,4-Oxadiazole Derivatives with 1-Sulfonyl-1,2,3- 
triazoles: Regioselective Synthesis of 5-Sulfonamidoimidazoles. J. Org. Chem. 2018, 83, $11232-11244$.

11. Li, X.; Du, Y.; Liang, Z.; Li, X.; Pan, Y.; Zhao, K. Simple Conversion of Enamines to $2 H$ Azirines and Their Rearrangements under Thermal Conditions. Org. Lett. 2009, 11, $2643-2646$.

12. Kuehne, M. E.; Weaver, S. J.; Franz, P. Enamines as 1,3-Dipolarophiles. J. Org. Chem. 1964, 29, 1582-1586.

13. Griesbeck, A. G.; Franke, M.; Neudörfl, J.; Kotaka, H. Photocycloaddition of aromatic and aliphatic aldehydes to isoxazoles: Cycloaddition reactivity and stability studies. Beilstein J. Org. Chem. 2011, 7, 127-134.

14. (a) Berridge, M. V.; Herst, P. M.; Tan, A. S. Tetrazolium Dyes as Tools in Cell Biology: New Insights into Their Cellular Reduction. Biotechnol. Annu. Rev. 2005, 11, 127-152. (b) Mosmann, T. Rapid Colorimetric Assay for Cellular Growth and Survival: Application to Proliferation and Cytotoxicity Assays. J. Immunol. Methods 1983, 65, 55-63.

15. Khlebnikov, A. F.; Novikov, M. S.; Gorbunova, Y. G.; Galenko, E. E.; Mikhailov, K. I.; Pakalnis, V. V.; Avdontceva, M. S. Isoxazolium N-Ylides and 1-Oxa-5-azahexa-1,3,5trienes on the Way from Isoxazoles to $2 \mathrm{H}$-1,3-Oxazines. Beilstein J. Org. Chem. 2014, 10, 1896-1905.

16. Dolomanov, O. V.; Bourhis, L. J.; Gildea, R. J; Howard, J. A. K.; Puschmann, H. OLEX2: a Complete Structure Solution, Refinement and Analysis Program. J. Appl. Cryst. 2009, $42,339-341$.

17. Sheldrick, G. M. SHELXT - Integrated Space-Group and Crystal-Structure Determination. Acta Cryst. 2015, A71, 3-8.

18. Sheldrick, G. M. Crystal Structure Refinement with SHELXL. Acta Cryst. 2015, C71, 3-8.

19. Gaussian 09, Revision D.01, Frisch, M. J.; Trucks, G.W.; Schlegel, H. B.; Scuseria, G. E.; Robb, M. A.; Cheeseman, J. R.; Scalmani, G.; Barone, V.; Mennucci, B.; Petersson, G. A.; Nakatsuji, H.; Caricato, M.; Li, X.; Hratchian, H. P.; Izmaylov, A. F.; Bloino, J.; Zheng, G.; Sonnenberg, J. L.; Hada, M.; Ehara, M.; Toyota, K.; Fukuda, R.; Hasegawa, J.; Ishida, M.; Nakajima, T.; Honda, Y.; Kitao, O.; Nakai, H.; Vreven, T.; Montgomery, J. A.; Peralta, J. E.; Ogliaro, F.; Bearpark, M.; Heyd, J. J.; Brothers, E.; Kudin, K. N.; Staroverov, V. N.; Kobayashi, R.; Normand, J.; Raghavachari, K.; Rendell, A.; Burant, J. C.; Iyengar, S. S.; Tomasi, J.; Cossi, M.; Rega, N.; Millam, N. J.; Klene, M.; Knox, J. E.; Cross, J. B.; Bakken, V.; Adamo, C.; Jaramillo, J.; Gomperts, R.; Stratmann, R. E.; Yazyev, O.; Austin, A. J.; Cammi, R.; Pomelli, C.; Ochterski, J. W.; Martin, R. L.; 
Morokuma, K.; Zakrzewski, V. G.; Voth, G. A.; Salvador, P.; Dannenberg, J. J.; Dapprich, S.; Daniels, A. D.; Farkas, Ő.; Foresman, J. B.; Ortiz, J. V.; Cioslowski, J.; Fox, D. J. Gaussian 09, Revision C.01; Gaussian: Wallingford CT, 2013. 


\section{NMR spectra of new compounds}

${ }^{1} \mathrm{H}$ NMR spectrum of compound $1 \mathbf{e}\left(400 \mathrm{MHz}, \mathrm{CDCl}_{3}\right)$

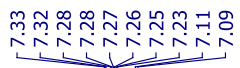<smiles>Cc1ccccc1-c1c(C)noc1C</smiles>

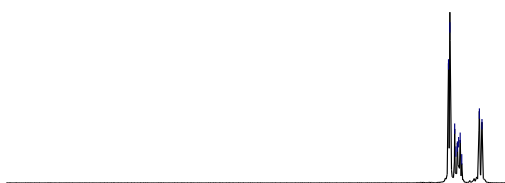

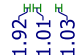

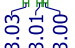

$\begin{array}{llllllllllllllllllllll}10.0 & 9.5 & 9.0 & 8.5 & 8.0 & 7.5 & 7.0 & 6.5 & 6.0 & 5.5 & 5.0 & 4.5 & 4.0 & 3.5 & 3.0 & 2.5 & 2.0 & 1.5 & 1.0 & 0.5 & 0.0 & -0.4\end{array}$

${ }^{13} \mathrm{C}\left\{{ }^{1} \mathrm{H}\right\}$ NMR spectrum of compound $1 \mathrm{e}\left(100 \mathrm{MHz}, \mathrm{CDCl}_{3}\right)$

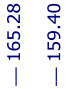

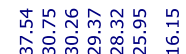
1.

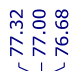

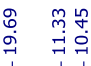<smiles>Cc1ccccc1-c1c(C)noc1C</smiles>

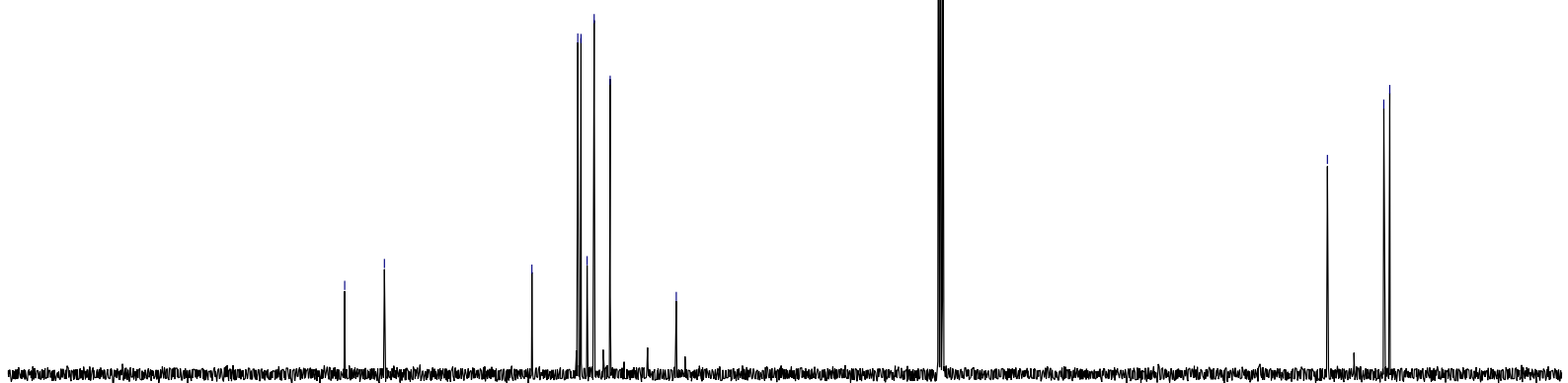

$\begin{array}{llllllllllll}210 & 200 & 190 & 180 & 170 & 160 & 150 & 140 & 130 & 120 & 110 & 1\end{array}$ 
${ }^{1} \mathrm{H}$ NMR spectrum of compound $1 \mathbf{m}\left(400 \mathrm{MHz}, \mathrm{CDCl}_{3}\right)$

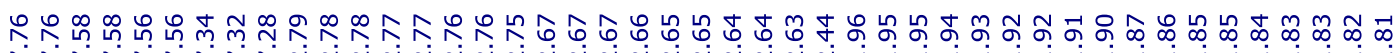

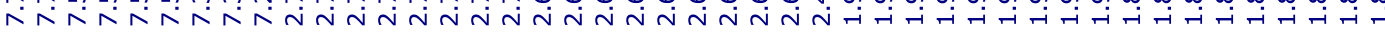
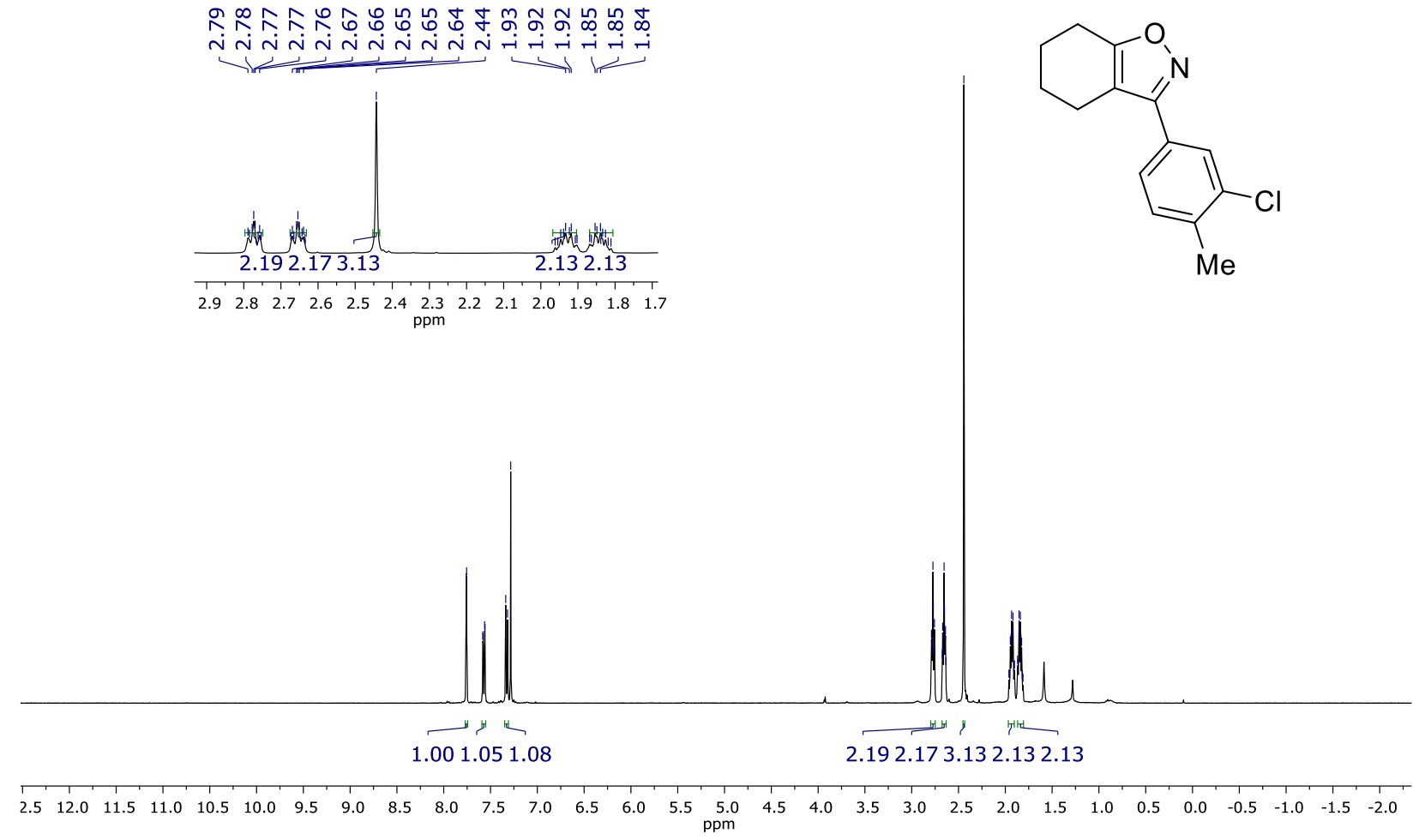

${ }^{13} \mathrm{C}\left\{{ }^{1} \mathrm{H}\right\}$ NMR spectrum of compound $1 \mathbf{m}\left(100 \mathrm{MHz}, \mathrm{CDCl}_{3}\right)$

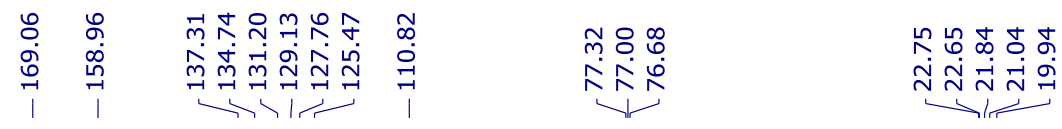<smiles>Cc1ccc(-c2noc3c2CCCC3)cc1Cl</smiles>

$\begin{array}{lllllllllllll}30 & 220 & 210 & 200 & 190 & 180 & 170 & 160 & 150 & 140 & 130 & 120 & 110 \\ \mathrm{ppm}\end{array}$ 
${ }^{1} \mathrm{H}$ NMR spectrum of compound $10\left(400 \mathrm{MHz}, \mathrm{CDCl}_{3}\right)$

$\stackrel{\substack{n \\ i}}{i}$

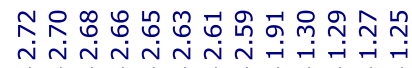<smiles>CCc1noc(CC)c1C</smiles>

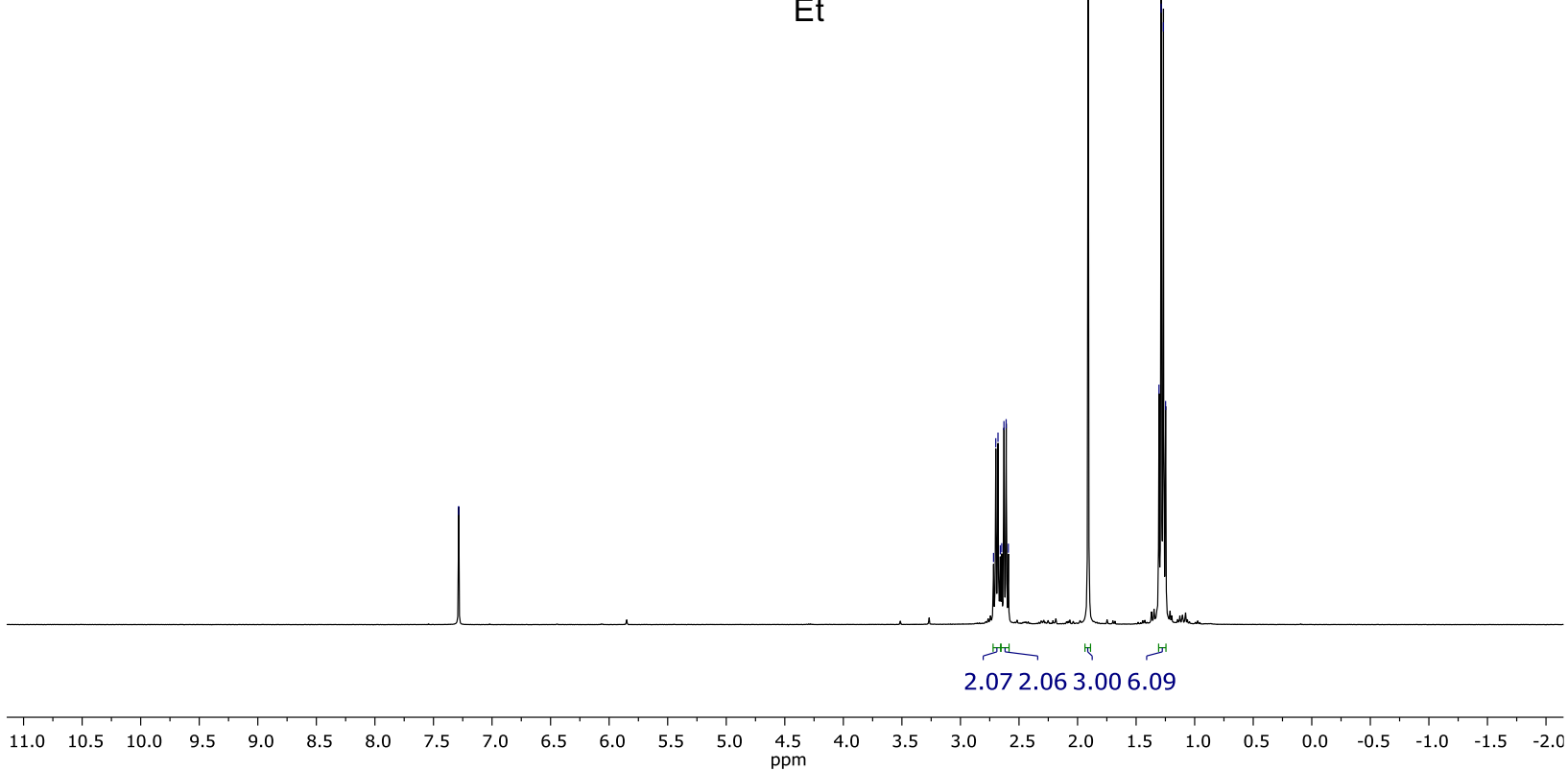

${ }^{13} \mathrm{C}\left\{{ }^{1} \mathrm{H}\right\}$ NMR spectrum of compound $10\left(100 \mathrm{MHz}, \mathrm{CDCl}_{3}\right)$

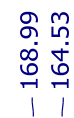

䓹

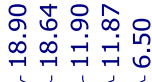<smiles>CCc1noc(CC)c1C</smiles>

$\begin{array}{llllllllllllll}30 & 220 & 210 & 200 & 190 & 180 & 170 & 160 & 150 & 140 & 130 & 120 & 110 & 100\end{array}$ 
${ }^{1} \mathrm{H}$ NMR spectrum of compound $\mathbf{3 a}\left(400 \mathrm{MHz}, \mathrm{CDCl}_{3}\right)$

†ำ

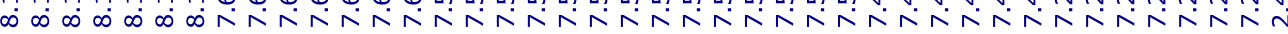<smiles>Cc1nc(C(=O)c2ccccc2)nc(C)c1-c1ccccc1</smiles>

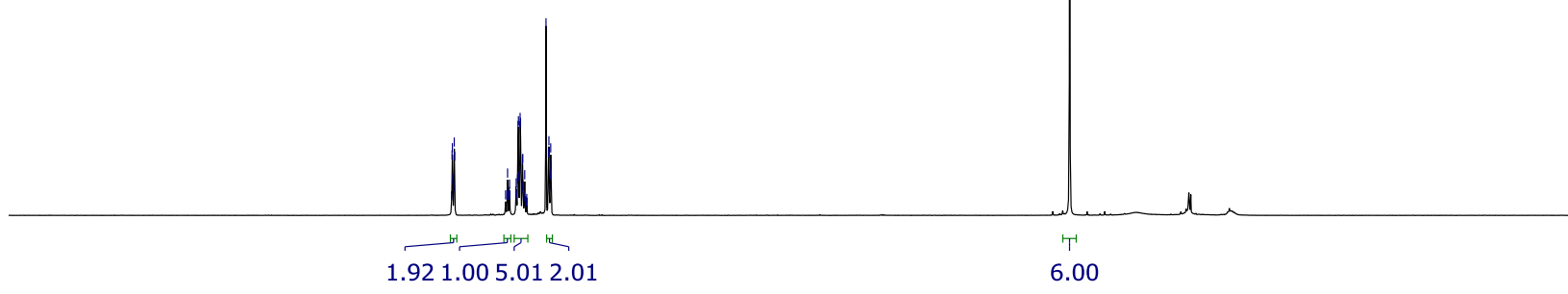
$\begin{array}{lllllllllllllllllllllllllllllllllll}12.0 & 11.5 & 11.0 & 10.5 & 10.0 & 9.5 & 9.0 & 8.5 & 8.0 & 7.5 & 7.0 & 6.5 & 6.0 & 5.5 & \begin{array}{c}5.0 \\ \mathrm{ppm}\end{array} & 4.5 & 4.0 & 3.5 & 3.0 & 2.5 & 2.0 & 1.5 & 1.0 & 0.5 & 0.0 & -0.5 & -1.0 & -1.5 & -2.0\end{array}$

${ }^{13} \mathrm{C}\left\{{ }^{1} \mathrm{H}\right\}$ NMR spectrum of compound $3 \mathbf{a}\left(100 \mathrm{MHz}, \mathrm{CDCl}_{3}\right)$

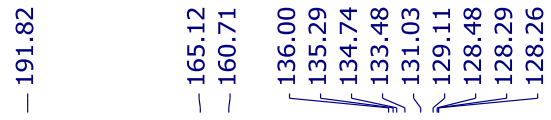

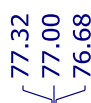

구ำ<smiles>Cc1nc(C(=O)c2ccccc2)nc(C)c1-c1ccccc1</smiles>

$\begin{array}{lllll}30 & 220 & 210 & 200 & 190\end{array}$ $70 \quad 160$ 140 $30 \quad 1$ 
2D ${ }^{1} \mathrm{H}_{-}{ }^{13} \mathrm{C}$ HSQC spectrum $\left(\mathrm{CDCl}_{3}\right)$ of compound $\mathbf{3 a}$<smiles>Cc1nc(C(=O)c2ccccc2)nc(C)c1-c1ccccc1</smiles>
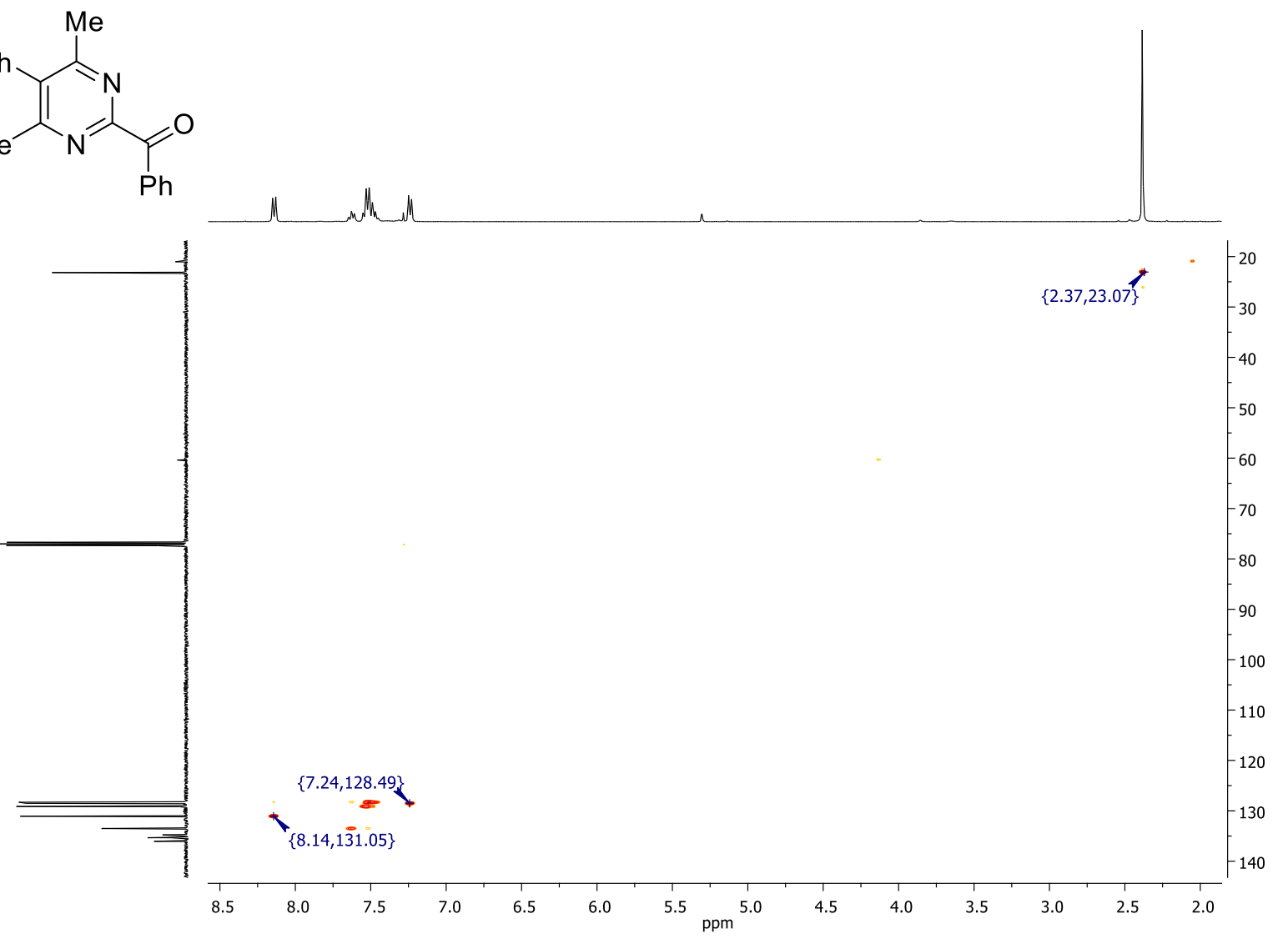

$2 \mathrm{D}{ }^{1} \mathrm{H}_{-}{ }^{13} \mathrm{C} \mathrm{HMBC}$ spectrum $\left(\mathrm{CDCl}_{3}\right)$ of compound 3a<smiles>Cc1nc(C(=O)c2ccccc2)nc(C)c1-c1ccccc1</smiles>

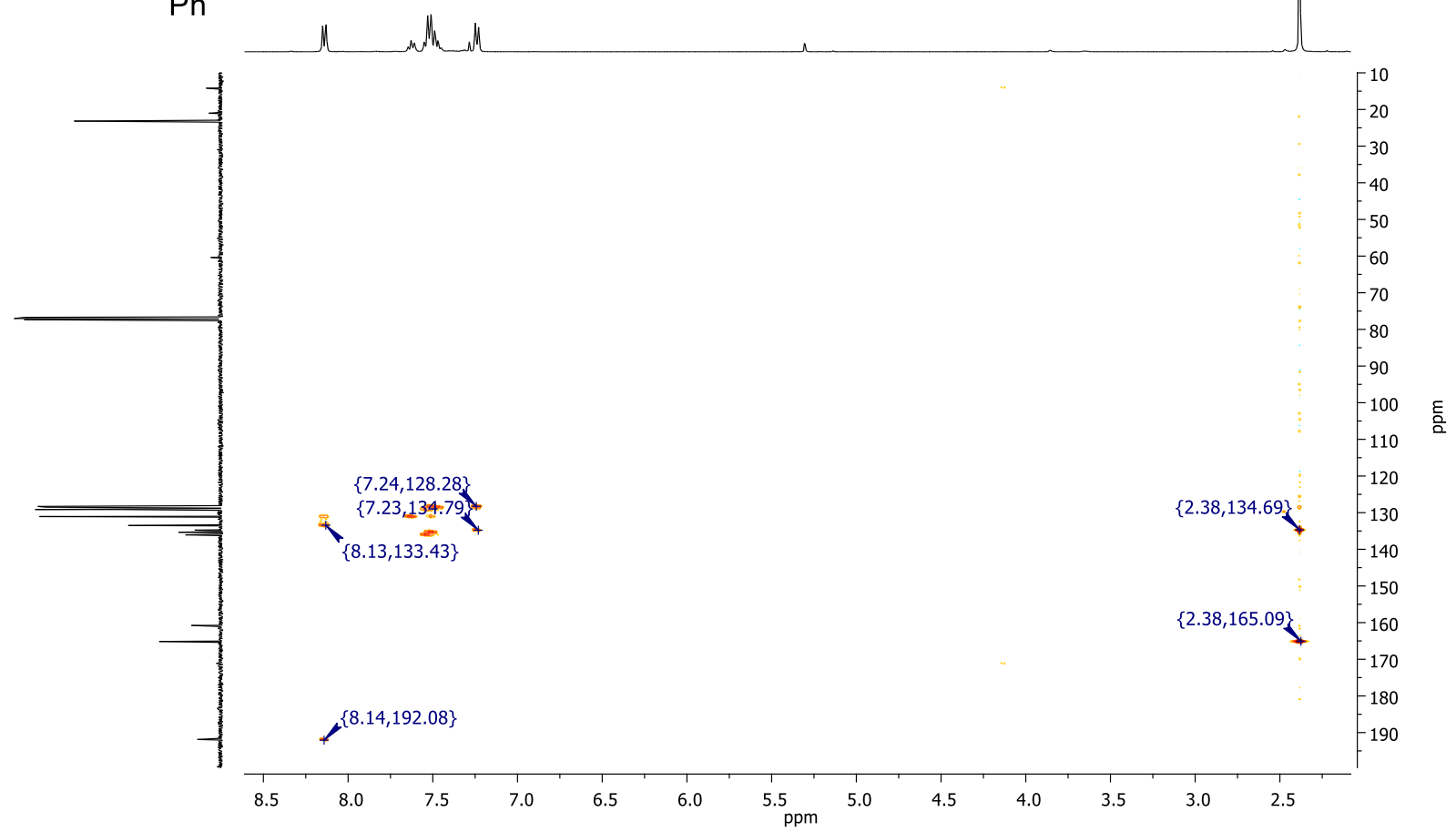


${ }^{1} \mathrm{H}$ NMR spectrum of compound $\mathbf{3 b}\left(400 \mathrm{MHz}, \mathrm{CDCl}_{3}\right)$

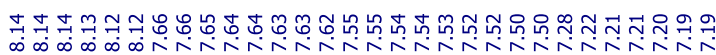<smiles>Cc1nc(C(=O)c2ccccc2)nc(C)c1-c1ccc(Cl)cc1</smiles>

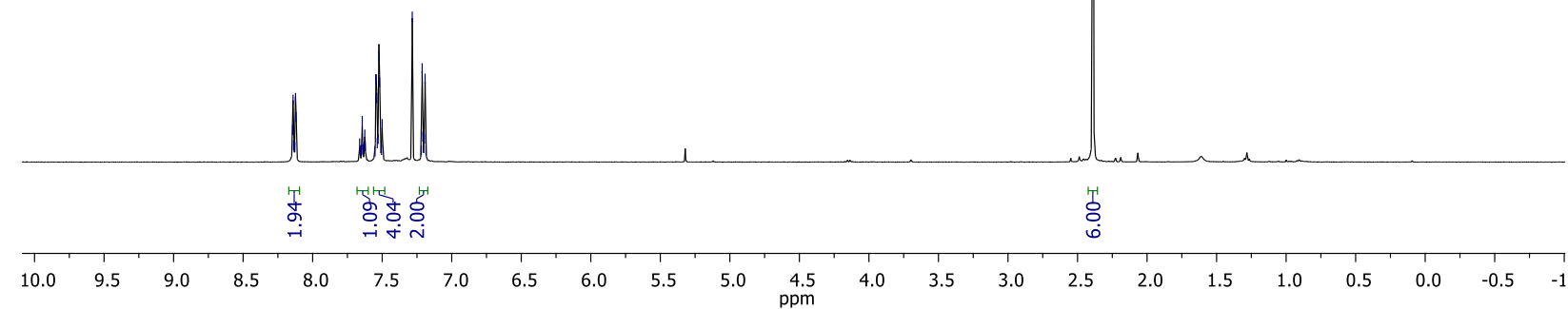

${ }^{13} \mathrm{C}\left\{{ }^{1} \mathrm{H}\right\}$ NMR spectrum of compound $\mathbf{3 b}\left(100 \mathrm{MHz}, \mathrm{CDCl}_{3}\right)$

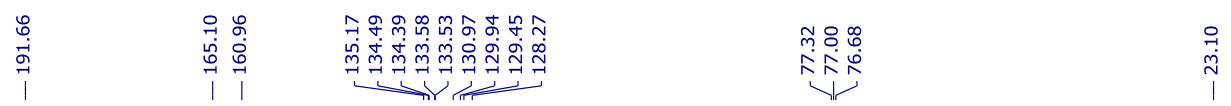

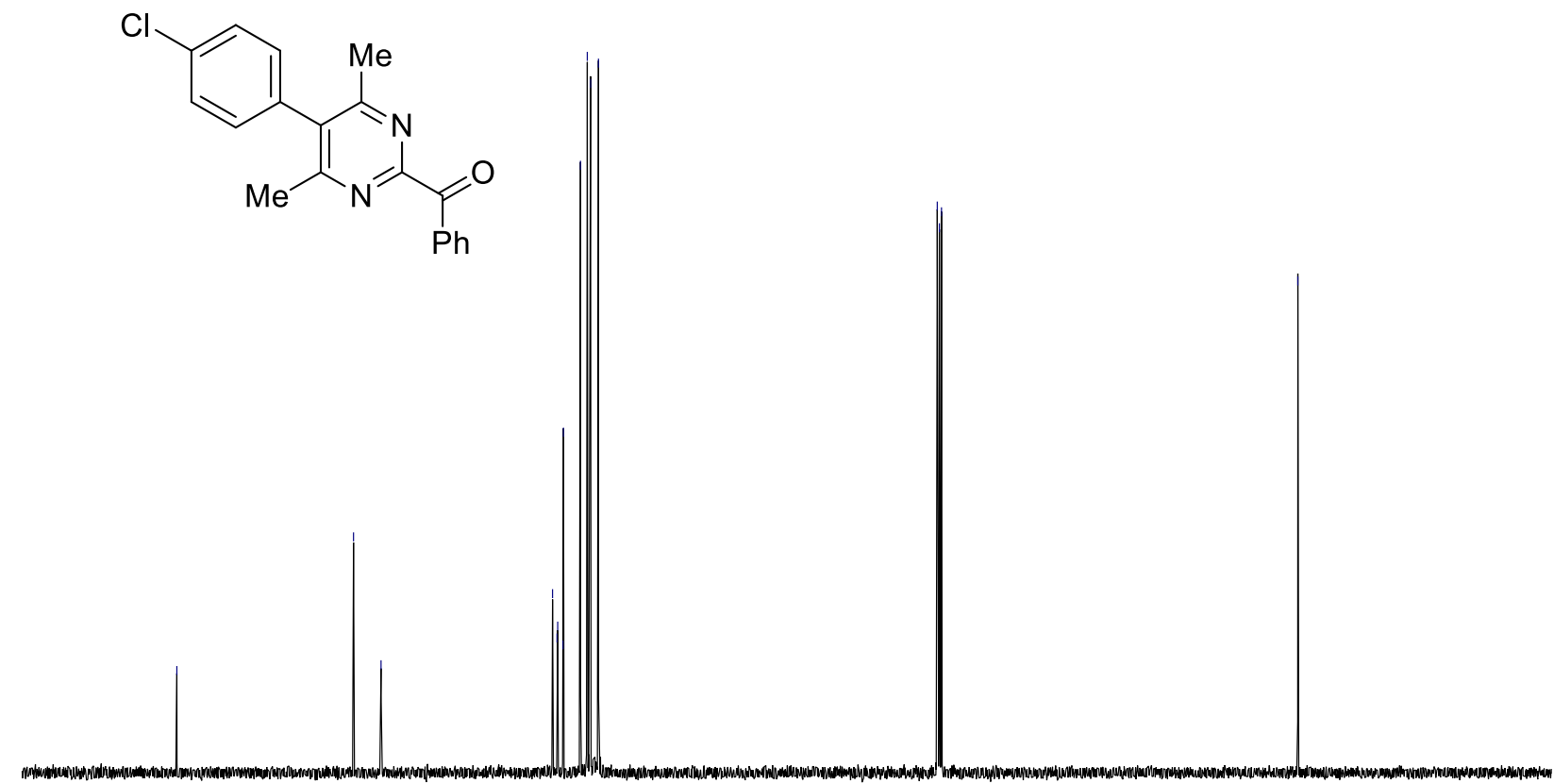

$\begin{array}{llllllllllll}210 & 200 & 190 & 180 & 170 & 160 & 150 & 140 & 130 & 120 & 110 & \begin{array}{l}100 \\ \mathrm{ppm}\end{array}\end{array}$ 
${ }^{1} \mathrm{H}$ NMR spectrum of compound $3 \mathbf{c}\left(400 \mathrm{MHz}, \mathrm{CDCl}_{3}\right)$

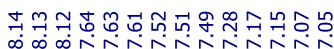

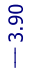

$\mathrm{MeO}$<smiles>Cc1nc(C(=O)c2ccccc2)nc(C)c1-c1ccccc1</smiles>

$\mathrm{Ph}$

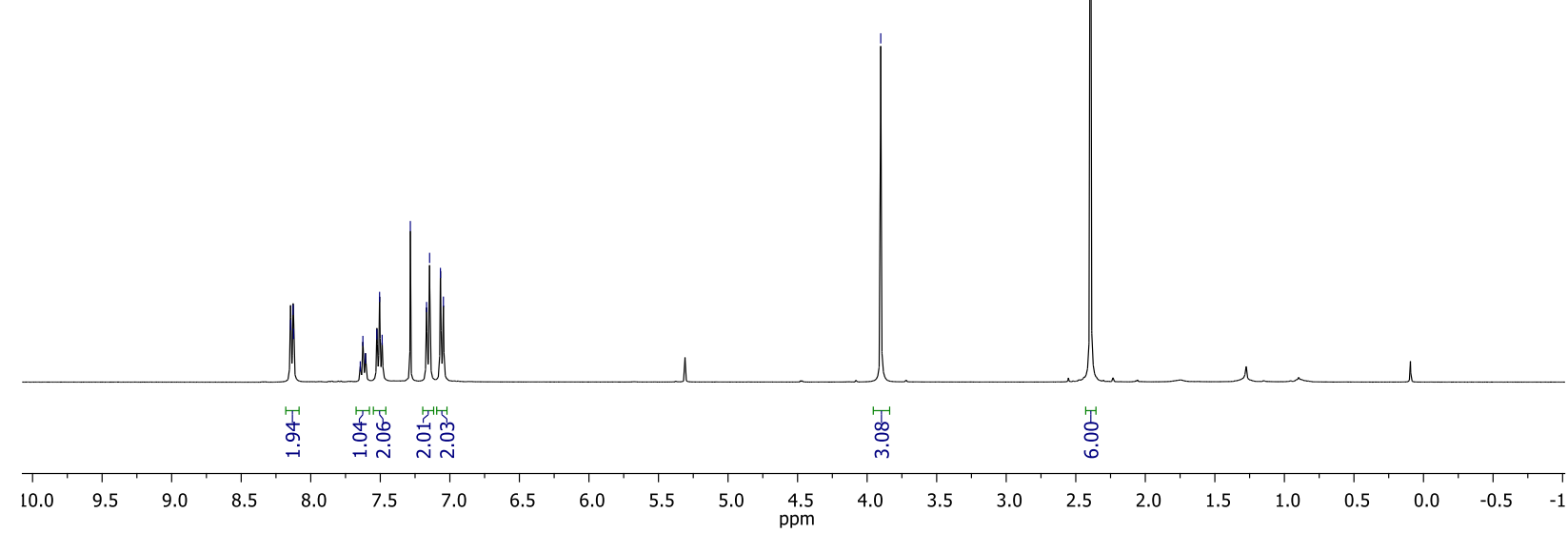

${ }^{13} \mathrm{C}\left\{{ }^{1} \mathrm{H}\right\}$ NMR spectrum of compound $3 \mathbf{c}\left(100 \mathrm{MHz}, \mathrm{CDCl}_{3}\right)$

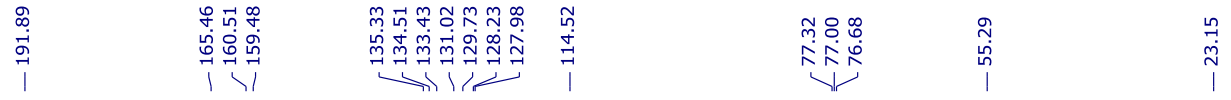

$\mathrm{MeO}$<smiles>Cc1nc(C(=O)c2ccccc2)nc(C)c1-c1ccccc1</smiles>

$\begin{array}{llllllllllll}210 & 200 & 190 & 180 & 170 & 160 & 150 & 140 & 130 & 120 & 110 & 100\end{array}$ 
${ }^{1} \mathrm{H}$ NMR spectrum of compound $\mathbf{3 d}\left(400 \mathrm{MHz}, \mathrm{CDCl}_{3}\right)$

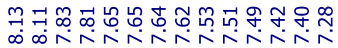<smiles>Cc1nc(C(=O)c2ccccc2)nc(C)c1-c1ccc(C(F)(F)F)cc1</smiles>

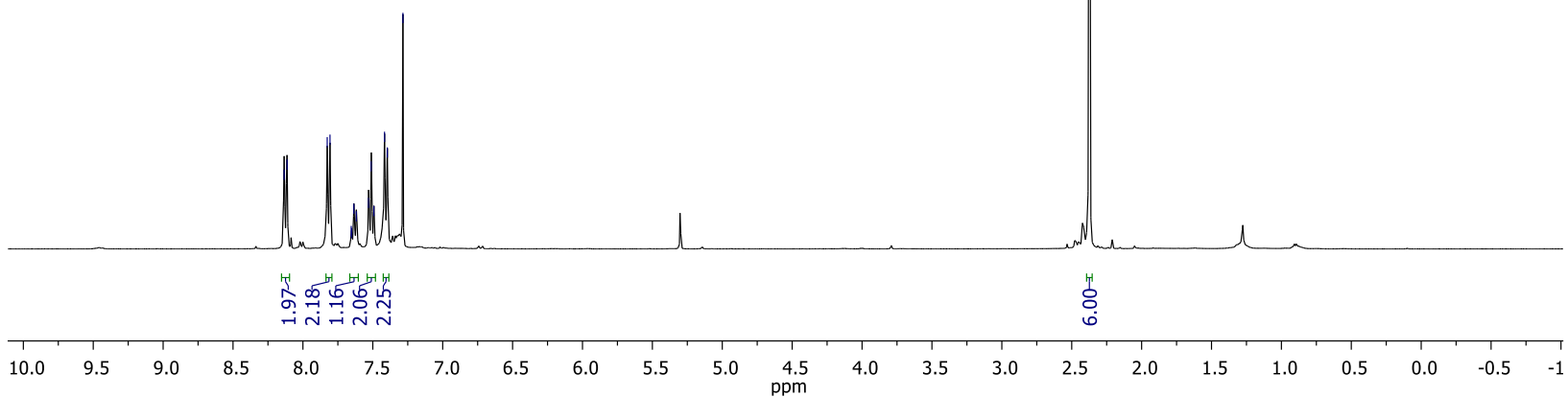

${ }^{13} \mathrm{C}\left\{{ }^{1} \mathrm{H}\right\}$ NMR spectrum of compound $3 d\left(100 \mathrm{MHz}, \mathrm{CDCl}_{3}\right)$

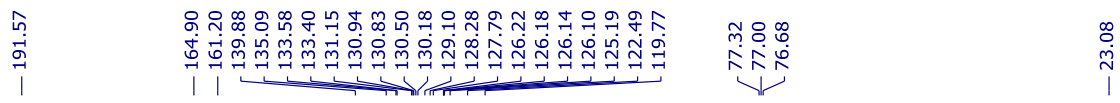

$\mathrm{F}_{3} \mathrm{C}$

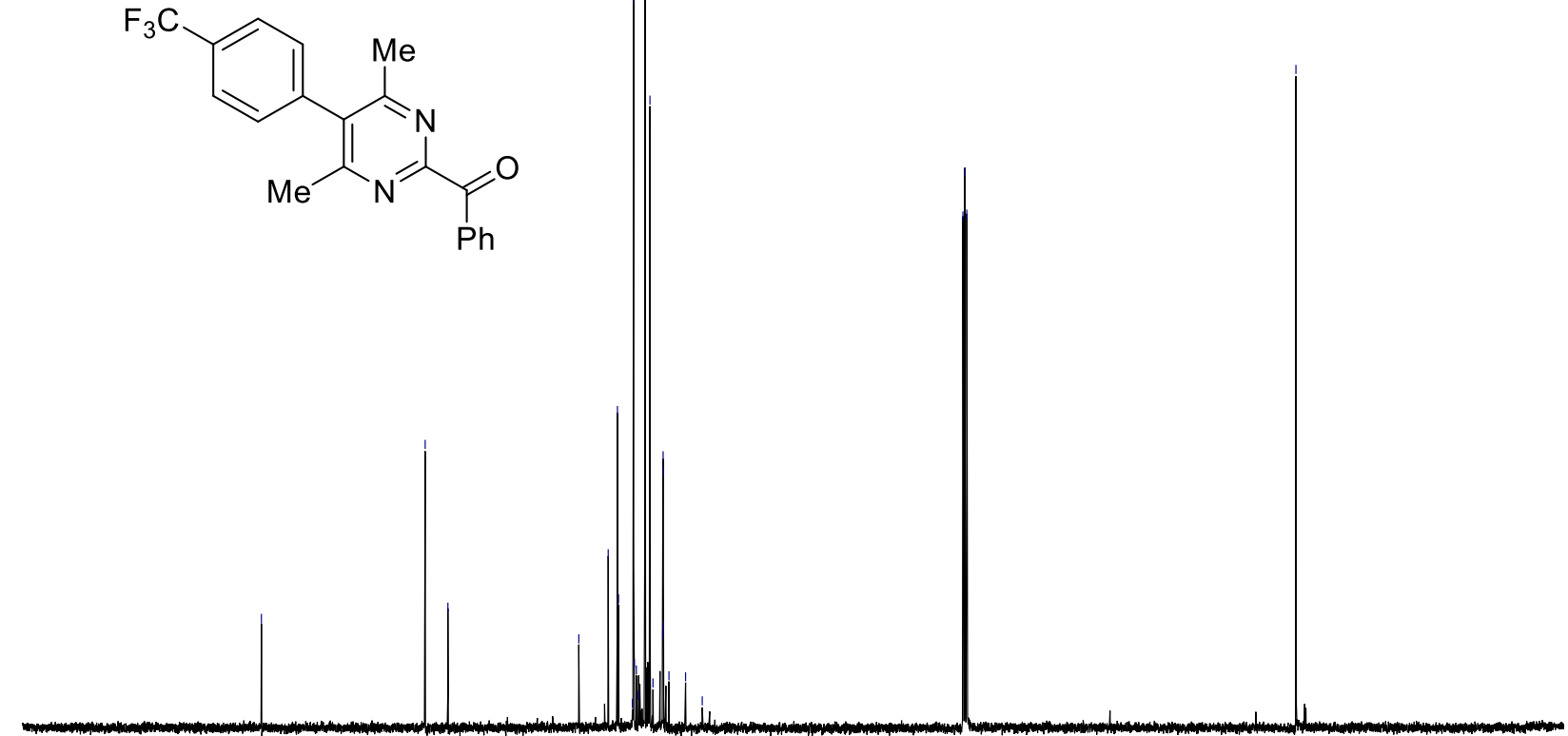

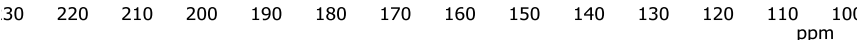


${ }^{1} \mathrm{H}$ NMR spectrum of compound $\mathbf{3 e}\left(400 \mathrm{MHz}, \mathrm{CDCl}_{3}\right)$

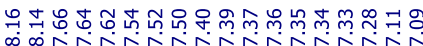

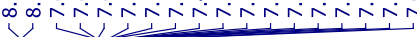<smiles>Cc1ccccc1-c1c(C)nc(C(=O)c2ccccc2)nc1C</smiles>

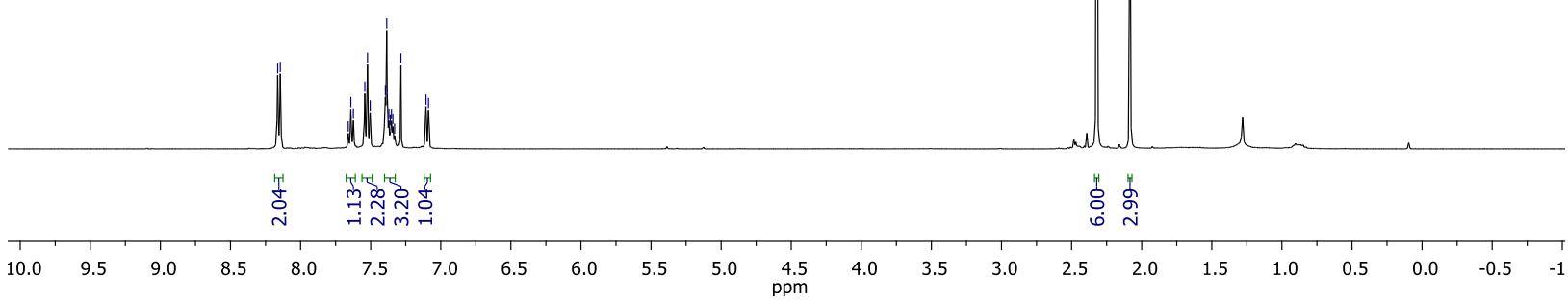

${ }^{13} \mathrm{C}\left\{{ }^{1} \mathrm{H}\right\}$ NMR spectrum of compound $3 \mathbf{e}\left(100 \mathrm{MHz}, \mathrm{CDCl}_{3}\right)$

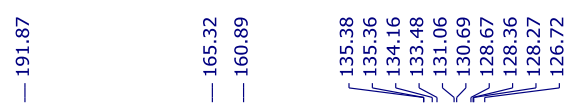

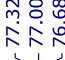

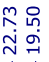<smiles>Cc1ccccc1-c1c(C)nc(C(=O)c2ccccc2)nc1C</smiles>

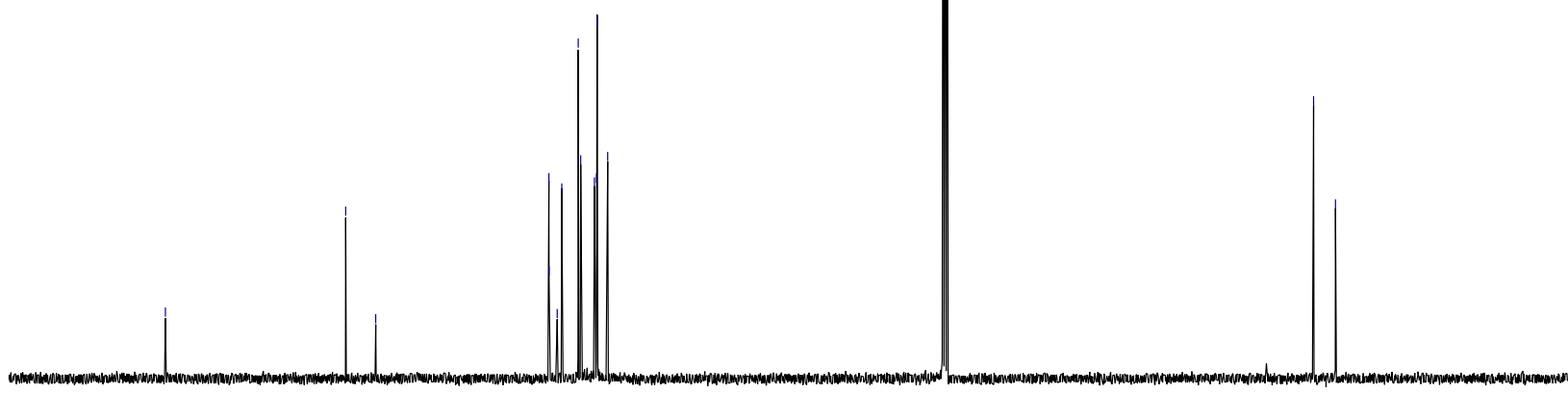

$\begin{array}{llllllllllll}210 & 200 & 190 & 180 & 170 & 160 & 150 & 140 & 130 & 120 & 110 & 1\end{array}$ 
${ }^{1} \mathrm{H}$ NMR spectrum of compound $\mathbf{3 f}\left(400 \mathrm{MHz}, \mathrm{CDCl}_{3}\right)$

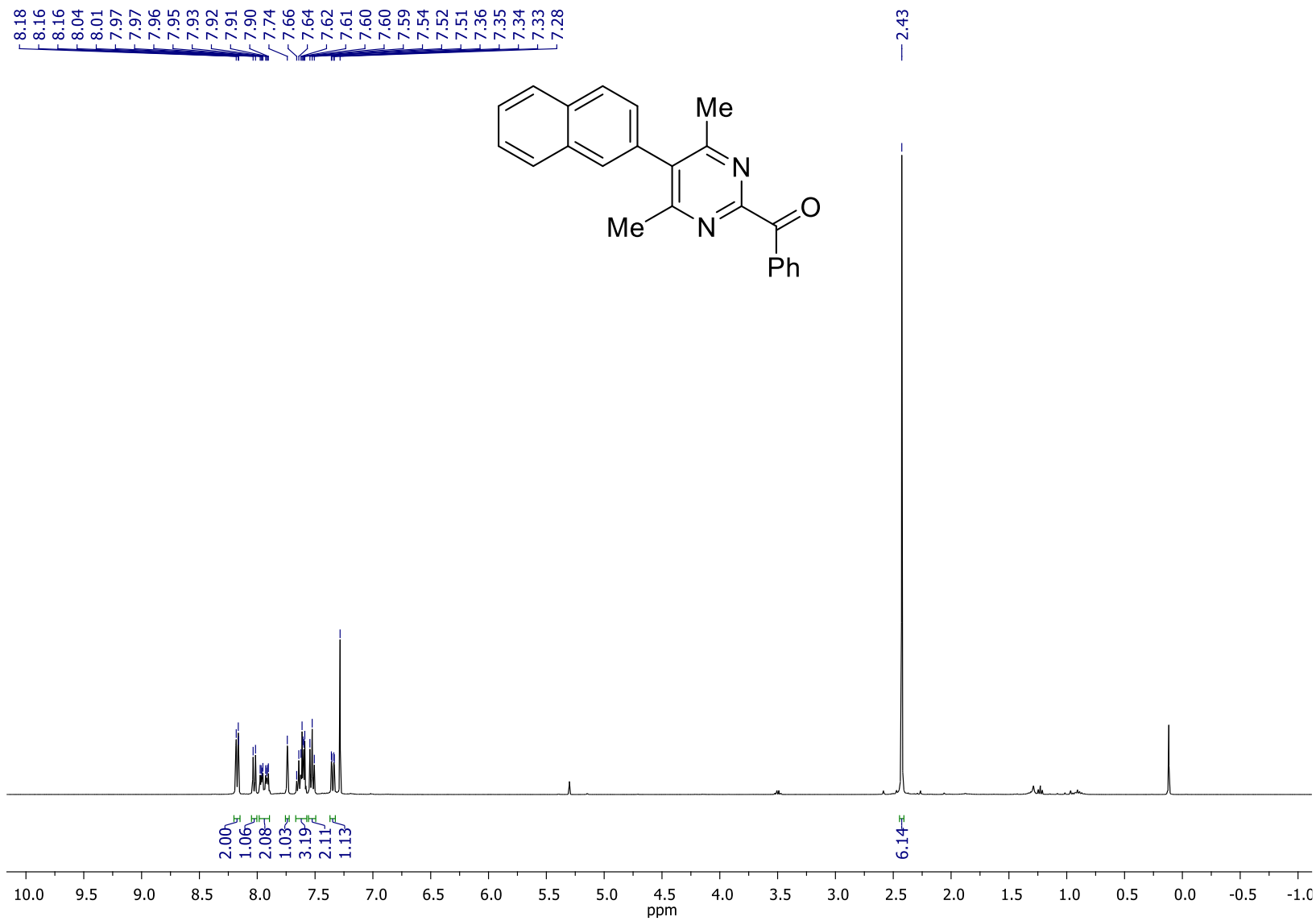

${ }^{13} \mathrm{C}\left\{{ }^{1} \mathrm{H}\right\}$ NMR spectrum of compound $3 f\left(100 \mathrm{MHz}, \mathrm{CDCl}_{3}\right)$

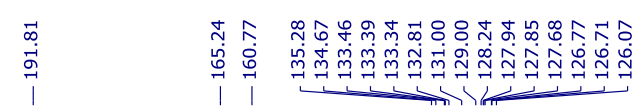

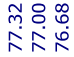

积<smiles>Cc1nc(C(=O)c2ccccc2)nc(C)c1-c1ccc2ccccc2c1</smiles>

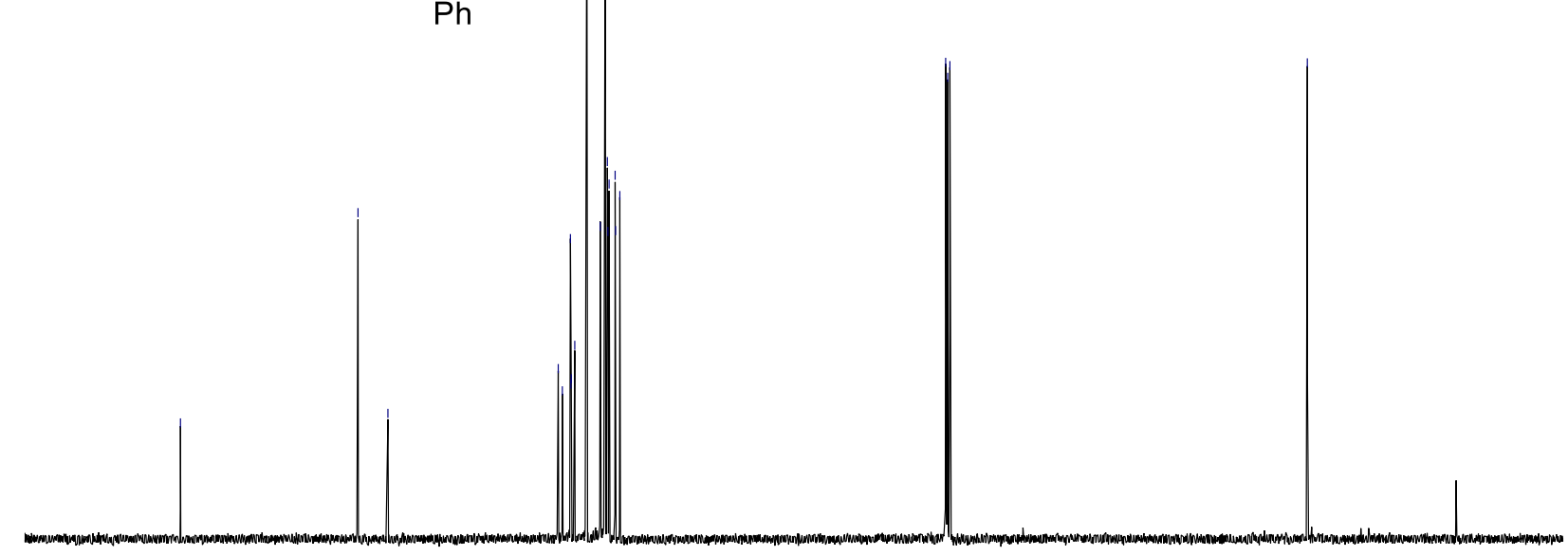

$\begin{array}{llllllllllll}210 & 200 & 190 & 180 & 170 & 160 & 150 & 140 & 130 & 120 & 110 & 100\end{array}$ 
${ }^{1} \mathrm{H}$ NMR spectrum of compound $\mathbf{3 g}\left(400 \mathrm{MHz}, \mathrm{CDCl}_{3}\right)$

ఫ

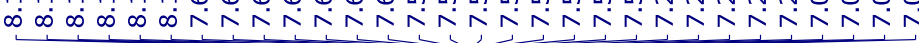<smiles>Cc1nc(C(=O)c2ccccc2)nc(C)c1-c1ccsc1</smiles>

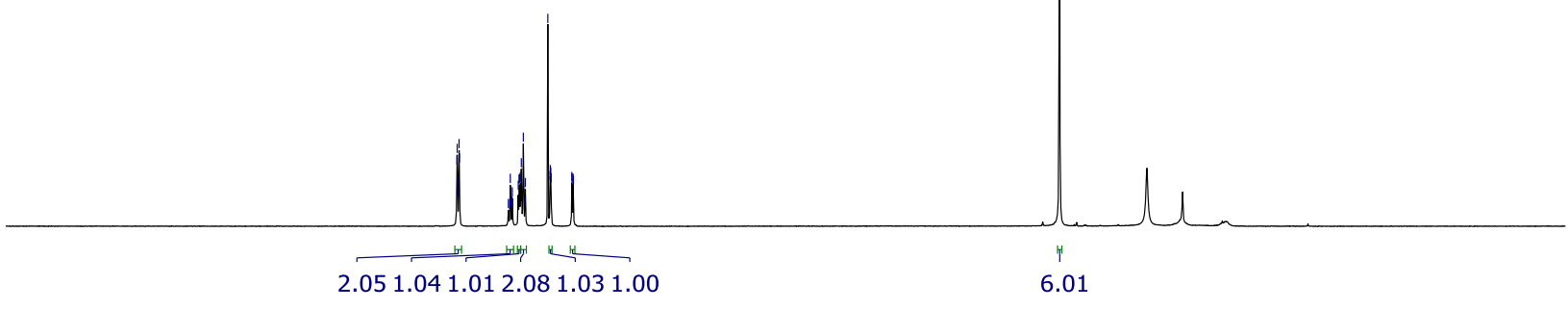

$\begin{array}{llllllllllllllllllllllllllllll}12.0 & 11.5 & 11.0 & 10.5 & 10.0 & 9.5 & 9.0 & 8.5 & 8.0 & 7.5 & 7.0 & 6.5 & 6.0 & 5.5 & \begin{array}{r}5.0 \\ \mathrm{ppm}\end{array} & 4.5 & 4.0 & 3.5 & 3.0 & 2.5 & 2.0 & 1.5 & 1.0 & 0.5 & 0.0 & -0.5 & -1.0 & -1.5 & -2.0\end{array}$

${ }^{13} \mathrm{C}\left\{{ }^{1} \mathrm{H}\right\}$ NMR spectrum of compound $\mathbf{3 g}\left(100 \mathrm{MHz}, \mathrm{CDCl}_{3}\right)$

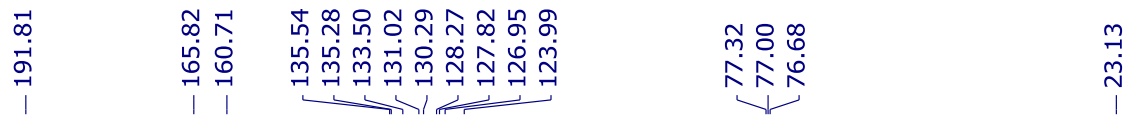<smiles>Cc1nc(C(=O)c2ccccc2)nc(C)c1-c1ccsc1</smiles> 
${ }^{1} \mathrm{H}$ NMR spectrum of compound $\mathbf{3 h}\left(400 \mathrm{MHz}, \mathrm{CDCl}_{3}\right)$

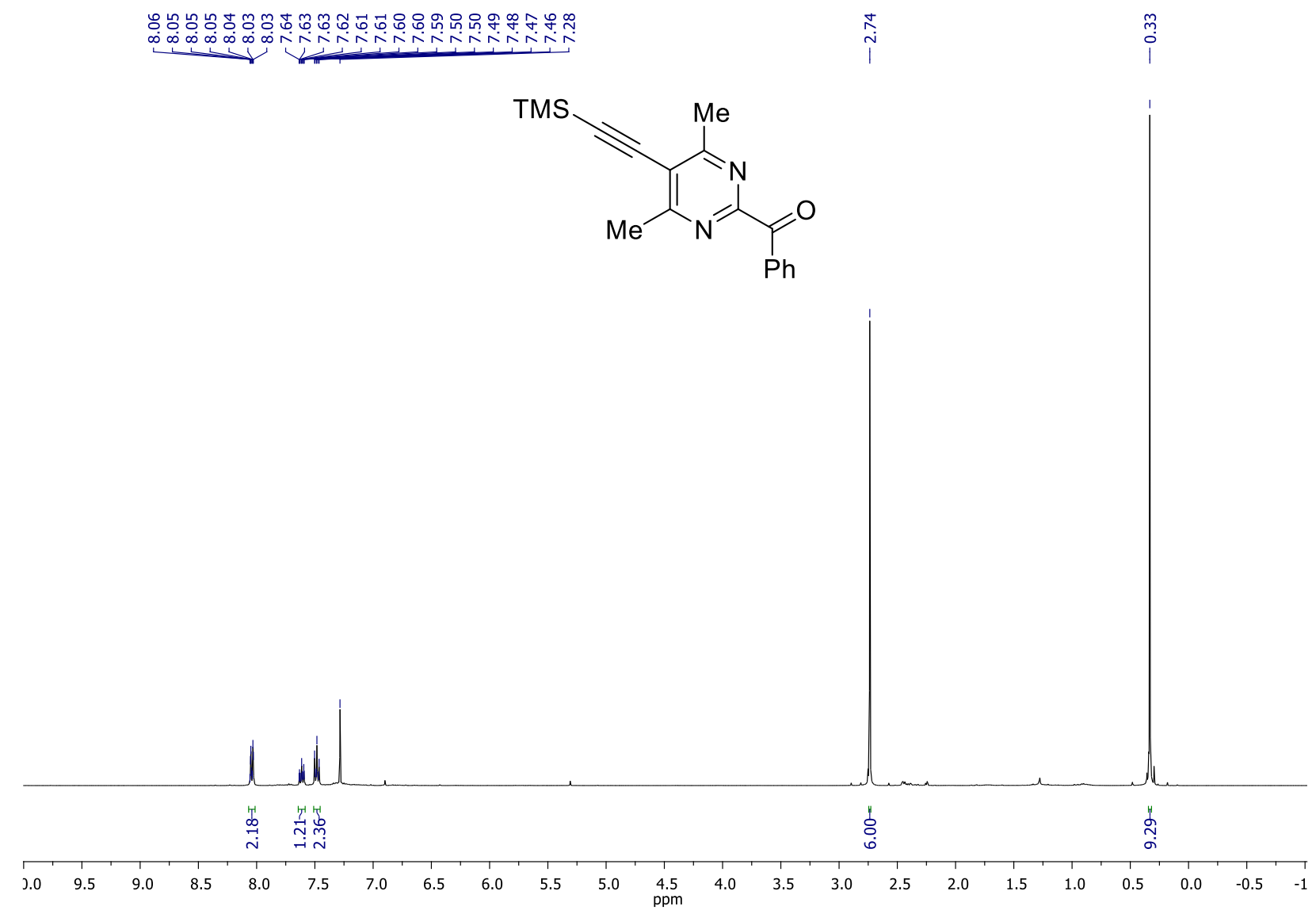

${ }^{13} \mathrm{C}\left\{{ }^{1} \mathrm{H}\right\}$ NMR spectrum of compound $\mathbf{3 h}\left(100 \mathrm{MHz}, \mathrm{CDCl}_{3}\right)$

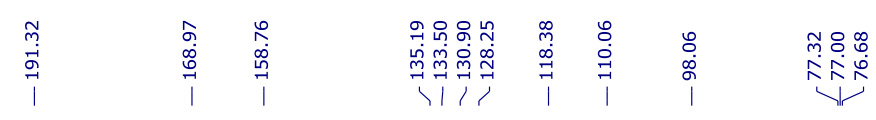

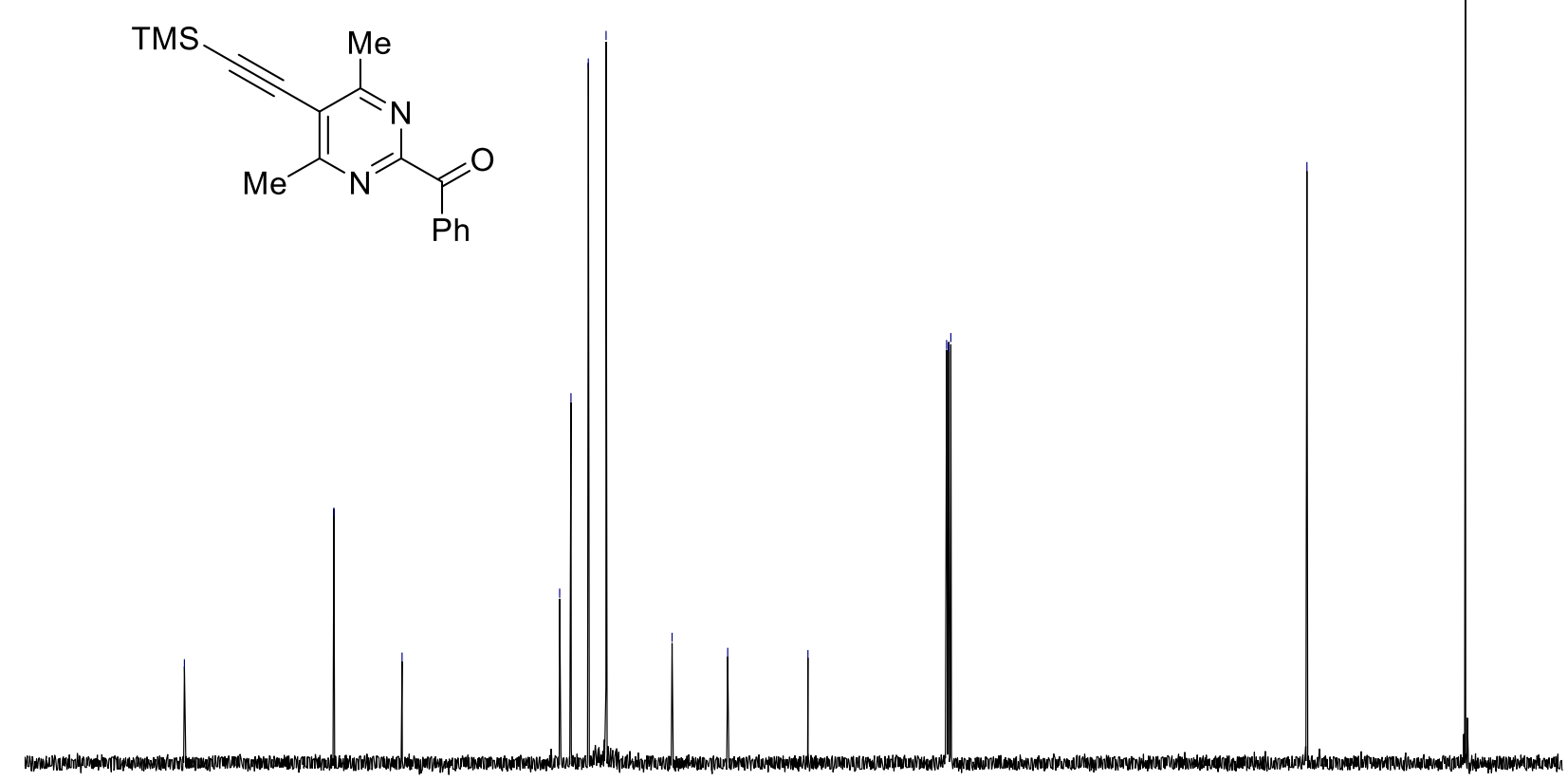

$\begin{array}{llllllllllllllllllllllll}210 & 200 & 190 & 180 & 170 & 160 & 150 & 140 & 130 & 120 & 110 & \begin{array}{l}100 \\ \mathrm{ppm}\end{array} & 90 & 80 & 70 & 60 & 50 & 40 & 30 & 20 & 10 & 0 & -10\end{array}$ 
${ }^{1} \mathrm{H}$ NMR spectrum of compound $3 \mathbf{i}\left(400 \mathrm{MHz}, \mathrm{CDCl}_{3}\right)$

包

$\infty \infty_{\infty}^{\infty} \infty \infty^{\infty} \hat{N}$<smiles>Cc1nc(C(=O)c2ccccc2)nc(C)c1I</smiles>

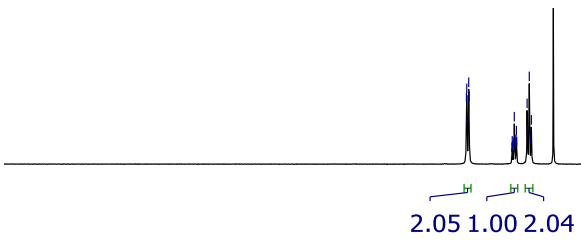

$\begin{array}{llllllllllllllllllllllllllllllllllll}12.0 & 11.5 & 11.0 & 10.5 & 10.0 & 9.5 & 9.0 & 8.5 & 8.0 & 7.5 & 7.0 & 6.5 & 6.0 & 5.5 & 5.0 & 4.5 & 4.0 & 3.5 & 3.0 & 2.5 & 2.0 & 1.5 & 1.0 & 0.5 & 0.0 & -0.5 & -1.0 & -1.5 & -2.0 & \end{array}$

${ }^{13} \mathrm{C}\left\{{ }^{1} \mathrm{H}\right\}$ NMR spectrum of compound $3 \mathbf{i}\left(100 \mathrm{MHz}, \mathrm{CDCl}_{3}\right)$

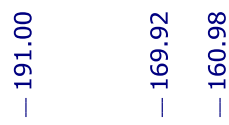

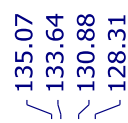

年

$\underset{\substack{M \\ \stackrel{N}{i}}}{\stackrel{m}{i}}$<smiles>Cc1nc(C(=O)c2ccccc2)nc(C)c1I</smiles>

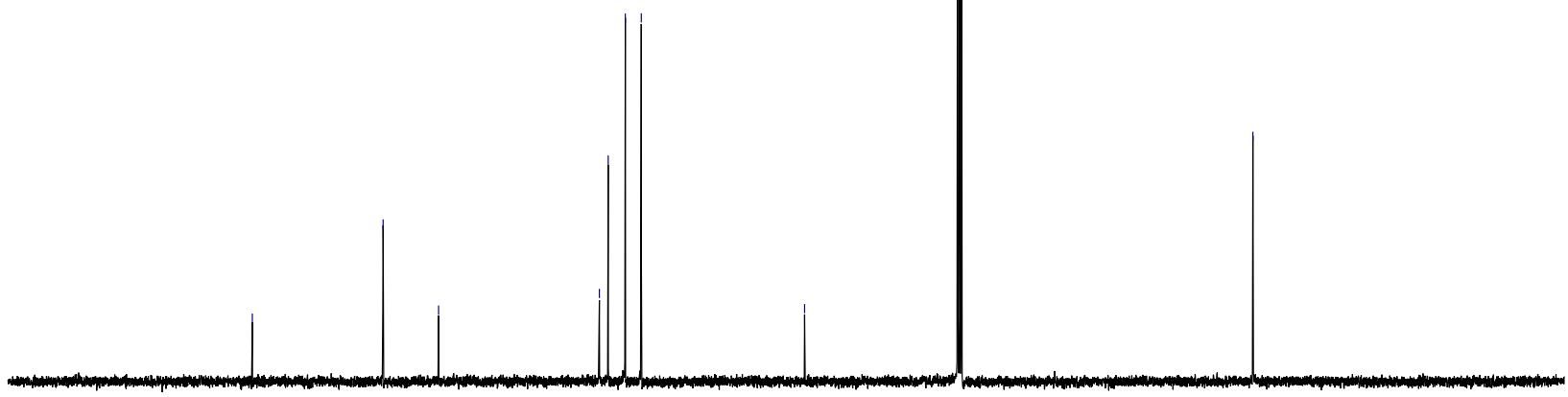

$\begin{array}{lllllllllllllllllllllllllllllll}30 & 220 & 210 & 200 & 190 & 180 & 170 & 160 & 150 & 140 & 130 & 120 & 110 & 100 & 90 & 80 & 70 & 60 & 50 & 40 & 30 & 20 & 10 & 0 & -10 & -2\end{array}$ 
${ }^{1} \mathrm{H}$ NMR spectrum of compound $\mathbf{3 j}$ (400 $\mathrm{MHz}, \mathrm{CDCl}_{3}$ )

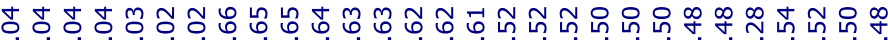
象

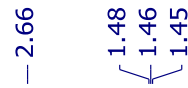<smiles>CCOC(=O)c1c(C)nc(C(=O)c2ccccc2)nc1C</smiles>

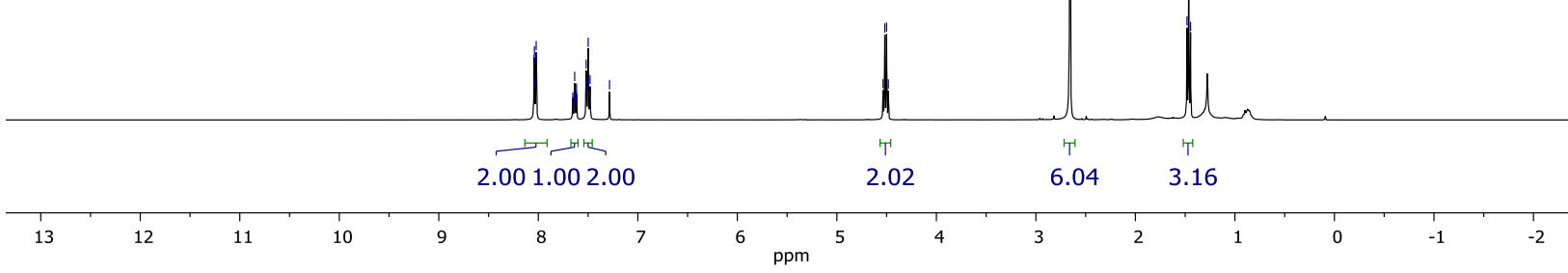

${ }^{13} \mathrm{C}\left\{{ }^{1} \mathrm{H}\right\}$ NMR spectrum of compound $3 \mathbf{j}\left(100 \mathrm{MHz}, \mathrm{CDCl}_{3}\right)$

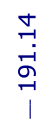

$$
\begin{aligned}
& \infty \\
& \infty \\
& \infty \\
& 0 \\
& 0 \\
& 0
\end{aligned}
$$

रा?

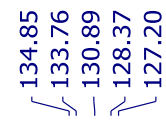

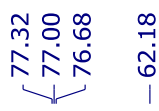

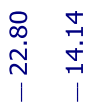<smiles>CCOC(=O)c1c(C)nc(C(=O)c2ccccc2)nc1C</smiles>
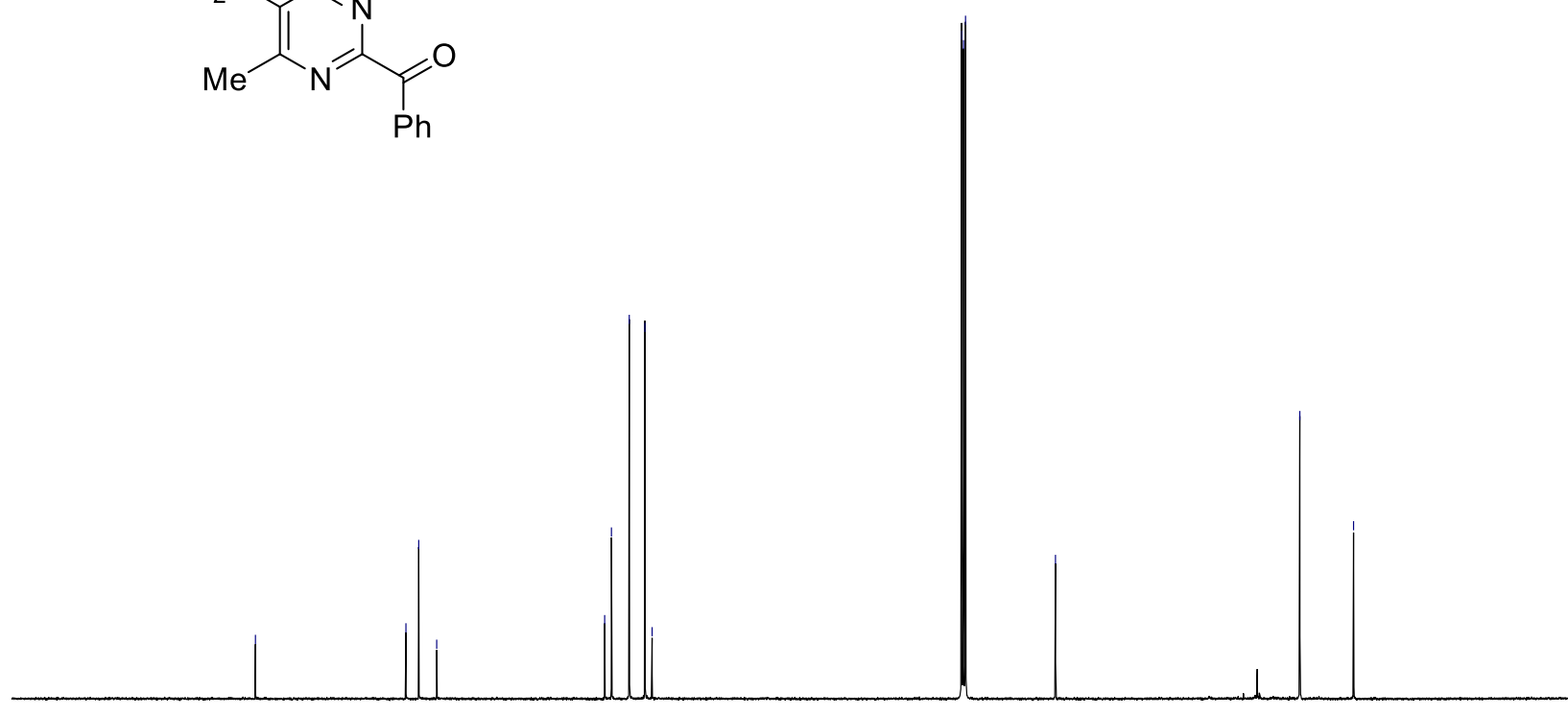

$\begin{array}{lllllllllllllllllllllllllll}1 & 220 & 210 & 200 & 190 & 180 & 170 & 160 & 150 & 140 & 130 & 120 & 110 & 100 & 90 & 80 & 70 & 60 & 50 & 40 & 30 & 20 & 10 & 0 & -10 & -2\end{array}$ 
${ }^{1} \mathrm{H}$ NMR spectrum of compound $3 \mathbf{k}\left(400 \mathrm{MHz}, \mathrm{CDCl}_{3}\right)$

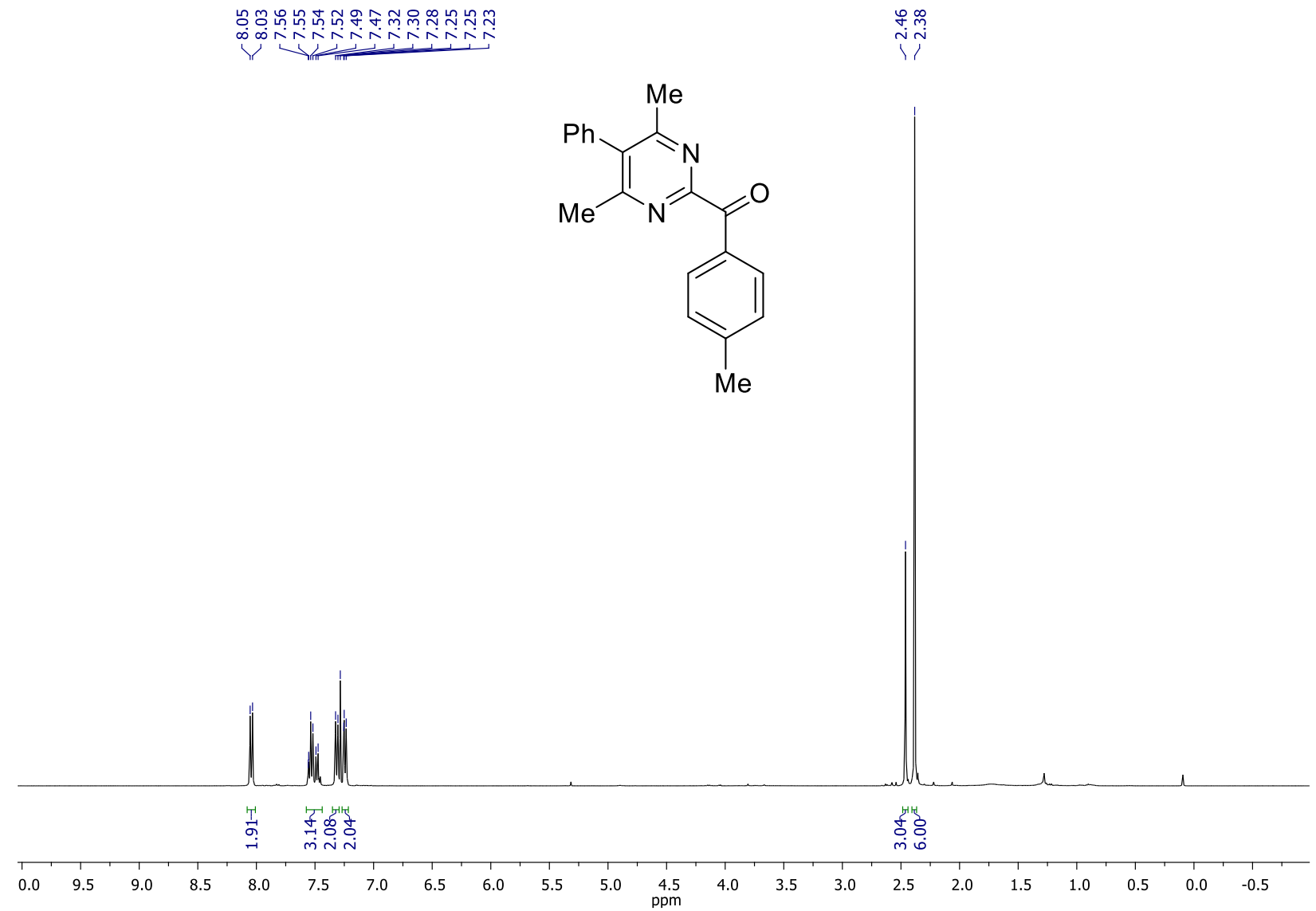

${ }^{13} \mathrm{C}\left\{{ }^{1} \mathrm{H}\right\} \mathrm{NMR}$ spectrum of compound $3 \mathbf{k}\left(100 \mathrm{MHz}, \mathrm{CDCl}_{3}\right)$

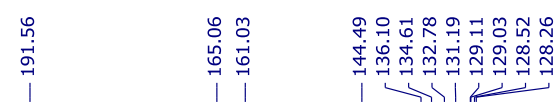

ํํํㅇํำ

ฟiv<smiles>Cc1ccc(C(=O)c2nc(C)c(-c3ccccc3)c(C)n2)cc1</smiles>

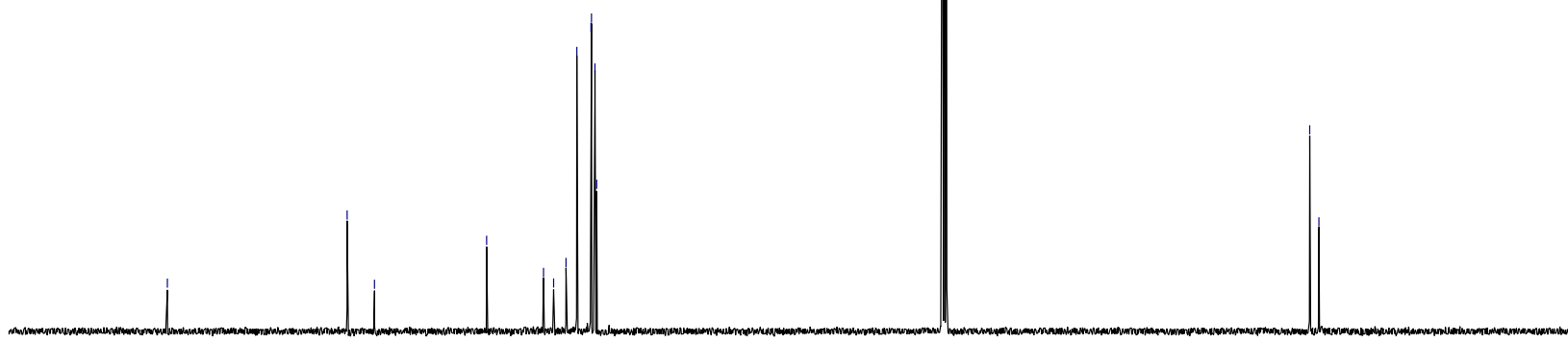

$\begin{array}{lllllllllllllllllllllllll}210 & 200 & 190 & 180 & 170 & 160 & 150 & 140 & 130 & 120 & 110 & 100 & 90 & 80 & 70 & 60 & 50 & 40 & 30 & 20 & 10 & 0 & -10\end{array}$ 
${ }^{1} \mathrm{H}$ NMR spectrum of compound $3 \mathbf{3}\left(400 \mathrm{MHz}, \mathrm{CDCl}_{3}\right)$
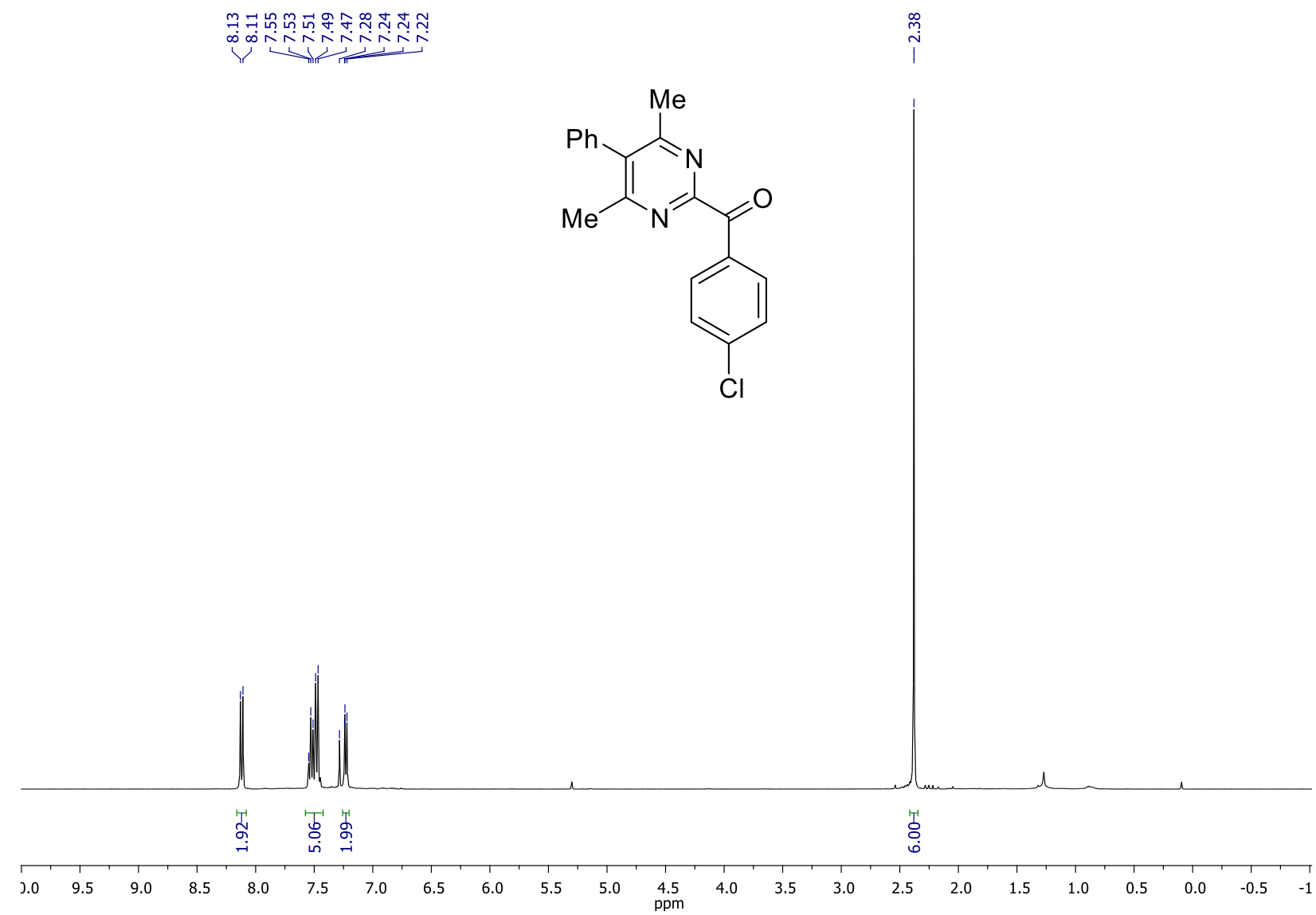

${ }^{13} \mathrm{C}\left\{{ }^{1} \mathrm{H}\right\}$ NMR spectrum of compound $3 \mathrm{l}\left(100 \mathrm{MHz}, \mathrm{CDCl}_{3}\right)$

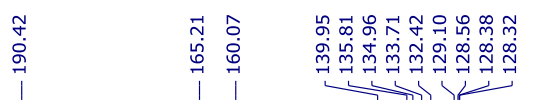

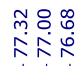<smiles>Cc1nc(C(=O)c2ccc(Cl)cc2)nc(C)c1-c1ccccc1</smiles> 
${ }^{1} \mathrm{H}$ NMR spectrum of compound $3 \mathbf{m}\left(400 \mathrm{MHz}, \mathrm{CDCl}_{3}\right)$

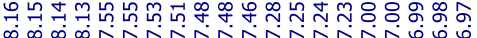

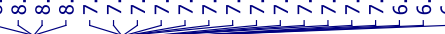

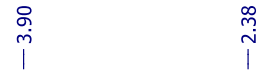

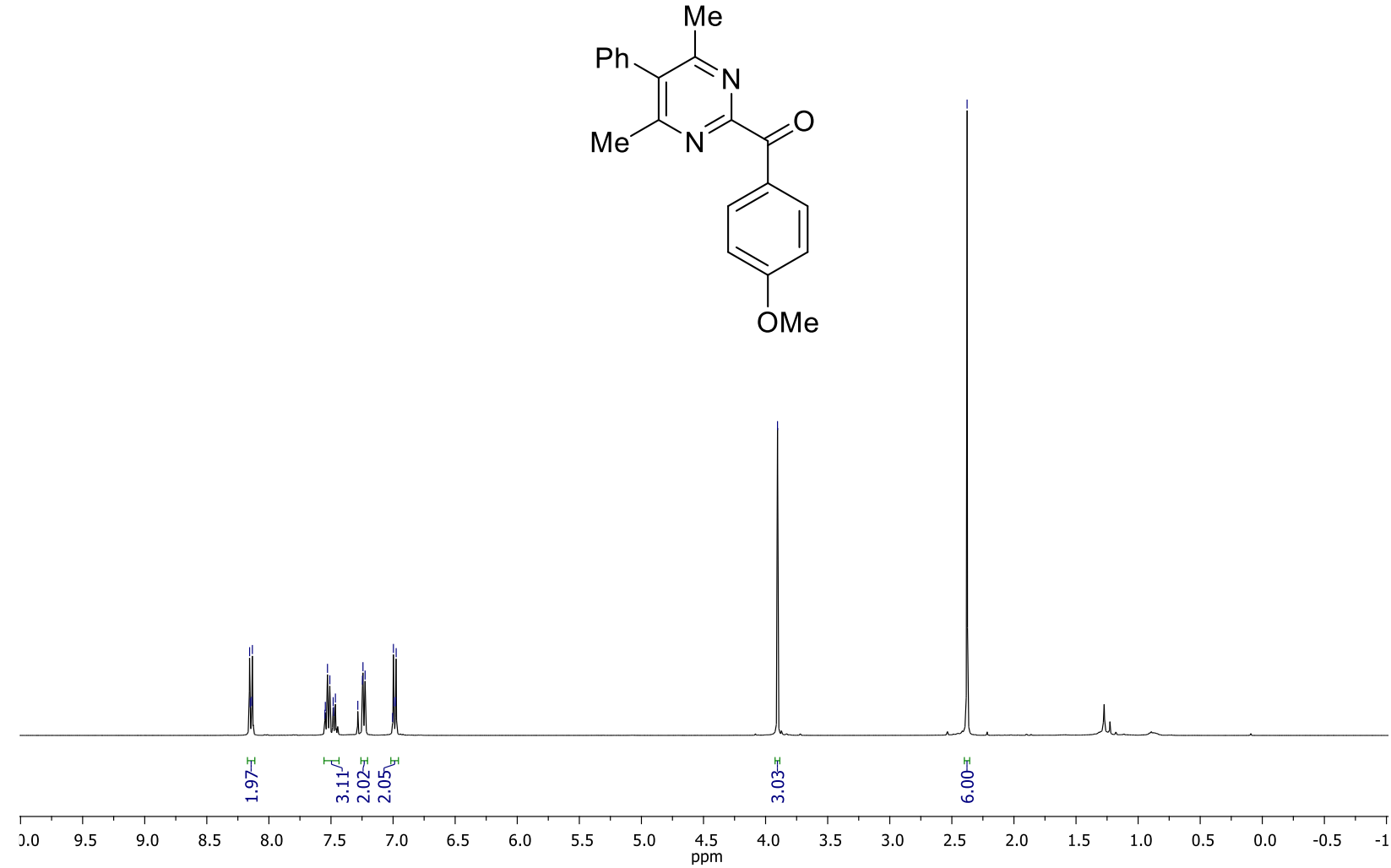

${ }^{13} \mathrm{C}\left\{{ }^{1} \mathrm{H}\right\}$ NMR spectrum of compound $3 \mathbf{m}\left(100 \mathrm{MHz}, \mathrm{CDCl}_{3}\right)$

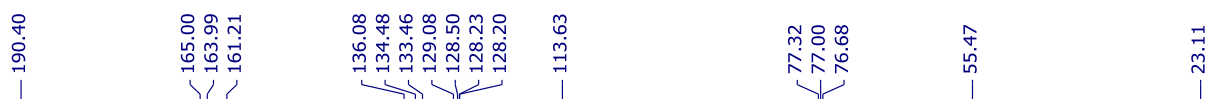<smiles>COc1ccc(C(=O)c2nc(C)c(-c3ccccc3)c(C)n2)cc1</smiles>

$\begin{array}{lllllllllll}210 & 200 & 190 & 180 & 170 & 160 & 150 & 140 & 130 & 120 & 110\end{array}$ 
$2 \mathrm{D}{ }^{1} \mathrm{H}^{-13} \mathrm{C}$ HMBC spectrum $\left(\mathrm{CDCl}_{3}\right)$ of compound $3 \mathbf{m}$

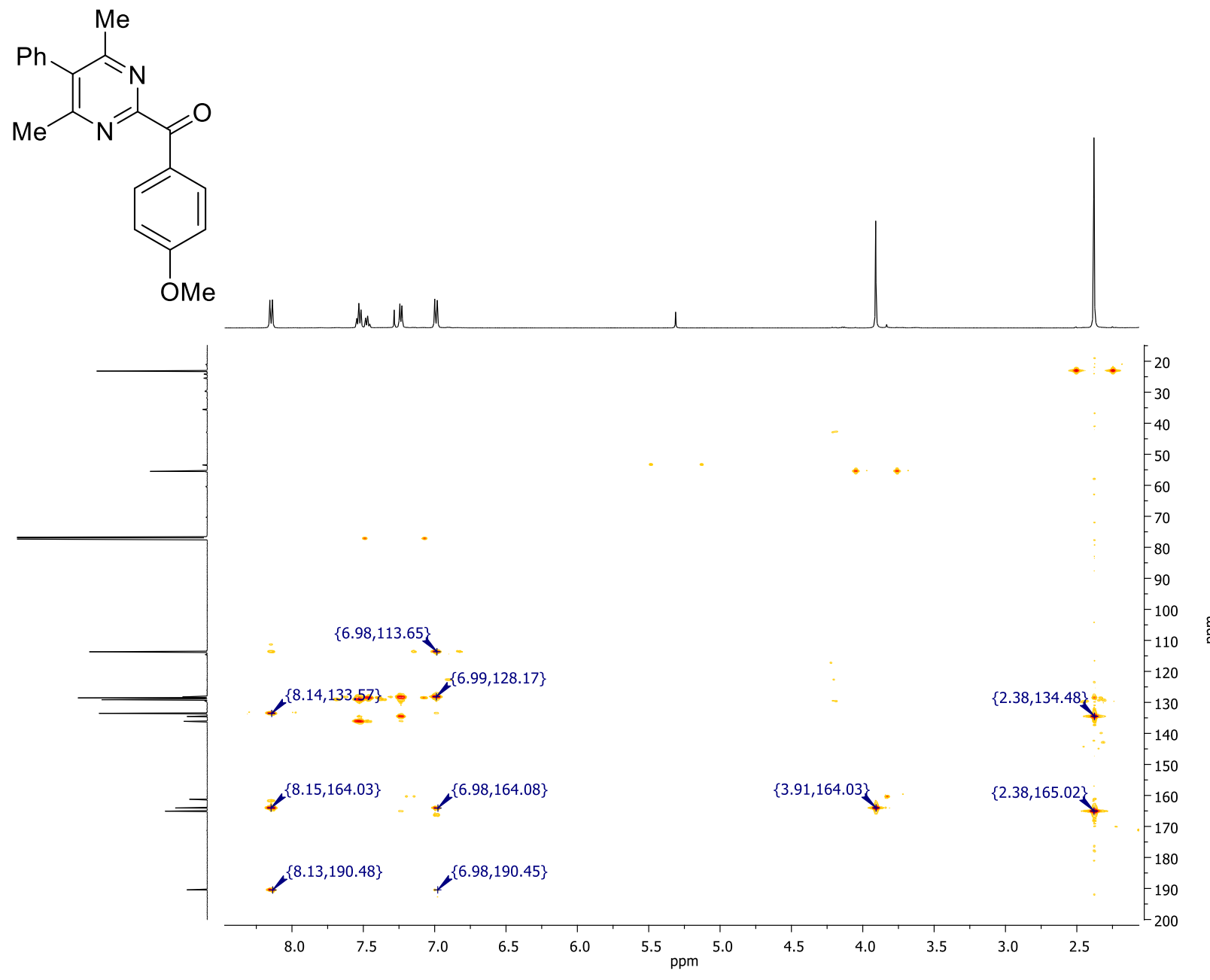


${ }^{1} \mathrm{H}$ NMR spectrum of compound $3 \mathbf{n}\left(400 \mathrm{MHz}, \mathrm{CDCl}_{3}\right)$

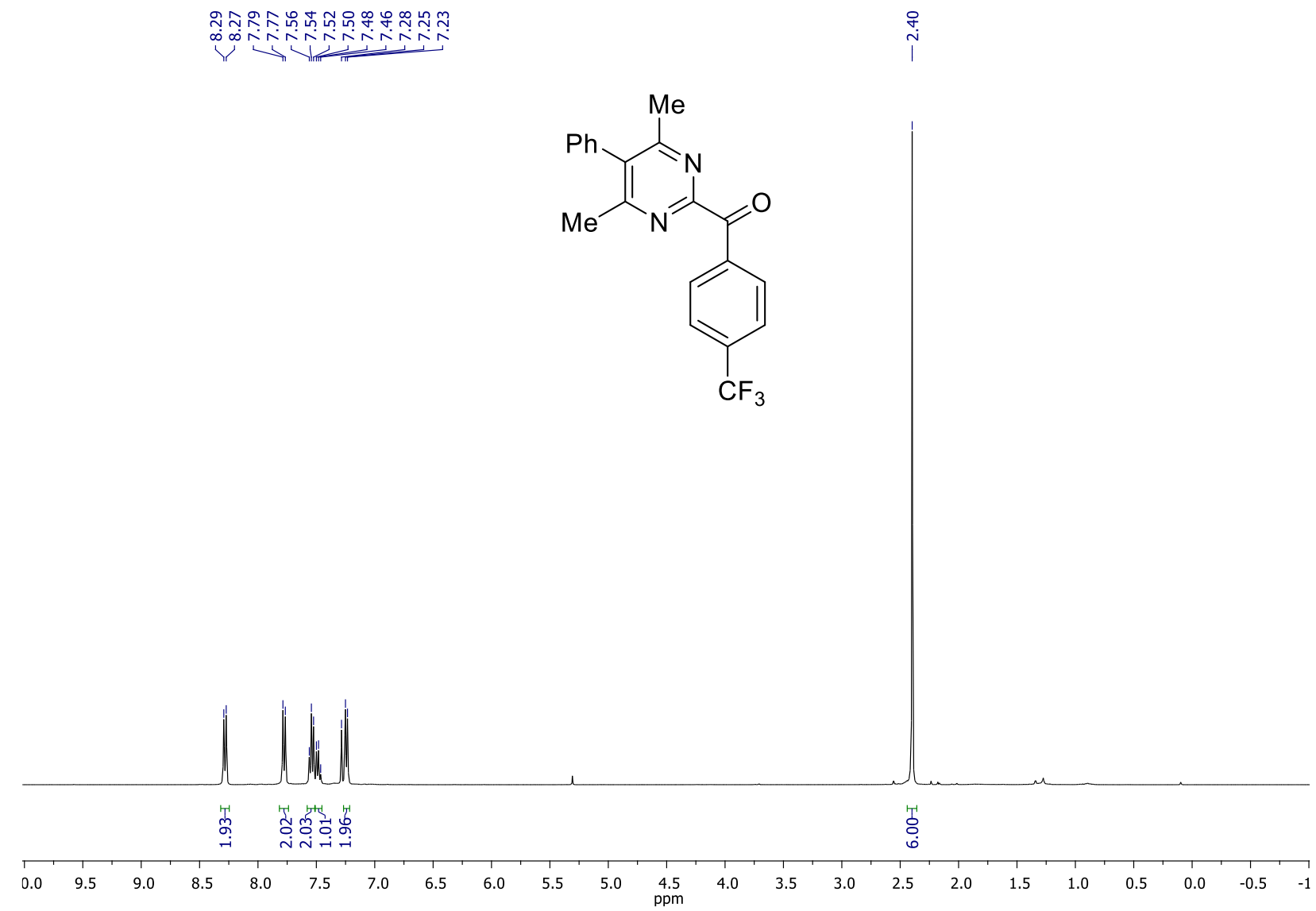

${ }^{13} \mathrm{C}\left\{{ }^{1} \mathrm{H}\right\} \mathrm{NMR}$ spectrum of compound 3n $\left(100 \mathrm{MHz}, \mathrm{CDCl}_{3}\right)$
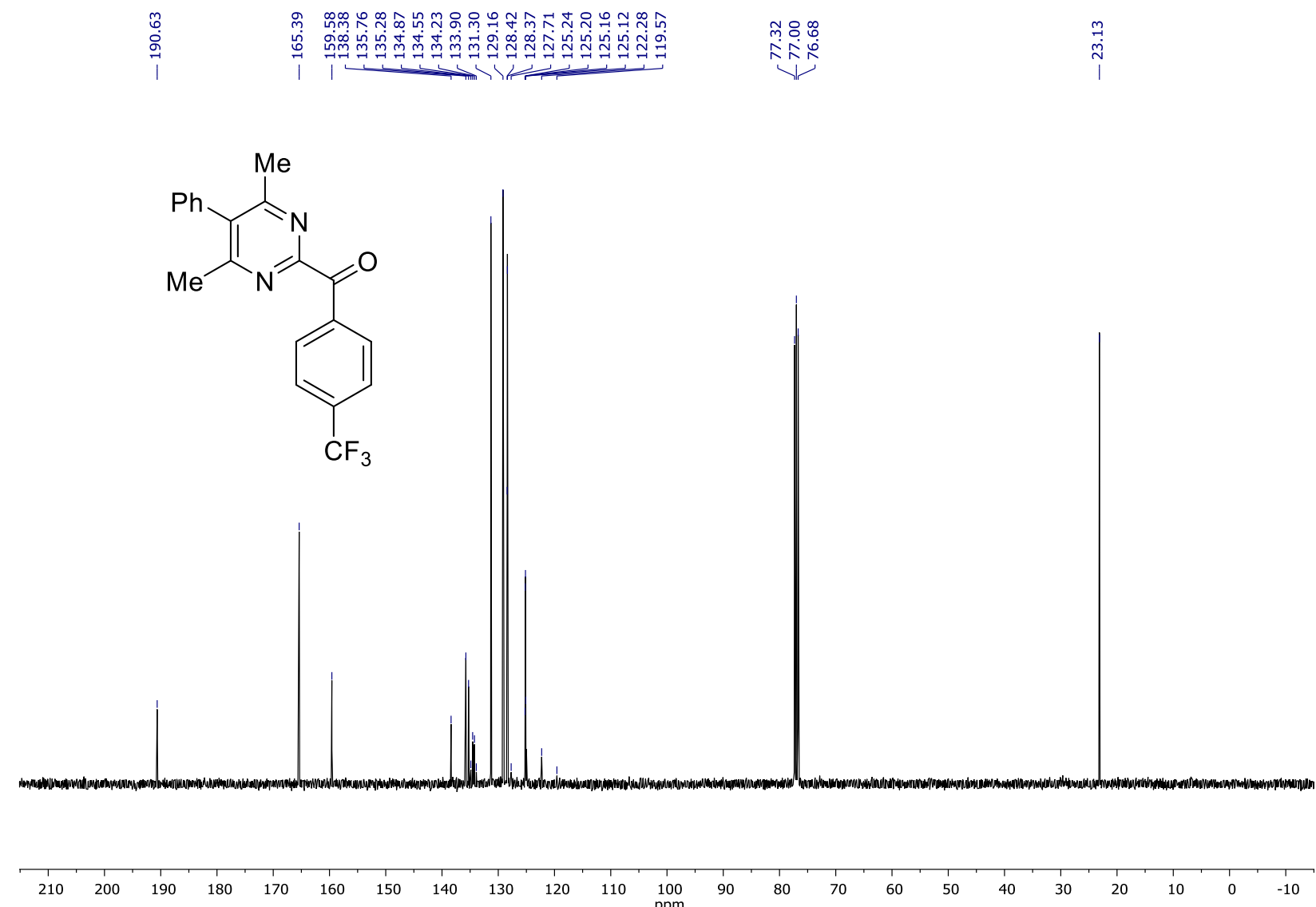
${ }^{1} \mathrm{H}$ NMR spectrum of compound $30\left(400 \mathrm{MHz}, \mathrm{CDCl}_{3}\right)$

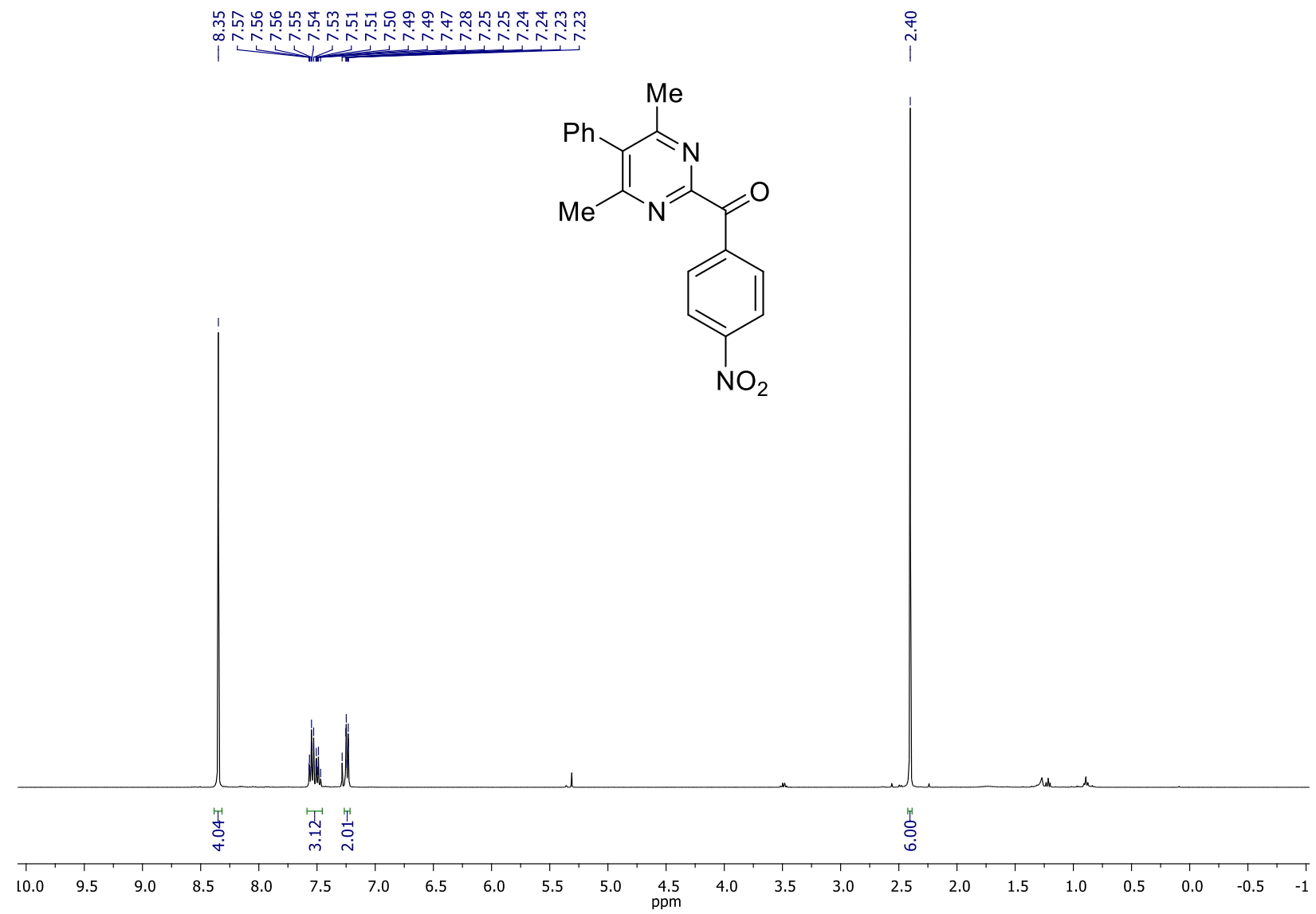

${ }^{13} \mathrm{C}\left\{{ }^{1} \mathrm{H}\right\} \mathrm{NMR}$ spectrum of compound 3o $\left(100 \mathrm{MHz}, \mathrm{CDCl}_{3}\right)$
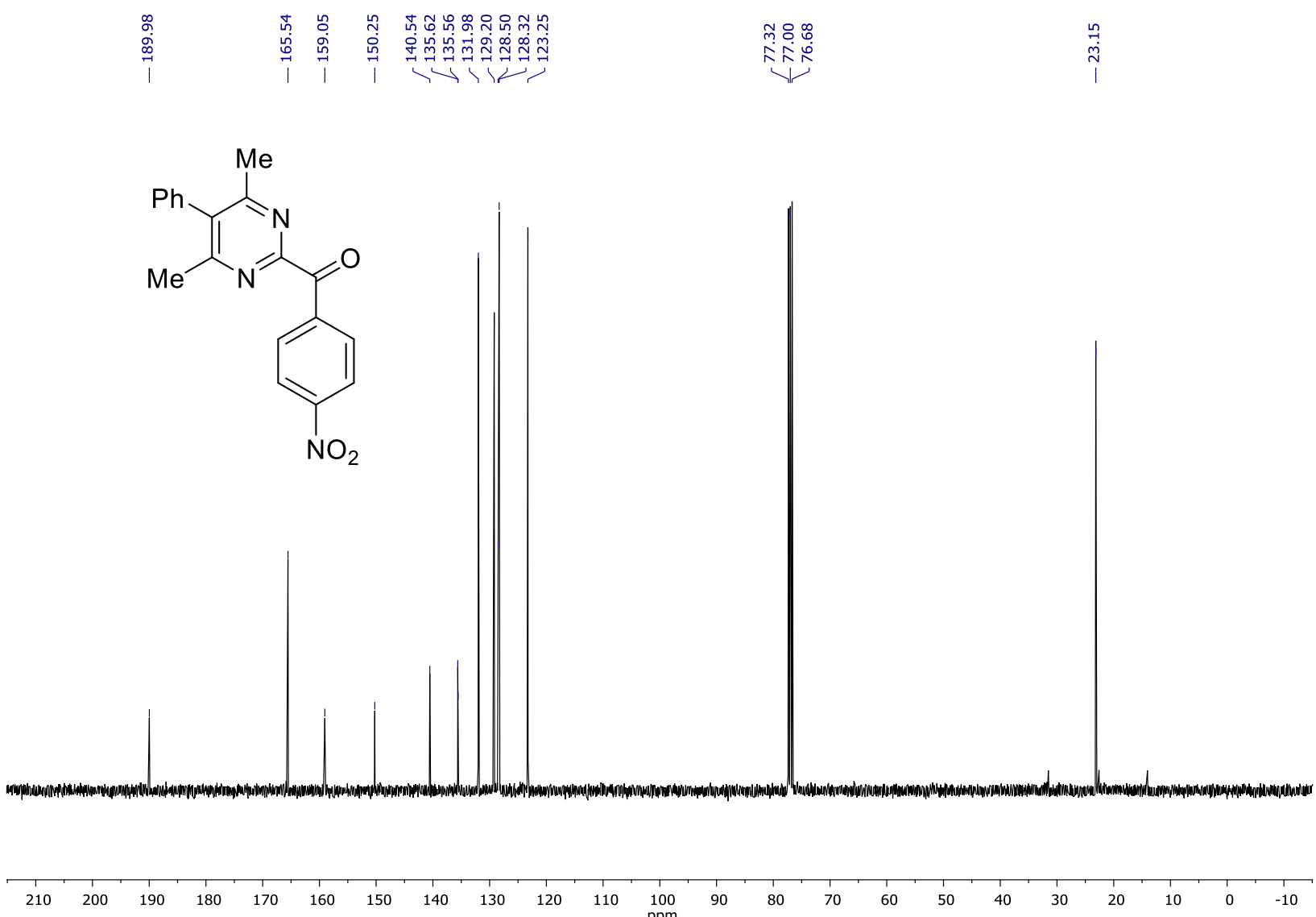
${ }^{1} \mathrm{H}$ NMR spectrum of compound $\mathbf{3 p}\left(400 \mathrm{MHz}, \mathrm{CDCl}_{3}\right)$

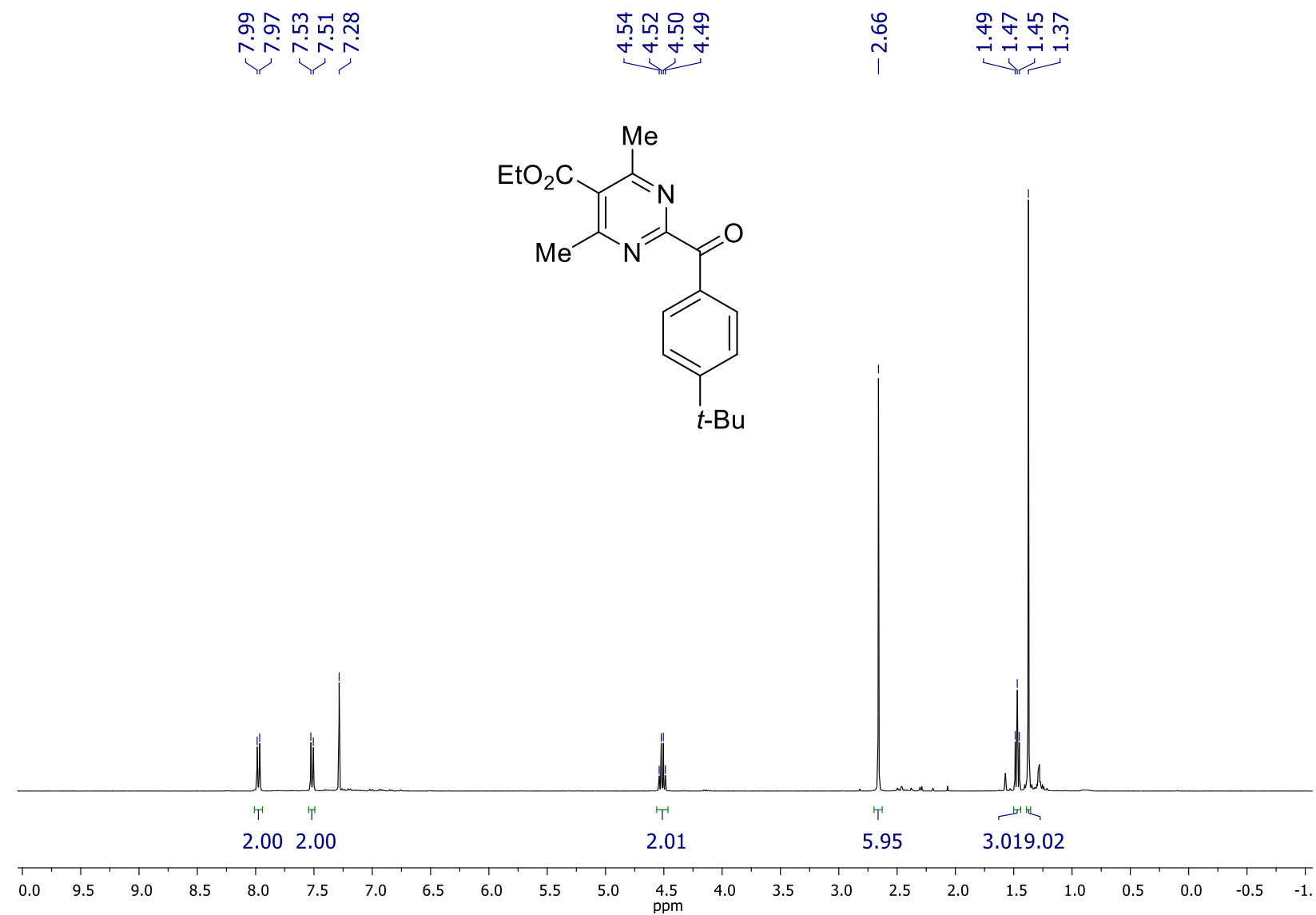

${ }^{13} \mathrm{C}\left\{{ }^{1} \mathrm{H}\right\}$ NMR spectrum of compound $\mathbf{3 p}\left(100 \mathrm{MHz}, \mathrm{CDCl}_{3}\right)$

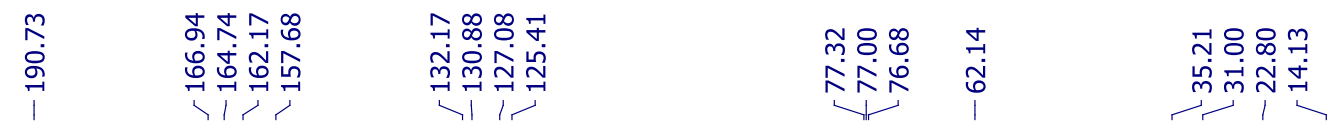

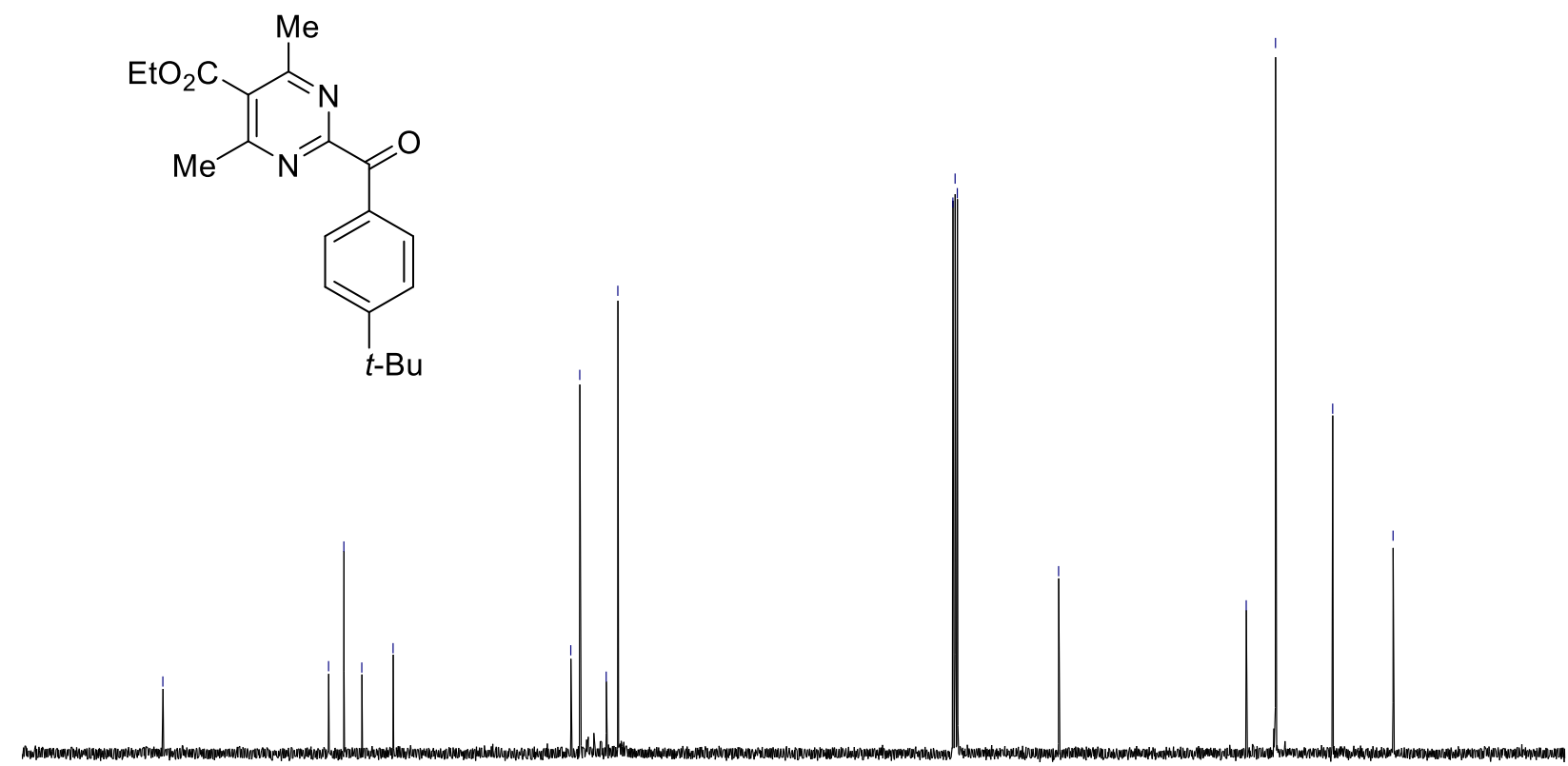

$\begin{array}{llllllllllllllllllllllllllll}210 & 200 & 190 & 180 & 170 & 160 & 150 & 140 & 130 & 120 & 110 & 100 & 90 & 80 & 70 & 60 & 50 & 40 & 30 & 20 & 10 & 0 & -1\end{array}$ 
${ }^{1} \mathrm{H}$ NMR spectrum of compound $\mathbf{3 q}\left(400 \mathrm{MHz}, \mathrm{CDCl}_{3}\right)$

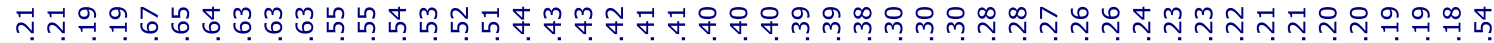

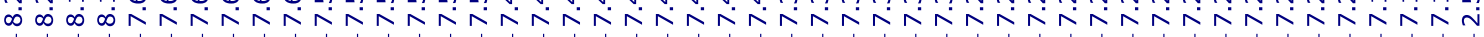<smiles>Cc1nc(C(=O)c2ccccc2)nc(-c2ccccc2)c1-c1ccccc1</smiles>

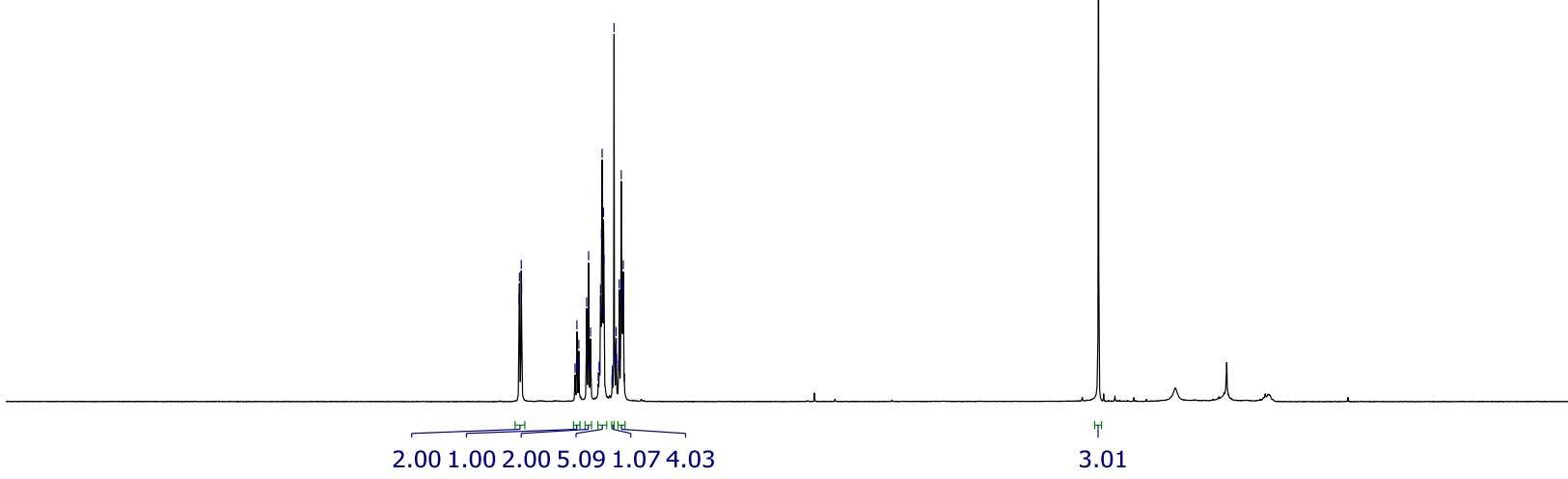

$\begin{array}{rlllllllllllllllllllllllllllllllllll}13.0 & 12.5 & 12.0 & 11.5 & 11.0 & 10.5 & 10.0 & 9.5 & 9.0 & 8.5 & 8.0 & 7.5 & 7.0 & 6.5 & 6.0 & 5.5 & 5.0 & 4.5 & 4.0 & 3.5 & 3.0 & 2.5 & 2.0 & 1.5 & 1.0 & 0.5 & 0.0 & -0.5 & -1.0 & -1.5 & -2 .\end{array}$

${ }^{13} \mathrm{C}\left\{{ }^{1} \mathrm{H}\right\}$ NMR spectrum of compound $3 q\left(100 \mathrm{MHz}, \mathrm{CDCl}_{3}\right)$

ㄱ. $\quad$ ำ

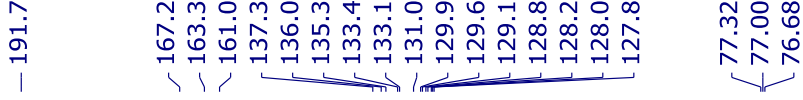

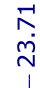<smiles>Cc1nc(C(=O)c2ccccc2)nc(-c2ccccc2)c1-c1ccccc1</smiles>

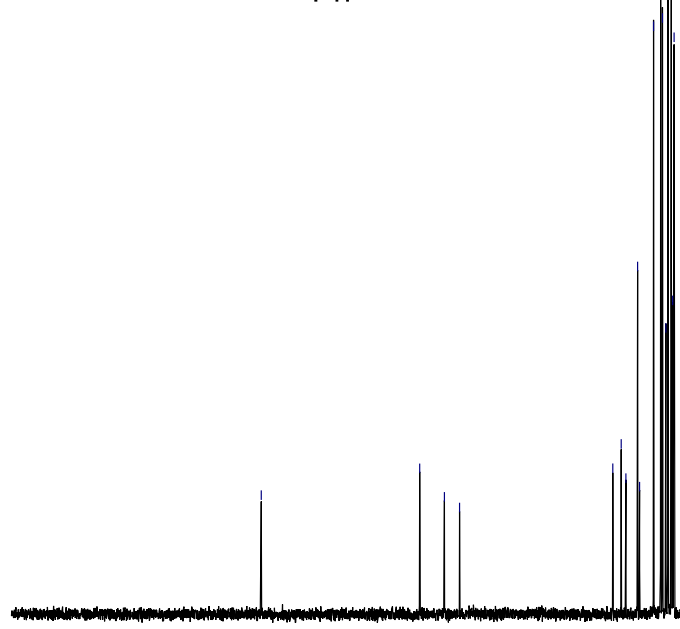

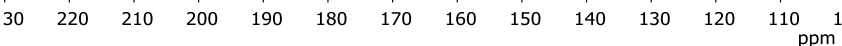


${ }^{1} \mathrm{H}$ NMR spectrum of compound $3 \mathbf{r}\left(400 \mathrm{MHz}, \mathrm{CDCl}_{3}\right)$

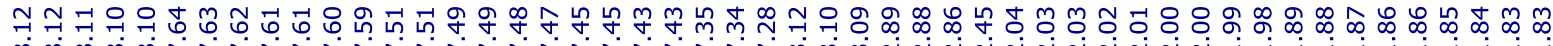

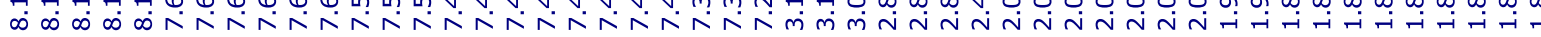<smiles>Cc1ccc(-c2nc(C(=O)c3ccccc3)nc3c2CCCC3)cc1Cl</smiles>

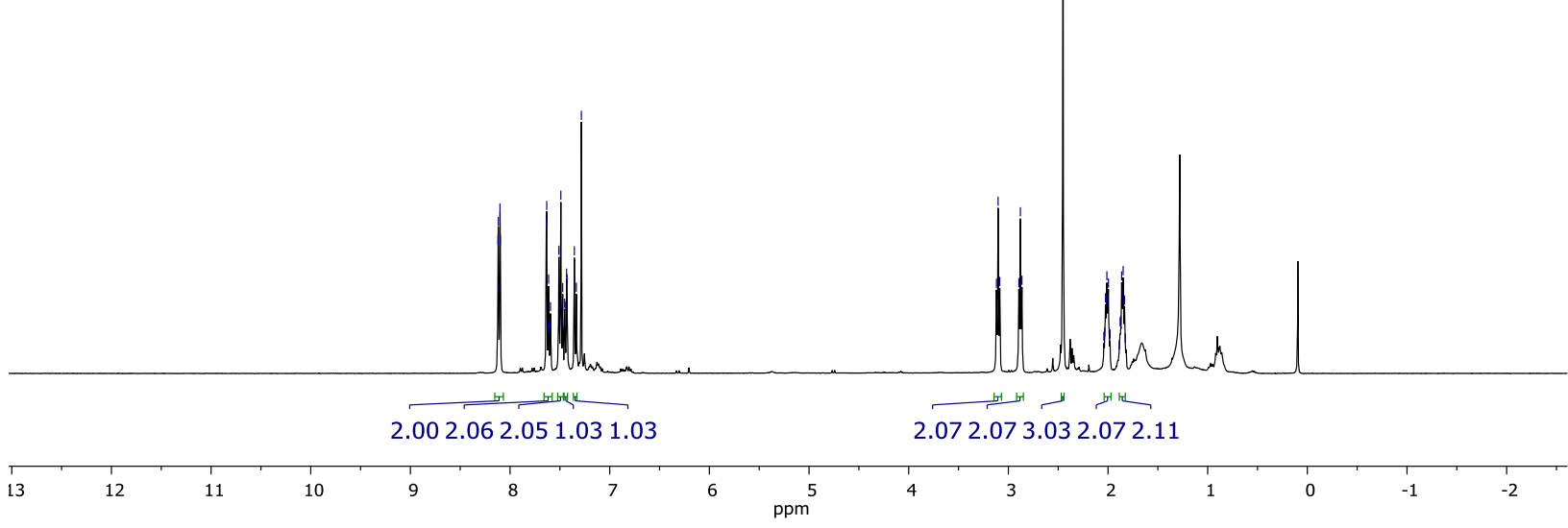

${ }^{13} \mathrm{C}\left\{{ }^{1} \mathrm{H}\right\}$ NMR spectrum of compound $3 \mathbf{r}\left(100 \mathrm{MHz}, \mathrm{CDCl}_{3}\right)$

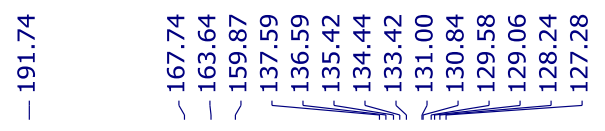<smiles>Cc1ccc(-c2nc(C(=O)c3ccccc3)nc3c2CCCC3)cc1Cl</smiles>

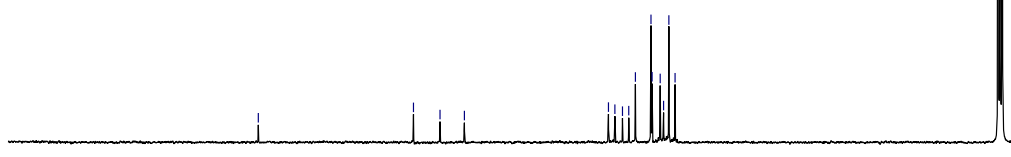


${ }^{1} \mathrm{H}$ NMR spectrum of compound $4 \mathbf{b}\left(400 \mathrm{MHz}, \mathrm{CDCl}_{3}\right)$

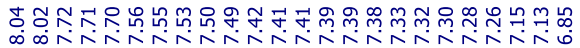

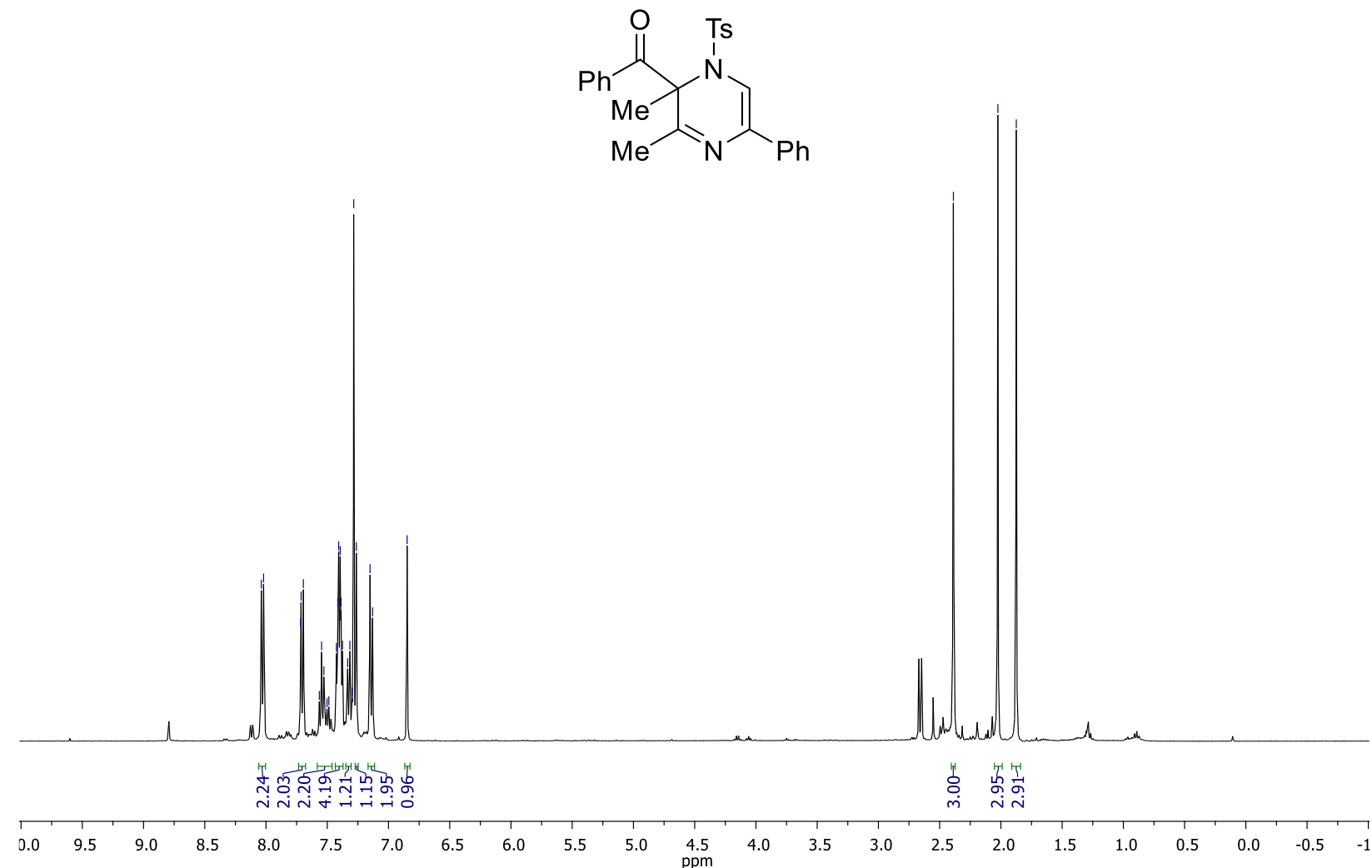

${ }^{13} \mathrm{C}\left\{{ }^{1} \mathrm{H}\right\}$ NMR spectrum of compound $4 \mathbf{b}\left(100 \mathrm{MHz}, \mathrm{CDCl}_{3}\right)$<smiles>[3H]N1C=C(c2ccccc2)N=C(C)C1(C)C(=O)c1ccccc1</smiles>
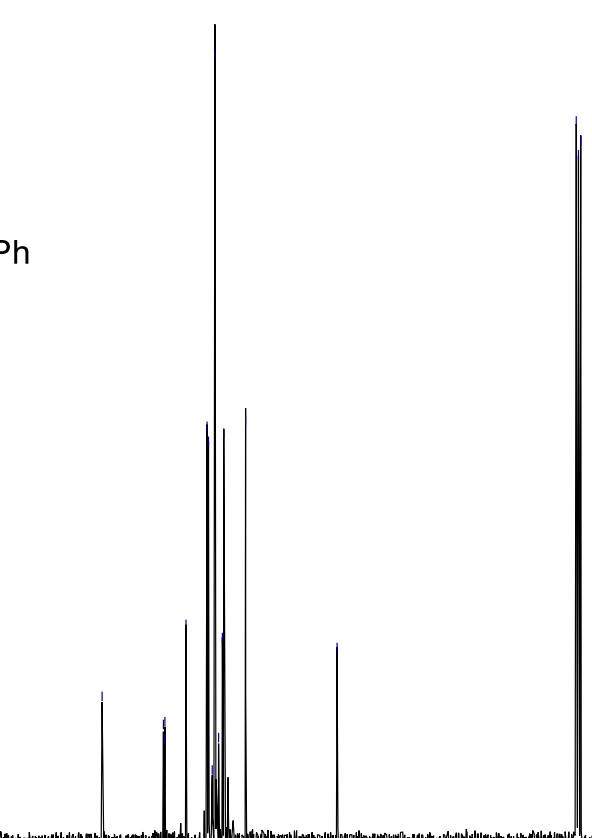
${ }^{1} \mathrm{H}$ NMR spectrum of compound $\mathbf{4 c}\left(400 \mathrm{MHz}, \mathrm{CDCl}_{3}\right)$

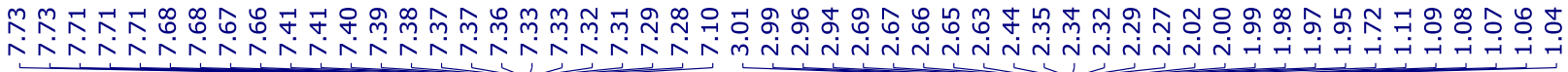

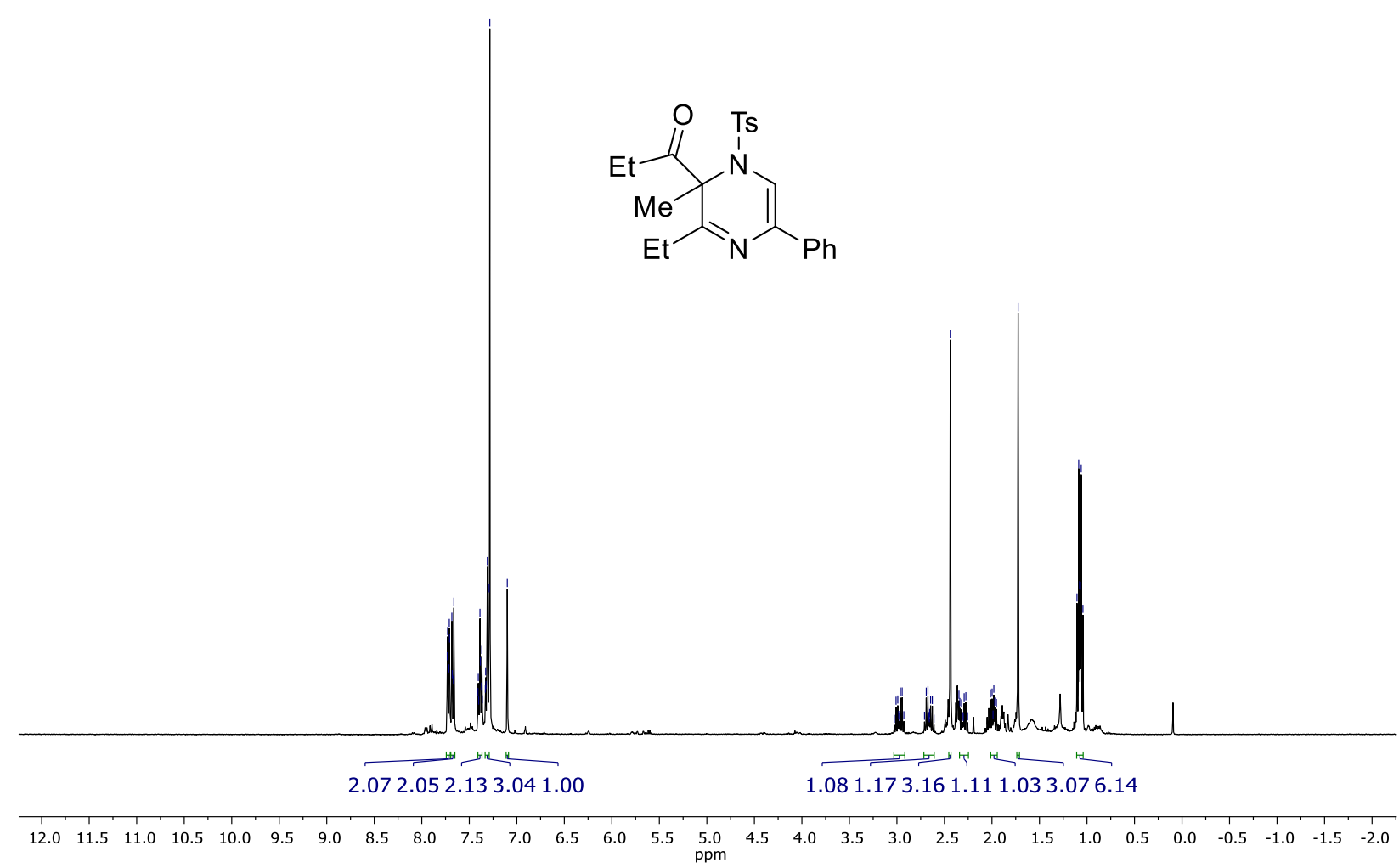

${ }^{13} \mathrm{C}\left\{{ }^{1} \mathrm{H}\right\}$ NMR spectrum of compound $4 \mathbf{c}\left(100 \mathrm{MHz}, \mathrm{CDCl}_{3}\right)$

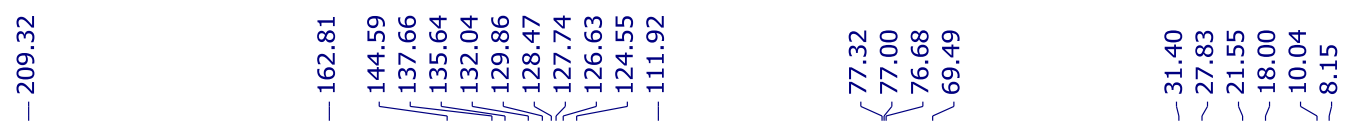<smiles>[3H]N1C=C(c2ccccc2)N=C(CC)C1(C)C(=O)CC</smiles>

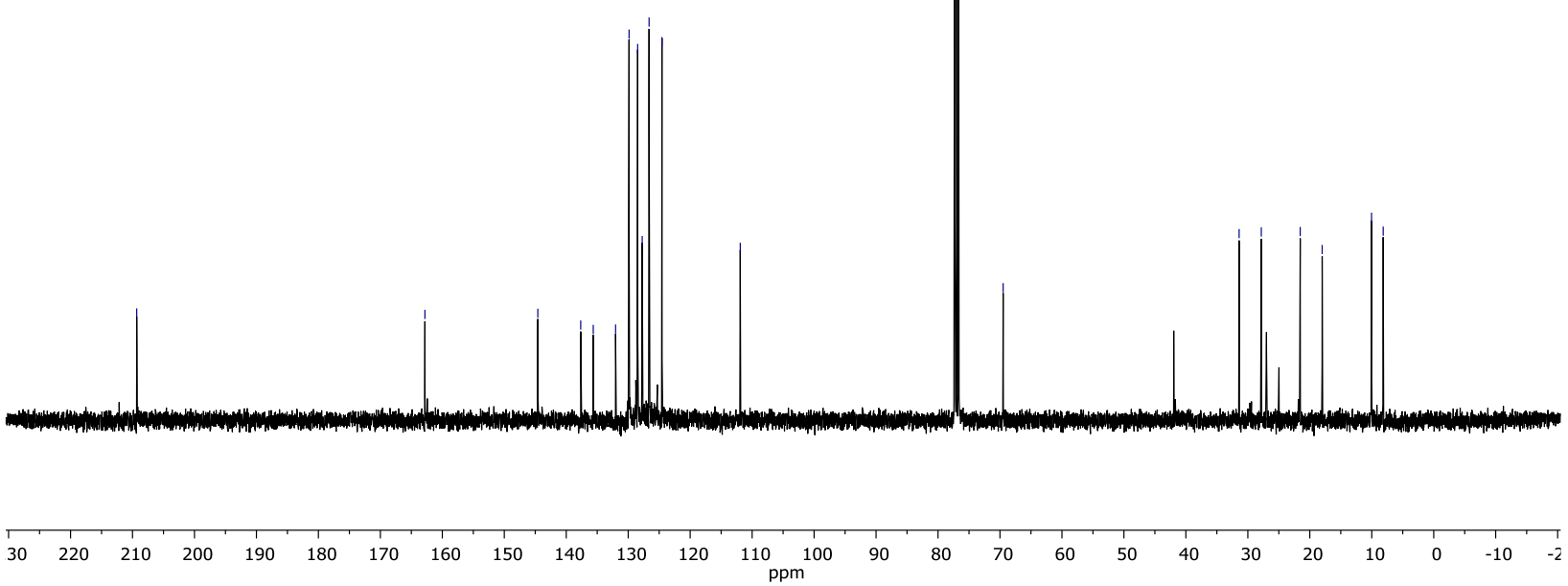


$2 \mathrm{D}{ }^{1} \mathrm{H}-{ }^{13} \mathrm{C}$ HSQC spectrum $\left(\mathrm{CDCl}_{3}\right)$ of compound $4 \mathbf{c}$

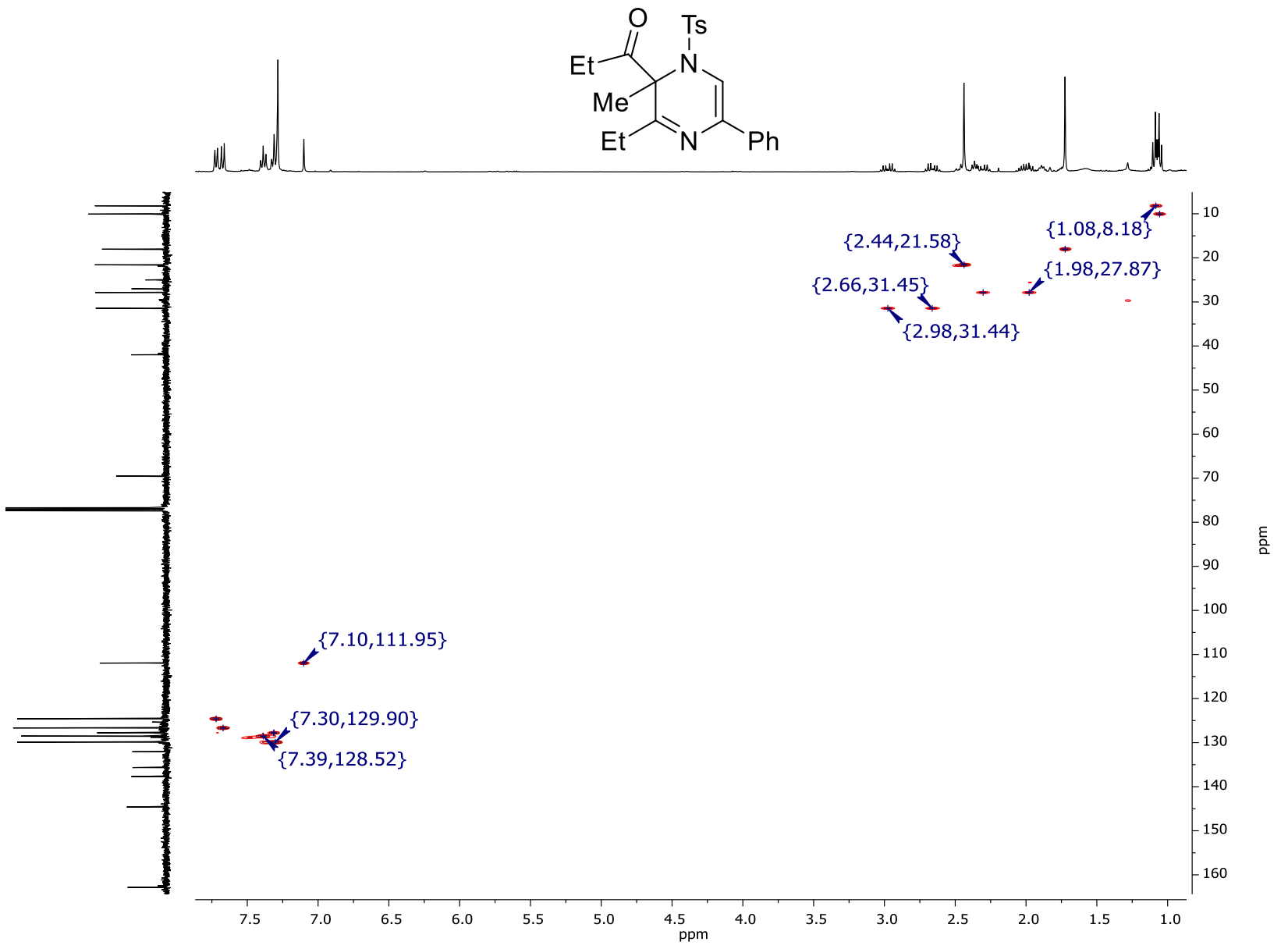

